\title{
Legal and economic approach to tying and other potentially unfair and anticompetitive commercial practices: focus on financial services
}

\author{
Andrea Renda \\ CEPS - LUISS University
}

\author{
Diego Valiante \\ CEPS
}

February 2010

\begin{abstract}
This paper analyses the economic and legal aspects related to practices such as tying, bundling and other potentially unfair commercial practices widely used in the financial services industry. Authors draw special attention to the European financial services market. Their law and economics approach aims at illustrating the rationales for applying both antitrust and consumer protection legislation to the practices subject to analysis in this paper and observed in the retail financial services market. The author explores the main findings of the legal and economic theory as regards the applicability of antitrust rules to the practices at hand, and the possibility to treat new commercial practices under antitrust law. The paper then illustrates the economics of tying, bundling and other unfair commercial practices from a consumer policy perspective, and reports some empirical data on switching costs and patterns of consumer behaviour in retail financial services and in other relevant sectors of the economy. Cognitive biases that may cause irrational behaviours in judgement and decisionmaking processes of a retail consumer are widely assessed. Finally, the author proposes a new multi-stage test for the joint assessment of selling practices under competition and consumer policy.
\end{abstract}

Keywords: Financial Services, Financial Regulation, Competition Law and Economics, Tying, Behavioural Law and Economics, Investment services, banking. 


\section{TABLE OF CONTENTS}

\section{Introduction}

1 The competition policy dimension of tying and other potentially unfair commercial practices

1.1 Cross-selling strategies 6

1.1.1 The antitrust law and economics of tying and bundling ........................ 6

1.1.1.1 The leverage theory and the Chicago School criticism........................ 9

1.1.1.2 Anti-competitive effects and the revival of the leverage theory.. 11

1.1.1.3 Post-Chicago theories and other efficiency-enhancing features of tying and bundling practices.

1.1.2 Tying and bundling under EC competition law .................................... 19

\subsubsection{US approach to tying and other potentially unfair commercial}

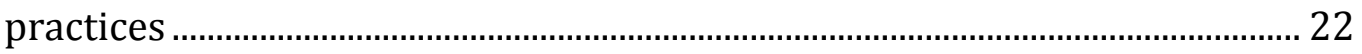

1.1.3.1 Tying and similar practices in US antitrust law ............................... 23

1.1.3.2 The US ban on tying in the banking sector: few cases and systematic circumvention 25

1.1.4 Preferential or exclusive agreements ....................................................... 27

1.2 Other potentially unfair commercial practices as exclusionary abuses in competition law 29

1.2.1 Conditional sales practices …………………………………………..... 31

1.2.1.1 Conditions attached as essential for the conclusion of the contract31

1.2.1.2 Conditional rebates as an antitrust infringement 34

1.2.1.3 Loyalty rebates 37

1.2.2 Aggressive commercial practices in competition law 39

\section{Tackling tying and other potentially unfair commercial} practices in consumer policy

2.1 The rationale for protecting consumers and SMEs against unfair commercial practices 42 
2.1.1 Informational asymmetry between providers and customers.

2.1.1.1 Financial education and customer effort in "shopping around".. 47

2.1.1.2 Information asymmetry, relationship banking and switching costs49

2.1.2 Behavioural economics and decision-making biases 51

2.2 A closer look into switching costs. 55

2.3 Potentially unfair commercial practices in the retail financial services sector 59

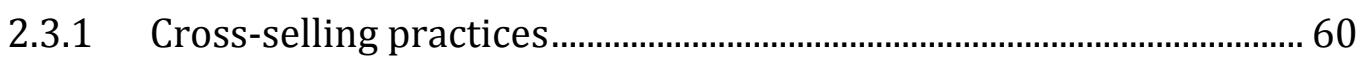

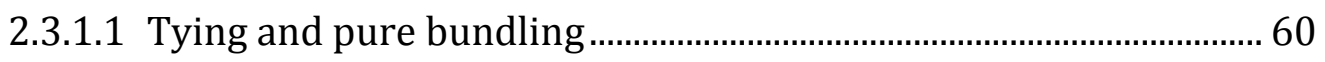

2.3.1.2 Mixed bundling and multi-product rebates...................................... 63

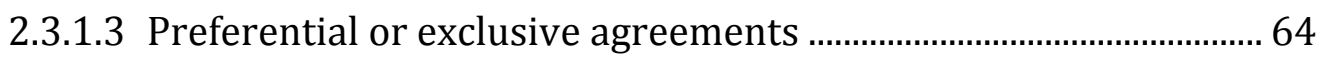

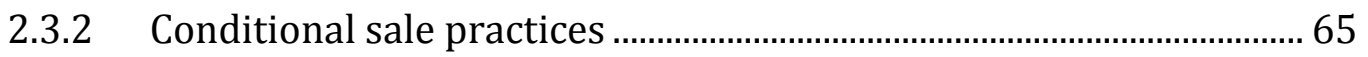

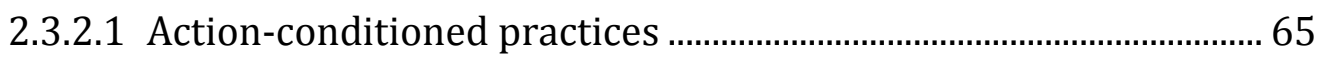

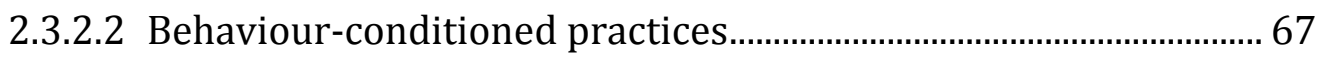

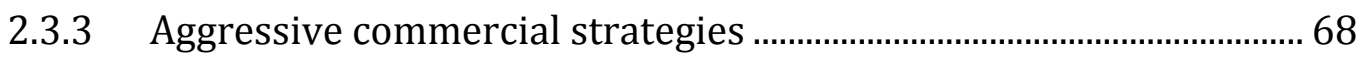

2.3.3.1 Unsolicited Offers................................................................................. 70

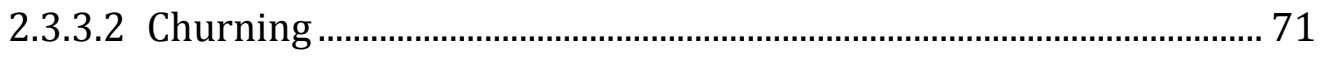

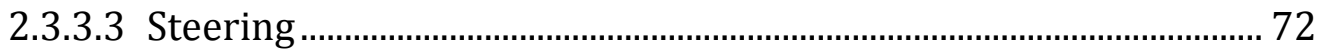

3 Measuring the impact of tying and other potentially unfair practices in the retail financial services sector: a multi-stage $\begin{array}{ll}\text { test } & 73\end{array}$

$\begin{array}{ll}\text { Conclusions } & 79\end{array}$ 


\section{Introduction}

Tying, bundling and other potentially unfair commercial practices in the retail financial services sector have been subject to attention in the economic theory, especially as far as competition policy is concerned (less for consumer policy). The findings of the economic literature have been also translated into legal rules, especially as far as antitrust law is concerned. Accordingly, in many countries around the world tying and an array of other cross-selling practices - including conditional rebates, exclusivity agreements, etc. - are considered to be potentially distorting competition and leading to anti-competitive foreclosure. This is reflected in the current policy of the European Commission on exclusionary abuses, as highlighted in the recent Guidance paper adopted on December 2008.

Against this background, the analysis of the effects of tying and other potentially unfair commercial practices from the standpoint of consumer policy is substantially more fragmented and sparse in the literature. This is probably due to the fact that tying is universally considered to be a ubiquitous practice, and that only under certain circumstances can be considered as detrimental to customers - the fact that the tying firm is dominant on its relevant market for the tying product is indeed one of these circumstances. Since the 1960s, increased attention to consumer protection in contractual relations with firms has led to a better understanding of the behavioural and informational issues that emerge in these particular types of contracts. Specific legislation on standard form contracts (such as the Loi Scrivener adopted in 1978 in France, the Gesetz über Allgemeine Geschäftsbedingungen AGBG passed in 1976 in Germany, but also the Supreme Court decisions in Henningsen v. Bloomfield Motors and Williams v. Walker-Thomas Furniture, Inc. in the US) has marked the first step towards consumer protection in several countries, and culminated at EU level with the approval of Directive 93/13 on 5 April 1993 on unfair terms in consumer contracts ${ }^{1}$. Subsequently, issues that had been postponed during the debate on Directive 93/13 -

See e.g. Willett, C., Fairness in Consumer Contracts. The case of Unfair Terms, Ashgate Publishing, 2007. On US cases, see Williams v. Walker Thomas Furniture, 350 F.2d 445 (D.C. Cir. 1965); and Henningsen v. Bloomfield Motor Inc., 161 A.2d 69 (N.J. 1960). In Henningsen, 22 the buyers of a car sued a carmaker for the consequential damages from an accident caused by a defective steering mechanism. The carmaker defended on the ground that the buyers waived any right to sue for consequential damages in fine print, but the court ruled in favor of the buyers, holding the waiver ineffective on the basis of "[t]he gross inequality of bargaining position". In Williams, the plaintiff had bought several pieces of household furniture from Walker-Thomas for about $\$ 1300$ and had paid all but $\$ 164$ of this amount; she then bought a stereo from Walker-Thomas for $\$ 514$. The contract she signed included a cross-collateralization clause that gave Walker-Thomas a security interest in both the stereo and all the other furniture she bought from it over the years. The clause was held unconscionable by the Supreme Court - a finding that led to a shift from the "duty to read" rule in place since the 1860 judgment of the Court of Exchequer in Lewis v. Great Western Railways. See Todd D. Rakoff, Contracts of Adhesion: An Essay in Reconstruction, 96 Harv. L. Rev. 1174 (1983). And Baird, D., The Boilerplate Puzzle, Michigan L. Rev Vol. 104, 933, March 2006. 
such as, i.a. the sale of goods and associated guarantees - were addressed by other EU Directives ${ }^{2}$.

More recently, also due to developments in the law and economics literature in this field, the attention of regulators has also focused on the pre-contractual phase of consumer contracts, i.e. to the moment in which consumers make up their mind on their willingness to purchase and accept the contractual conditions. In this phase, consumers are often dependent on the information that is provided by their counterpart, and for this reason legal rules must be devised to ensure that the communication of information is not misleading or affected by cognitive biases. Accordingly, unfair commercial practices have been tackled by legislators in several EU countries, especially with the Unfair Commercial Practices Directive.

In this paper we explore the rationales for applying both antitrust and consumer protection legislation to the practices subject to analysis in this paper, i.e. tying and other potentially unfair commercial practices observed in the retail financial services sector. Section 1 below illustrates the main findings of the legal and economic theory as regards the applicability of antitrust rules to the practices at hand. Section 2 illustrates the economics of tying, bundling and other unfair commercial practices from a consumer policy perspective, and reports empirical data on switching costs and patterns of consumer behaviour in retail financial services and in other sectors of the economy. Section 3 proposes a test for the assessment of these practices under the umbrella of competition and consumer policy. We then draw conclusions on the potential impact of the practices under scrutiny on consumer welfare.

\section{The competition policy dimension of tying and other potentially unfair commercial practices}

This section deals with tying and other potentially unfair commercial practices as defined in the economic theory and in the EU and US case law. The following paragraphs give an overview of the historical evolution of the different legal and economic approaches in the law and economics literature, focusing on benefits and costs of these practices under the competition policy view. The final part identifies four categories of potentially unfair commercial practices looking at the EU legislation and the common practices adopted in the retail financial services sector. We will analyse how to deal with these practices under competition law.

2 See http://ec.europa.eu/consumers/rights/gen_rights en.htm. 


\section{$1.1 \quad$ Cross-selling strategies}

\subsubsection{The antitrust law and economics of tying and bundling}

Tying is a ubiquitous business practice, which occurs when two or more products are sold together in a package and at least one of these products is not sold separately ${ }^{3}$. In this case, the consumer can buy the tied product alone, but not the tying product without the tied one. This implies that customers that would not buy all the tied goods may be forced to purchase extra products that they did not want (see figure 2 below).

Tying is usually distinguished from another similarly widespread cross-selling strategy, named pure bundling. Pure bundling occurs when none of the package components is available separately, and the components are offered in fixed proportions ${ }^{4}$. Pure bundling is in fact the simultaneous sale of two or more products only as bundle, not individually. The main difference concerns the proportions requirement ${ }^{5}$. Pure bundling implies fixed proportions, while tying involves variable proportions and - most often two distinct sales (figure 2) ${ }^{6}$. The incentives to bundle are higher when the number of items produced by a firm is high enough to achieve high costs savings (distribution, etc) and better price coordination (i.e., internalization of complements cross-price effects) through the bundle?

If products are also sold on a stand-alone basis, the practice is defined as "mixed bundling"; in this case the bundle is usually sold at a discounted price (multi-product rebate) compared to the sum of the prices for the bundled goods when purchased separately.

From a competition policy perspective, several different variants of tying practices have been considered. For example, the purchase of a product with the requirement to buy consumables linked to that product from the same seller. Another typical example of tying is the cross-selling practice to tie the purchase of a "blockbuster" movie to the purchase of a less famous one (i.e. block booking) ${ }^{8}$. In this case, although consumers can

See the European Commission Staff Working Document accompanying the Communication from the Commission - Sector Inquiry under Art 17 of Regulation 1/2003 on retail banking (Final Report) [COM(2007) 33 final], SEC(2007) 106 of 31 January 2007, at 49.

4 See, e.g. O'Donoghue, R. and A. J. Padilla, The Law and Economics of Article 82 EC, Hart Publishing, Oxford, 2006, Chapter 9, at 477.

5 Motta M., Competition Policy. Theory and Practice, Cambridge University Press, Cambridge, 2004, p. 460.

6 In this text, it will be used indifferently the word tying to define every kind of packaged sale that is not bundling or mixed bundling, as described above.

7 See Motta (2004), cit.

8 Stigler, George J., United States v. Loew's, Inc.: A Note on Block Booking, 1963 Sup. Ct. Rev. 152 (1963); "A Note on Block Booking", in Stigler, G. J., The Organization of Industry, The University of Chicago Press, Chicago, 1968, pp. 165-170. The argument was already known as "Full-line forcing", Burstein N., "A Theory of Full-Line Forcing", Northwestern University Law Review, 1960, Vol. 55, pp. 62-95. 
buy variable proportions of the tied product itself, they must buy the tying product with the tied movie (at least one copy). The variability of the quantity proportions is "complete" for the tied product (consumer can decide to take two or more copies of the tied product and one or none of the tying movie) and "fixed" for the tying product (one to one). Other examples are usually related to durable goods, which need consumables from the same supplier and so on.

On the contrary, a newspaper is a pure bundled product because consumers access different kinds of topic-specific news sold together, without any possibility to buy just the "sports" section or to decide how much "sport" they want in that specific newspaper (fixed proportions). There is a clear economical and practical justification to this solution, since selling a newspaper in different sections would generally be more costly for distributors and consumers. However, in other cases these justifications may be less clear, so raising legitimate objections on the impact of the practice on consumers and competition in general. Other bundled products are cars, radio, shoes and so on.

\section{Figure 1 - Bundling, Tying and Separate Component Selling}

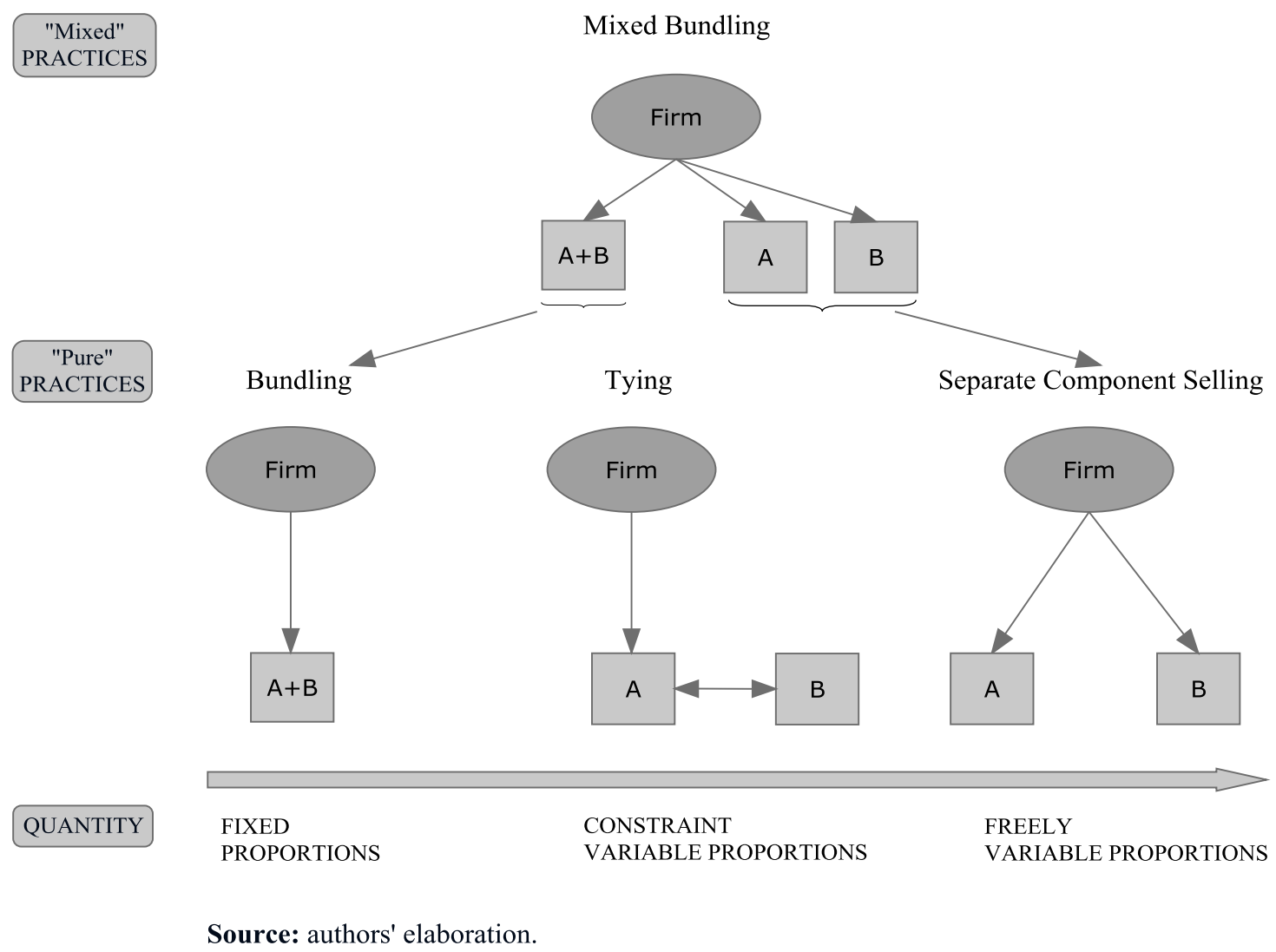

Tying and bundling are widespread phenomena that permeate every single aspect of consumers' daily life. From retail banking products (e.g. the common operation to tie the provision of a loan to the concurrent opening of a current account) to consumer goods (e.g. hotel room and breakfast, personal computers and operating systems, etc.), it is possible to list a huge number of cases. Moreover, a typical case of tying 
(contractual and technological) may likely come up in the so-called aftermarket or in the market for consumables where simple reasons of technological efficiency or exclusionary behaviours (or both) can increase the number of tie-in sales ${ }^{9}$. Cross-selling strategies in the retail financial services sector occur mainly through tying strategies (number 5 and 6 in Table 1), by offering only the bundle (n. 4), or offering the bundle at a discounted price (n. 7) ${ }^{10}$.

Table 1 - Possible product combinations

\begin{tabular}{lccc}
\hline Possible product combinations & X & Y & XY \\
\hline \hline 1. Components Selling & $\mathrm{X}$ & $\mathrm{Y}$ & - \\
2. Component Selling & $\mathrm{X}$ & & \\
3. Component Selling & & $\mathrm{Y}$ & \\
4. Pure Bundling & & & $\mathrm{XY}$ \\
5. Tying (X to Y) & $\mathrm{X}$ & & $\mathrm{XY}$ \\
6. Tying (Y to X) & & $\mathrm{Y}$ & $\mathrm{XY}$ \\
7. Mixed Bundling & $\mathrm{X}$ & $\mathrm{Y}$ & $\mathrm{XY}$ \\
\hline \hline
\end{tabular}

Source: author's elaboration based on Evans (2006).

In terms of antitrust scrutiny, the insights of economic literature and the latest developments in the US case law have shown a tendency to move from a formalistic approach to tying - the so-called per se rule approach - to a "rule of reason" approach, in which proof of the likely anti-competitive effect is required, and efficiencies created by the conduct may redeem it under antitrust rules ${ }^{11}$. As will be shown in the next paragraphs, the likelihood that a tying practice leads to anti-competitive foreclosure depends on a number of factors, including the structural features of the market and the characteristics of the product (e.g. fixed and marginal costs).

9 See, e.g., Kaserman, D., Efficient Durable Good Pricing and Aftermarket Tie-In Sales, Economic Inquiry, Volume 45 Issue 3, 2007, at 533-537.

10 U.S. Department of Justice (DOJ), Antitrust Division, Report on "Competition and Monopoly: SingleFirm Conduct Under Section 2 of the Sherman Act", Chapter 5, September 2008, http://www.usdoj.gov/atr/public/reports/236681.htm.

11 In the US, the first move away from the per se rule was done by the Supreme Court decision in Jefferson Parish Hospital Dist. N. 2 et al. v. Hyde, 466 U.S. 2, 16 (1984). Later, in the Microsoft III decision, the US Court of Appeals introduced a rule of reason approach, limited to "platform innovation for PCs, network computers and information appliances", see id. 


\subsubsection{The leverage theory and the Chicago School criticism}

Tying has been largely and heatedly debated during the last century and in recent years. The dispute between scholars on the likely anti-competitive and pro-competitive effects of this practice dates back to the beginning of the 20th century with the recognition by the US Courts of the "leverage theory" 12 . The leverage theory states that

\section{"[t]ying provides a mechanism whereby a firm with monopoly power in one market can use the leverage provided by this power to foreclose sales in, and thereby monopolize, a second market"13.}

Therefore, tying may be an exclusionary conduct that forecloses the tied market (through the tying market) to new potential competitors. This theory holds in many cases even though the criticisms coming from the Chicago School have strongly weakened $i^{14}$. Indeed, it is unquestionable that, under specific assumptions, the leverage theory may not hold. In particular, Chicago scholars have argued that tying cannot increase the monopolist's profits if the tied market is competitive (the so-called "single monopoly profit theorem"), as this would eventually reduce the monopolist's aggregate sales ${ }^{15}$. The underlying assumptions are however very strong:

- There must be perfect competition in the tied-market (no barriers to entry, price-taker firms, etc.) ${ }^{16}$;

12 Tying was firstly analyzed in patent case, Motion Pictures Patents Co. v. Universal Film Manufacturing Co., 243 U.S. 502 (1917); then under Section 1 of the Sherman Act and Section 3 of the Clayton Act (illegal trades), International Salt v. U.S., 332 U.S. 392 (1947) and Northern Pacific Railway Co. v. U.S. 356 U.S. 1 (1958). Under Section 2 of the Sherman Act (for U.S.) and Article 82 ECT (for E.C.; abuse of dominant position) a more solid jurisprudence came up. For the U.S., U.S. v. United Shoe Mach. Co. of N.J., 247 U.S. 32 (1918); IBM v. U.S. 298 U.S. 131 (1936); U.S. v. Paramount Pictures, Inc., 334 U.S. 131, 156 (1948); Jefferson Parish (1984), id. For the European Community, Case T30/89 Hilti v Commission [1991] ECR II-1439; case IV/31.043 Elopak v. TetraPak (1992) 0J L72/1.

13 Whinston Michael D., "Tying, Foreclosure and Exclusion”, The American Economic Review, Vol. 80, N. 4, September 1990, pp. 837-859.

14 See Director, A. and E. Levi, "Law and the Future: Trade Regulation", Northwestern University Law Review, 1956, 51, pp. 281-296; W.S. Bowman, "Tying Arrangements and the Leverage Problem", Yale Law Review, November 1957, pp. 19-36; Richard A. Posner, Antitrust Law: An Economic Perspective, University of Chicago Press, Chicago, 1976; Robert H. Bork, The Antitrust Paradox, New York, Basic Books, 1978.

15 For an explanation, see Motta M. (2004), cit.

16 A market is purely or perfectly competitive if each firm assumes that the market price is independent of its own level of output. The model of perfect competition is based on three assumptions: product homogeneity (when the products of all of the firms in a market are perfectly substitutable between each other); price taking (each individual sells a sufficiently small proportion of total market output that its decision have no impact on market price, so taken as given); free entry and exit (when there are no special costs that make it difficult for a firm to enter or exit the market [perfectly contestable market]). See Hal R. Varian, Intermediate Microeconomics. A Modern Approach, W.W. Norton \& Company, New York, $7^{\text {th }}$ ed., 2006, p. 384; Robert S. Pindyck and Daniel L. Rubinfeld, Microeconomics, Pearson - Prentice Hall, $6^{\text {th }}$ ed., 2005, p. 262-263; William Baumol, John Panzar and Robert Willig, Contestable Markets and the Theory of Industry Structure, New York: Harcourt Brace Jovanovich, 1982. 
- The tied products are sold in fixed proportions (as a bundle);

- The tied products are complementary, not substitutes.

Under these conditions, Chicago scholars observed that there would be no incentive for the monopolist to engage in tie-in practices, since it can extract only one monopolistic profit. Therefore, it is more plausible to justify tied sales with a desire for price discrimination (increasing total surplus ${ }^{17}$ ) and/or a search for other efficiencies. In fact, Nobel Laureate George Stigler was the first to show that this conduct can reduce the variance between consumers' reservation prices, allowing price discrimination with a larger extraction of the consumer's surplus and a reduced deadweight loss ${ }^{18}$. The practice is particularly advantageous for the firm if the consumers' valuation of the products is inversely related.

Moreover, other Chicago scholars supported the single monopoly profit through their further formalizations around tie-in strategies. In a very famous article, Adams and Yellen (1976) showed that, with two separate products and a heterogeneous and independent demand, a mixed bundling solution seems to be optimal to increase the total surplus available ${ }^{19}$. The classic example is that of two consumers, Adam and Bob, with different willingness-to-pay (wtp). Adam has a modest wtp for both products, while Bob has a high wtp just for one of the two products. In this case, mixed bundling is the only strategy that allows catching both consumers. In effect, the first consumer (modest wtp for the two products) will choose the bundle, while the second one (high $w t p$ for one of the two products) will only choose one product.

In 1982, Richard Schmalensee extended the model to a monopolist in the tying market facing perfect competition in the adjacent tied market and independent demand for the

17 See Bowman W.S. (1957), cit.; Burstein Meyer L., "The Economics of Tie-in Sales", Review of Economics and Statistics, February 1960, 42, pp. 68-73. Surplus represents a measure of welfare for consumers or firms in a specific transaction or market outcome; it is calculated as the area beneath the inverse demand curve, delimitated by the price and such demand curve. The total surplus refers to consumers and suppliers' surpluses: the total surplus increases because the supplier can perfectly price discriminate, through specific tying solutions, between single consumers (increasing his own surplus and reducing the consumers' one). If the supplier fixes a price there will be part of the demand that does not want the product at those conditions: by price discriminating, the supplier will also serve that part of the demand but the consumer's surplus will be reduced in favour of the supplier, who will catch more surplus than the surplus lost by the consumers (people out of the market will now be served). Therefore, even though this transfer of surplus is questionable in a consumer's view, a mechanism of perfect price discrimination increases the total surplus and should be considered Kaldor-Hicks efficient, even though it involves distributional concerns. However, there is no unanimity on the increasing effect of the total surplus through perfect price discrimination, see for example Motta (2004), cit.

18 Stigler George J. (1963), cit.

19 Adams W. J. And Yellen J. L., "Commodity Bundling and the Burden of Monopoly”, Quaterly Journal of Economics, 1976, 90, pp. 475-498. These results were further extended by McAfee, R. P.; McMillan, J. and Whinston, M. D., "Multiproduct Monopoly, Commodity Bundling, and Correlation of Values", Quarterly Journal of Economics, 1989, 114, pp. 371-384; Michael A. Salinger, "A Graphical Analysis of Bundling”, 68 J. BUS., 85 (1995); Yannis Bakos and Eric Brynjolfsson, "Bundling Information Goods, Pricing Profits \& Efficiency", 45 MGMT. SCI., 1613 (1999); Hanming Fang and Peter Norman, An Efficiency Rationale for Bundling of Public Goods, mimeo (2004). 
two products (this time with a Gaussian demand, that is a joint normal distribution of reservation values), with non-negatively correlated valuations for separate components $^{20}$. He argued that, under these conditions, mixed bundling is an optimal strategy when the $w t p$ for the two products in the monopoly tying market and the competitive tied market are negatively correlated. The price of the bundle should be lower than the sum of the price of the single components. In effect, this strategy reduces variation in customers' reservation prices and generally increases total welfare. An important corollary of this finding is however that suppliers will be able to capture a significant portion of consumer welfare: in a nutshell, also in Schmalensee's analysis bundling practices lead to expanded access to the market for consumers, and to an extraction of consumer surplus by the supplier - in economic terms, total welfare increases, but consumer welfare decreases compared to a situation of pure unbundled sales. This situation involves distributional concerns but, for an economic point of view, it may be considered efficient ${ }^{21}$.

Even though the underlying assumptions are quite extreme, these theories have been largely sustained by Chicago school advocates and implemented until new scholars and Post-Chicago economists pointed out the weaknesses of this theory and the possibility, under certain conditions, that anti-competitive effects materialise.

\subsubsection{Anti-competitive effects and the revival of the leverage theory}

Looking at the developments in the law and economics theory of tying in the past two decades, a broad consensus seems to have emerged on the possibility that, under specific assumptions, this otherwise common practice proves harmful for competition and consumer welfare 22 . In a 1990 paper appeared in the American Economic Review, Michael Whinston pointed out the potential flaws of the Chicago School's "single monopoly profit" theorem ${ }^{23}$. In his revival of the leverage theory, the author correctly argued that the theorem fails to explain situations in which the proportions between products are variable (as in tying arrangements). Then, the strong assumptions of monopolistic setting in the tying market and perfect competition in the tied market further lessened the power of this general proposition. In particular, Whinston focused

20 Schmalensee Richard, "Commodity Bundling by Single Product Monopolies", 25 Journal of Law and Economics, 1982, pp. 67-71.

21 It can be considered as "Kaldor-Hicks efficient" or "potentially Pareto-efficient", since the practice produces a net benefit to society, despite the fact that one group (consumers) is left worse-off.

22 Whinston M. D. (1990), cit; Barry Nalebuff, "Bundling as a Way to Leverage Monopoly", National Bureau of Economic Research, WP N. 36, January 2004; Jay Pil Choi, "Antitrust Analysis of Tying Arrangements”, CESifo Working Paper, N. 1336, November 2004; Tirole J. (2005), cit; Carlton D. W. And Waldman M. (2005), cit.; Evans D. (2006), cit.

23 Whinston M. D. (1990), id. 
on the role of tying as a strategy to deter entry by new players by showing commitment to tie the sales of product should entry occur ${ }^{24}$.

According to Whinston, the single monopoly profit theorem holds only when ${ }^{25}$ :

- The tied market is perfectly competitive;

- The tied products are complementary (not substitutes); and

- The tied products are consumed in fixed proportions.

When one or more of these conditions do not hold, tying can still be seen as strategy to leverage the firm's own market power in the tying market into another (tied) market. This occurs in particular when:

- The tied product is consumed in variable proportions; or

- The market exhibits economies of scale or network externalities.

The latter situation can imply high entry barriers since competitors may not be able to reach a minimum efficient scale - or, in the case of network effects, the critical mass that makes sale of the good viable - that is reached by the monopolist through its tying practice $^{26}$.

More recently, in a series of papers commissioned by the UK Office of Fair Trading, Barry Nalebuff (2004) argued that, under specific assumptions, it is possible to deter entry also without commitment, if rivals can enter only one of the two markets ${ }^{27}$. More in detail, Nalebuff showed that if the products are subject to independent demand by consumer, they are sold in variable proportions, and the demand for the tied product is inelastic ${ }^{28}$, the incumbent may decide to charge customers less in the monopolistic market and to slightly increase the price in the tied market. In this way, the increased demand (marginally stronger in the monopolistic setting because already at supracompetitive price) will overcome the reduced income due to the discount. The same

24 More in detail, Whinston illustrates a two-period model to show that the mere pre-commitment to bundle complementary products (tied product with variable proportions) at period 1 can result in less earnings in period 2 for potential entrants in the relevant markets. The bundle (or tie) thus becomes a tool to deter market entry. However, this threat may not be credible if the potential entrants know the final outcome. In turn, the monopolist will not choose to bundle if it would not successfully deter the entry: in fact, bundling may be an optimal strategy from an ex-ante perspective, but it is clearly sub-optimal when the firm decides to enter. It is thus a constraint to more aggressive behaviours in the period 2.

25 Note that Whinston (1990) does not distinguish between tying and bundling. However, these assumptions are consistent with our previous definition of tying: as a matter of fact, in tying arrangements the tied product usually is in fixed proportion (you have to buy at least one tied product, while you can buy variable proportions of the tying product).

26 On network effects, see i.a. M. L. Katz and C. Shapiro, "Network Externalities, Competition, and Compatibility," American Economic Review (June 1985); and Pardolesi, R- and A. Renda, How Safe is the King's Throne? Network Externalities on Trial, Cucinotta, Pardolesi and Van Den Bergh (Eds), "Post-Chicago Developments in Antitrust Law", Edward Elgar Publishing, February 1, 2003.

$27 \quad$ Nalebuff B. (2004), cit.

28 "Independent demand" means that the demand for the tying product is not related to the demand of the tied product; "inelastic demand" means that the demand is less reactive to a price increase, namely a producer can raise prices without heavily reducing the demand for its product. 
theoretical argument was then refined by other authors including Greenlee, Reitman e Sibley (2008), who apply the rationale to famous antitrust cases such as $3 M$ Co v. LePage's, SmithKline Corp v. Eli Lily \& Co., and Ortho Diagnostics Systems v. Abbot Labs ${ }^{29}$.

Nalebuff's argument can be easily explained by means of two examples. First, let us assume that a firm $A$ sells two goods, $X$ and $Y$, and is dominant in the production of $Y$, while it faces actual or potential competition in $X$. Assume also that the two goods are not consumed in fixed proportions, and that the demand for the two products is independent (an increase in demand for one of the goods does not necessarily lead to an increase in demand for the other; and an increase in the price of one of the goods does not affect the demand for the other).

If this is the case, $A$ will be able to set a price for $Y\left(P_{Y}\right)$ in a way that maximises its profits, while the price for $X\left(P_{X}\right)$ will be set by market forces and will thus equal the marginal cost of producing the good, $c$. Nalebuff shows that $A$ can profitably engage in the following conduct:

- $A$ offers the bundle $(X+Y)$ at a price equal to $P_{Y}+P_{X}=P_{Y}+c$

- $A$ then increases the price for $Y$ (unbundled) by a small amount $\delta$.

In this situation, consumers that need both products have to choose whether to buy $Y$ at a higher price and $X$ from a competitive supplier, or buy both products from $A$ and get a discount from $Y$. This puts competitors in the $X$ market at a disadvantage: they will not be able to replicate this offer by $A$. In addition, consumers that only need $Y$ will be disadvantaged, as the price has increased to $\mathrm{P}_{Y}+\delta$.

This type of strategy reduces consumer welfare, as consumers that buy the bundle are not affected (the price remains the same), but consumers that buy only $Y$ will be disadvantaged. As stated by Greenlee, Reitman and Sibley (2008), a bundling strategy reduces social welfare if leads to a monopoly price for $Y$ greater than would occur absent the strategy.

Assume, now, that $A$ decides to sell $X$ at a discounted price equal to $P_{X}-\varepsilon$, under the condition that consumers buy also $Y$ at a higher price, say $P_{Y}+\delta$. For simplicity, assume that $\varepsilon=\delta$. The price for the bundle will still be equal to the sum of the prices for the two products separately. However, the monopolist's profits will increase alongside with total welfare.

What is more important, this strategy can deter the entry of new competitors. As a matter of fact, if a new entrant wanted to enter the $X$ market it would have to offer consumers at least the surplus value (if the following formula $<0$ ):

293 3M Co v. LePage's, 324 F.3d. 141 (2003), SmithKline Corp v. Eli Lily \& Co., 427 F. Supp 1089 (1976), e Ortho Diagnostics Systems v. Abbot Labs, 920 F. Supp. 455 (SDNY 1996). See Greenman, Reitman and Sibley, An Antitrust Analysis of Bundled Loyalty Discounts, International Journal of Industrial Organization, Volume 26, Issue 5, September 2008, Pages 1132-1152. 


$$
\left(\delta^{*} \mathrm{Q}_{Y-\mathrm{NB}}\right)+\left(-\varepsilon * \mathrm{Q}_{X-\mathrm{NB}}\right)^{30}
$$

(if $>0$ may be not convenient to buy the bundle instead the products separated) to compensate for their loss if they decide not to purchase the $X Y$ bundle altogether from $A$. This means that the new entrant $B$ should set a price that can be below cost. Since this type of bundling is not replicable by an as-efficient competitor, it does not pass muster under Nalebuff's test and - despite increasing social welfare in the short run - should be considered as leading to anti-competitive foreclosure.

More generally, according to Nalebuff:

- When $\mathrm{X}$ and $\mathrm{Y}$ are consumed in fixed proportions, bundling can have an exclusionary nature whenever the incremental price of the XY bundle compared to the price of $\mathrm{Y}$ alone is lower than the Long-Run Average Incremental Cost (LRAIC) faced by A for producing X.

- When $\mathrm{X}$ and $\mathrm{Y}$ are consumed in variable proportions, bundling can be anticompetitive if the price for $\mathrm{X}$ minus the discount needed to retain $\mathrm{A}^{\text {'s }}$ own customers is higher than the LRAIC faced by A for producing X (so-called "Ortho test").

Nalebuff's analysis has been very influential on competition authorities and courts in the past few years. The "leveraging" conduct described by Nalebuff deters entry even though there is no clear pre-commitment, and mitigates the inefficiency of monopoly pricing (making many consumers better off without harming anybody else, namely a Pareto improvement ${ }^{31}$ ). Of course, the foreclosure of competitors from the tied market $X$ may lead to long-run inefficiencies due to lack of innovation, absence of product variety and choice for consumers, and ultimately even an increase in price, once $A$ has obtained a large market share also in $X$.

However, Nalebuff's model was also subject to some criticism.

- First, the assumption of perfectly competitive $X$ and monopolistic $Y$ does not fit many of the tying and bundling cases observed in practice;

- The independence of the demand curves for $X$ and $Y$ is essential to reaching Nalebuff's result, and is difficult to reconcile with the assumption that the bundle will be bought by all purchasers of $Y$.

- Other background assumptions are questionable. For example, the fact that the demand for $X$ is inelastic, though this can intuitively be explained by the condition that the monopolist is the only player in that market. In addition, the

\footnotetext{
30 Assuming that $\delta, \varepsilon, \mathrm{Q}$ and $\mathrm{P}$ are natural positive values $\left(0<\delta<P_{Y} ; 0<\varepsilon<\mathrm{P}_{X}\right)$ and that $\varepsilon=\delta$, we can derive with some algebra this formula from $\left\{\left[\mathrm{P}_{X}-\left(\mathrm{P}_{X}-\varepsilon\right)\right] * \mathrm{Q}_{Y-\mathrm{NB}}\right\}+\left\{\left[\mathrm{P}_{Y}-\left(\mathrm{P}_{Y}+\delta\right)\right] * \mathrm{Q}_{X-\mathrm{NB}}\right\}$, which represents the original formula to calculate the surplus of the consumer if he decides to buy the bundle from $A$, instead Y from A and X from the new entrant B. NB refers to the quantity in the "no-bundle" situation.

31 A Pareto improvement is an action that harms no one but it makes at least one person better off.
} 
assumption that a perfectly competitive market exhibits an inelastic demand is quite extreme.

Accordingly, as acknowledged by both Nalebuff (2004) and Whinston (1990), the impact of tying and bundling strategies on the relevant market cannot be easily determined a priori, and a rule of reason appears more appropriate than a per se rule as a matter of fact, these authors do not analyse in detail the pro-competitive reasons for engaging in tying and bundling, but focus mostly on the strategic ones.

A similar view was also expressed by Jean Tirole (2005), who offers a number of justifications for differentiating between tying practices according to the nature of the products and the markets at stake. Tirole points out that: (i) when marginal costs are low (and fixed costs are high, as for information goods), bundling can reduce the price to near its lowest level if there is also the ability by competitors to differentiate in the tied market ${ }^{32}$. Moreover, the "multi-sidedness" of the tied product can be helpful to increase, in another way, the ability to differentiate in the market through the platform (as frequently happens in telecommunications markets). Bundling thus allows the metering of the demand and the market segmentation. Vice versa, when the marginal costs are high, the ability to differentiate is low and the product is not "multi-sided", there is a high probability that the tie-in practice is going to harm competition excluding competitors from the tied market. This is mainly due to the fact that, in a market with huge fixed costs and almost-zero marginal costs (as markets for information goods), these fixed costs need to be recouped and the inability to differentiate can significantly harm competition deterring the entry or potentially leaving one player in the market who is going to recoup losses in the subsequent period.

Another view of the potential harmful effects of tying comes from an article published in 2002 by Carlton and Waldman ${ }^{33}$. The two authors further weakened the seemingly granitic statement of Chicagoans. Whinston's assertion that tying can harm competition only when the monopolist's primary good is not in fixed proportions can be false in a two-period model with upgrades and switching costs (for example, durables and consumables). It is convenient to tie also if there is a superior alternative complementary product whose use requires the primary product. In fact, an entrant, in period 1, with a superior complementary product can decide to enter, in the period 2, also in the primary market. For the monopolist, tying in the first period can increase the entry costs for both primary and complementary products. In this way, tying is a device to preserve the monopolistic setting in the primary market ${ }^{34}$.

\footnotetext{
Tirole J. (2005), cit.
}

33 Dennis W.Carlton \& Michael Waldman, "The Strategic Use of Tying to Preserve and Create Market Power in Evolving Industries", 33 RAND J. ECON., pp. 194-220 (2002).

34 Choi and Stefanidis extended this reasoning stating that tying reduces also the incentives for each entrant to innovate since the reduced probability of successful innovation in all of the markets (requirement to succeed the innovation project); Choi J. P. and C. Stefanidis, "Tying, Investment, and the Dynamic Leverage Theory", 32 RAND J.ECON.,52-71 (2001). 
Other strategic arguments come up from the economic literature to address a different approach for tying. Carbajo et al. (1990) and Chen (1997) ${ }^{35}$ argue that (in different market settings; also in an oligopolistic market) tying can be a product differentiation device allowing market segmentation, hence restricting competition. The practice allows an increase in switching costs and marginal costs when products are homogeneous, eventually raising firms' profits in the market (avoiding perfect competition or a mechanism of competition à la Bertrand ${ }^{36}$ ). These circumstances will thus force consumers to engage in a practice that will lock them into those products ${ }^{37}$.

The figure below summarizes the features of the models described above by specifying the underlying assumptions on the market conditions assumed by the authors. The market's settings can be shaped through the effects of low or high marginal and fixed costs, switching costs (and lock-in effects), product multi-sidedness, information asymmetries, etc, in a way to adapt the analysis also to market settings in which there is not a monopolistic or perfectly competitive background but the effects of these features can almost recreate the same conditions of these two strong prepositions ${ }^{38}$.

35 Carbajo J., D. De Meza and D. J. Seidman, “A Strategic Motivation for Commodity Bundling”, Journal of Industrial Economics, 1990, 38, pp. 283-298; Chen Y., "Equilibrium Product Bundling”, Journal of Business, 1997, 70, pp. 85-103.

36 A mechanism of competition à la Bertrand is a one-shot oligopolistic game in which two firms end up competing through independently and simultaneously choosing the selling price. Considering other assumptions - as products' homogeneity, no capacity constraints and identical marginal costs (no fixed costs) - the unique price of equilibrium is the price of the perfect competition, which is at marginal cost. Although there are two firms, with these conditions, the oligopolistic setting will end up to price at marginal cost, getting zero profits. See Motta (2004).

37 While Tirole's analysis focused on the risk that the rivals' ability to differentiate in a low-marginal costs (high fixed costs) setting is low, Carbajo et al. (1990) and Chen (1997) mainly focus on a "standard" marginal costs setting which, deviating from the homogeneity of the product, can help to segment the market and restrict competition. In effect, following Tirole's view, the degree of foreclosure in the tied market is related to the dimension of marginal costs. A setting of high marginal costs increases switching costs, making harder to switch between products, unless the benefits of competitors' product is extremely high. Therefore, tying or bundling help competitors' foreclosure, potentially increasing barriers to competition. In a low-marginal costs setting (e.g. software products and so on), however, switching between products can be less expensive but competitors need to price over marginal costs to recover the high fixed costs. Tying, in this case, can be a way to sell close to the marginal cost (predatory strategy) and to finally reap the benefits of the following market monopolisation. It can also be a way to differentiate products and sustain a static competition between multiple firms (tacit collusion) as an alternative to market monopolisation strategies.

38 Although dominance or at least "economic power" (as in Kodak case) in one of the two markets seems still to prevail in the economic literature and in the current jurisprudence, there is also a growing literature performing models to analyze the anti-competitive effects of tying practices in a context of limited competition for the tied and tying markets, in Kobayashi, Bruce H., "The Economics of Loyalty Discounts and Antitrust Law in the United States”, 1 Competition Pol'y Int'l 115 (2005). Economides, for example, examined bundling practices in this market setting (duopoly) and showed that, with perfect complements, the dominant strategy is a mixed bundling, while, with perfect substitutes, bundling brings an inefficient outcome due to a Prisoner's Dilemma effect. See Economides Nicholas, Mixed Bundling in Duopoly, NYU Stern School of Business, WP EC 93-29 (1993); Matutes Carmen and Pierre Regibeau, "Compatibility and Bundling of Complementary Goods in a Duopoly", 40 Journal of Industrial Economics, pp. 37-54 (1992); Nalebuff B., "Competing Against Bundles", in Peter Hammond \& Gareth Myles, Eds., Incentives, Organization, And Public Economics, (Oxford U. Press 2000). 
Figure 2 - Relevant Models

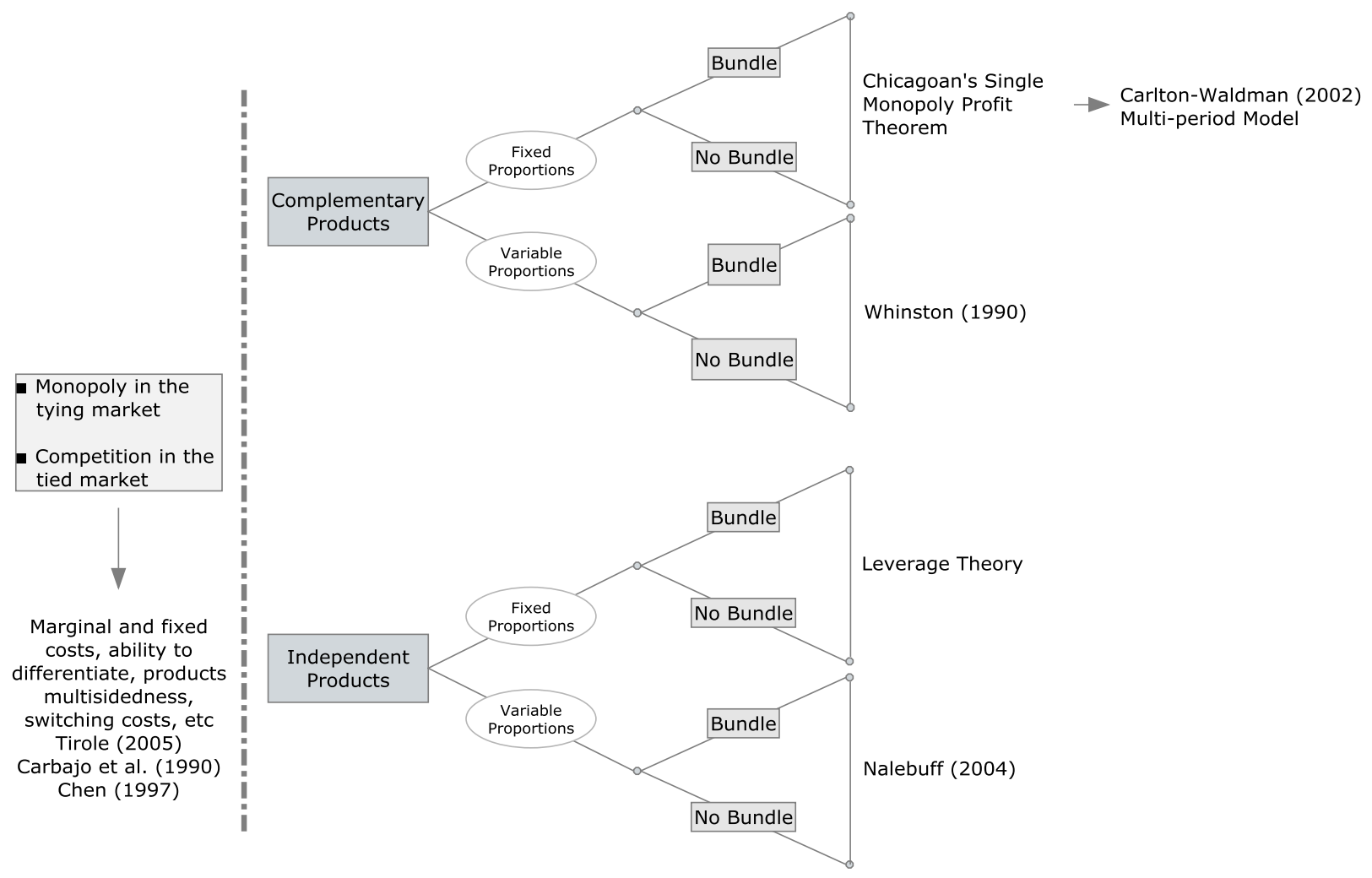

Source: authors' elaboration.

\subsubsection{Post-Chicago theories and other efficiency-enhancing features of tying and bundling practices}

The latest developments of economic literature on tie-in sales led the Chicagoans to rethink their theories and to find new insights about tying practices. This has led to a more flexible approach to these practices, which confirms the tendency of the economic theory toward the adoption of a rule of reason approach. For example, as recently explained by Choi (2004),
"the welfare implications of tying arrangements are in general ambiguous because tying could have efficiency effects even when it has harmful exclusionary effects". 39

Tying as a price discrimination mechanism is not the only likely efficient effect of these practices. In the last decade, many scholars ${ }^{40}$ have focused on the efficiency and pro-

39 Choi (2004), cit.

40 Some of them are Bowman W.S. (1957), cit.; Stigler George J. (1963), cit.; Nalebuff, B., "Bundling, Tying and Portfolio Effects, Parts 1 and 2," Department of Trade and Industry Economics Paper No. 1, 2003; Choi J. P., "Bundling New Products with Old to Signal Quality, With Application to the 
competitive effects of bundling and tying strategies. There are (other than the price discrimination) four main areas on which tie-in sales can act as a way to improve efficiency:

- Economies of scale and scope. These economies can emerge in both distribution and production processes. In particular, tying can allow firms to cross-subsidise highly demanded products and "niche" products - as in block booking and full line forcing - or better managing sales. In addition, tying can reduce costs of packaging and distribution, leading to economies of scale. It involves savings also for consumers, especially those ones who have a high reservation price for both products. In this respect, tying can lead to demandside advantages such as "one-stop-shop" effects.

- Reduction of information and transaction costs. For instance, a newspaper satisfies different consumer preferences (news on sports, politics, etc) involving a sort of "one-stop-shop" effect and reducing potential transaction costs that would come out if every single item would have to be purchased one by one. In many cases, producers are better informed than consumers on components to bundle. Moreover, tying can be also a way to signal the quality of the new product bundled to the old one, already known, to preserve the reputational capital with the new one ${ }^{41}$. In the financial services sector, cross-selling strategies can help to improve the risk management by assuring a more efficient flow of information from the customer to the bank. For example, in a recent paper on investment services, Laux and Walz (2009) show that cross selling can increase underwriters' incentives and even reduces rents in the underwriting business ${ }^{42}$.

- Avoiding double marginalization ${ }^{43}$. A cross-selling strategy can also avoid the risk of double marginalization in two complementary markets. Already in 1838, Augustin Cournot showed that bundling could improve the profits of two monopolists selling complementary products ${ }^{44}$. In effect, the practice leads to an inefficient equilibrium in which the firms do not take into account the impact of the cross-price elasticity and so firms and consumers can be better off if price would be lower (as it happens in the bundle). For instance, in case of

Sequencing of Products", 21 International Journal of Industrial Organization, 1179 (2003); Motta (2004), cit;; Tirole J. (2005), cit.; Evans (2006), cit.

41 Choi (2003), cit.

42 See, Laux and Walz, Cross-Selling Lending and Underwriting: Scope Economies and Incentives, Review of Finance (2009) 13: 341-367.

43 The double marginalization problem refers to the situation where vertically integrated firms (e.g. producer and retailer) add a double mark-up on the final price of the product due to their relevant market power along the value chain. See Spengler J., "Vertical integration and antitrust policy", Journal of Political Economy, 1950, Vol. 58, pp. 347-352; Motta (2004), cit., p. 307; Rey P. and Vergé T., "Economics of Vertical Restraints", in Buccirossi P. (eds.), Handbook of Antitrust Economics, MIT Press, 2008. See also Nalebuff (2004), cit.

44 Cournot, Augustin (1838). Recherches sur les principes mathématiques de la théorie des richesses, Paris: Hachette. 
complementary goods and prices set independently, the two monopolists of the complementary products will set price too high (monopolistic prices). A crossselling strategy leads the two monopolists to a common understanding through a price reduction to reap the benefits of a soaring demand. Therefore, both firms and consumers will be better off, avoiding the inefficient outcome.

- Quality improvements. When certain components are marketed together the risk of inefficient outcome due to the asymmetric information is drastically reduced. In effect, in some cases, the producer might know the best way to combine specific products in a way to increase the quality that the final consumer would enjoy. It can be a profitable practice for the firm, which increases the reputational capital, while the final consumer enjoys the highest possible level of quality 45 .

On the other hand, recent literature has also highlighted that tying arrangements, besides creating a potential restriction of competition, can also lead to other disadvantages for producers and consumers ${ }^{46}$. For example, combining products may increase the complexity and indirect costs for producers due, i.a., to higher maintenance and support costs; or increased risk due to the combination of risky products in financial services, which may lead to weaker risk management and lower transparency. Consumers, instead, can be generally harmed by tying practices in their freedom of choice, restricting their preferences to mix and match components.

\subsubsection{Tying and bundling under EC competition law}

Tying and bundling constitute so-called "exclusionary" abuses under Community competition law. The main competition concerns in this respect are the potential for these practices to foreclose existing competitors and inhibit the entry of new players, leading to consumer harm. Under Community competition policy, tying is treated by case law mainly in case of single and collective dominance under Article 82 of the European Community Treaty (ECT). Based on the pre-Chicago rationale of the "leverage theory" illustrated above, the role of market power ("dominance") in the tying or tied market is crucial in the analysis carried on by the European Commission and the EC

\footnotetext{
45 See Motta (2004), cit., p. 461.
}

46 Evans D. S. (2006), cit. 
Courts of these practices ${ }^{47}$. This implies that the undertaking must be found to be dominant in at least one of the relevant markets involved.

Dominance is defined, under EC law, as

"a position of economic strength enjoyed by an undertaking, which enables it to prevent effective competition being maintained on a relevant market, by affording it the power to behave to an appreciable extent independently of its competitors, its customers and ultimately of consumers" 48 .

Therefore, the Commission defines a firm as "dominant", with its "special responsibility" 49 , taking into account the following three factors ${ }^{50}$ :

1. The market position of the dominant undertaking and its competitors;

2. The existence of barriers to entry or expansion by actual and potential competitors;

3. The absence of a countervailing buyer power of the dominant undertaking's customers ${ }^{51}$

Concerning market shares in $A k z o^{52}$ the European Court of Justice established a $50 \%$ threshold to consider an undertaking to be dominant ${ }^{53}$. In the 2008 Guidance document on the treatment of exclusionary abuses under Article 82, the Commission confirmed that it "considers that low market shares are generally a good proxy for the absence of substantial market power"; and that its experience suggests that "dominance is not likely if the undertaking's market share is below 40\% in the relevant market."

47 A straightforward example is the famous merger GE $\backslash$ Honeywell prohibited by the Commission. The prohibition was principally based on the assessment of a potential "portfolio effect" that could result in non replicable bundles of complementary products, with a narrow definition of the relevant market See Case COMP/M.2220, General Electric/Honeywell, Commission decision of 3 July 2001; David S. Evans and Michael Salinger, "Competition Thinking at the European Commission: Lessons from the aborted GE-Honeywell Merger", 10 George Mason Law Review 489, 520 (2002).

48 See Case 27/76 United Brands Company and United Brands Continental v Commission [1978] ECR 207, paragraph 65; Case 85/76 Hoffmann-La Roche \& Co. v Commission [1979] ECR 461, paragraph 38.

49 This responsibility facilitates the finding of an abuse and makes easier that an efficient behaviour, if concerning a dominant firm, should be considered harmful for competition without "efficiency defence"; Case 322/81, Michelin v. Commission, § 10 [1983] ECR 3461.

50 European Commission, “Guidance on the Commission's Enforcement Priorities in Applying Article 82 EC Treaty to Abusive Exclusionary Conduct by Dominant Undertakings", C(2009) 864 final, Brussels, 09/02/2009, p.8-11.

51 See Case T-228/97 Irish Sugar v Commission [1999] ECR II-2969, paragraphs 97-104.

52 See Case Akzo C-62/86 (1991) ECR I-3359.

53 In Hilti, the Commission narrowed the relevant market so much to split it into three different markets and it found Hilti dominant in every market, condemning the firm for unlawful bundling practice. See Case IV/30.787, Eurofix-Bauco v. Hilti (1988) OJ L65/19. Clearer situation for Tetra Pak II and Microsoft (tipping through windows media player), a typical case of leveraging through tying (technological tying for Microsoft); case IV/31.043 Elopak v. TetraPak (1992) 0J L72/1. 
The likelihood of anti-competitive foreclosure of potential entrants or actual competitors relies on the analysis of several aspects ${ }^{54}$ : the position of the dominant undertaking; the conditions of the relevant market; the position of the dominant undertaking's competitors; the position of the customers or input suppliers; the extent of the allegedly abusive conduct; the possible evidence of actual foreclosure.

Therefore, the formal analysis of tying is based on a five-step assessment ${ }^{55}$ :

- Test of dominance (mainly based on market share held by the undertaking) in the tying market;

- Identification of two separate products (assessed on the basis of "commercial usage" or on the observation of the existence of a separate demand ${ }^{56}$ );

- Assessment of the coercion factor (i.e. customers are forced to buy tied products);

- Assessment of the anti-competitive effects (not clearly confirmed by case law ${ }^{57}$ );

- Evaluation of any exceptional justification or efficiency (reducing transaction costs and so on) for tying to exist.

Tying can be also seen as a predatory pricing strategy (with many similarities with the vertical price squeeze). As clarified by the Commission in its recent Guidance paper on Article 82, a multi-product rebate can be anti-competitive on the tying and tied market if the competitors, producing just one component, cannot compete against the discounted bundle ${ }^{58}$. The long run average incremental $\operatorname{cost}^{59}$ (LRAIC) is the parameter to measure the predation's aim. As stated by the Commission's Guidance paper,

"If the incremental price that customers pay for each of the dominant undertaking's products in the bundle remains above the LRAIC of the dominant firm from including this product in the

54 European Commission (2009), cit., p. 8-11.

55 See Christian Ahlborn, David S. Evans and A. Jorge Padilla, "The Antitrust Economics of Tying: A Farewell to Per Se Illegality", Antitrust Bulletin, 2003, p. 31.

56 The Court defines commercial usage narrowly and, to establish it, it is not sufficient that the tied sales are not the "predominant business practice" in the markets in question: as long as some untied sales occur in the relevant markets the condition for commercial usage is not satisfied. See Tetra Pak II, cit. In the 2008 Guidance paper on the application of Article 82 to exclusionary abuses, the Commission proposes the following formulation of the distinct product test (para. 51): "Two products are distinct if, in the absence of tying or bundling, a substantial number of customers would purchase or would have purchased the tying product without also buying the tied product from the same supplier, thereby allowing stand-alone production for both the tying and the tied product". See, for a comment, N. Economides and I. Lianos, The Elusive Antitrust Standard on Bundling in Europe and in the United States in the Aftermath of the Microsoft Cases, Antitrust Law Journal 76.3 (2009).

57 In British Sugar, the Commission did not accept this test, while, in Hilti, the Commission confirmed that the elimination of the possibility to buy the tied product was an abusive exploitation (if there is a restriction of consumer choice, there should be no evaluation of the foreclosure effects, enacting a per se prohibition). See Napier Brown v. British Sugar, Commission Decision 88/519/EEC, 1988 0.J. (L 284) 41; Eurofix-Banco v. Hilti, id.

58 European Commission (2009), cit., p. 19.

59 The LRAIC is a good proxy of the average total costs (ATC), since it represents the average of all the (variable and fixed) costs that a company incurs to produce a particular product. 
bundle, the Commission will normally not intervene since an equally efficient competitor with only one product should in principle be able to compete profitably against the bundle". 60

Where firms compete "bundle against bundle", the attention is on the price of the bundle as a whole and on the effect of this price on the possibility to compete by sellers of one product. This "equally efficient competitor" test must be carefully applied, in order to avoid that firms are punished for having lower costs (and consequently prices) than its rivals. In general, a firm should not be punished for having lower costs and so prices than its rivals. ${ }^{61}$ However, as mentioned above, bundling can be a way to enforce exclusionary strategies, such as predatory pricing. Therefore, the legitimate aim to encourage efficient entrant should be balanced with the risk coming from exclusionary strategies.

In summary, a multi-product rebate ${ }^{62}$ may be found to infringe Article 82 if a firm holding a dominant position in at least one of the bundled products offers it. On one hand, if competitors offer a subset of the products included in the bundle or only one product, the LRAIC of these latter products will be compared with their price in the dominant firm's bundle. On the other hand, if competitors can replicate the bundle, the price-cost test will be run on the whole bundle instead of the individual products in the bundle ${ }^{63}$.

\subsubsection{US approach to tying and other potentially unfair commercial practices}

For the purposes of assessing the impact of policy on cross-selling practices, a "natural experiment" is provided by the US experience, where anti-tying restrictions have been enacted since the 1970s. Cross-selling strategies have been for long time and are, still today, part of a heated debate not only in the economic literature but also in the US and EC case law. In the United States, tying is covered by four laws ${ }^{64}$ plus a specific regulation in the banking sector:

- Section 1 of the Sherman Act (prohibition of contracts in restraint of trade) ${ }^{65}$;

- Section 2 of the Sherman Act (monopolization) ${ }^{66}$;

$60 \quad$ European Commission (2009), cit., p. $19 \S 59$.

61 See Posner Richard A., Antitrust Law, The University of Chicago Press, Chicago, $2^{\text {nd }}$ ed., 2001 (stating that "It would be absurd to require the firm to hold a price umbrella over less efficient entrant [...] because we want to encourage efficiency").

62 A multi-product rebate refers to the cross-selling strategy of giving a big discount on one product when the consumer buys a specific quantity of another product. The practice is harmful when firms with relevant market power and through a predatory rebate enact it. See Choi (2003), cit.

63 In addition, if competitors can offer a sub-set of the bundled products, it makes sense to run the test on this subset of products. See, i.a. CEPS, The Treatment of Exclusionary Abuses under Article 82 EC Treaty, Report of a CEPS Task Force, forthcoming, July 2009.

${ }^{64}$ See US DOJ (2008), id.

6515 U.S.C. $§ 1(2000)$. 
- Section 3 of the Clayton Act (arrangements that "substantially lessen competition; in the special sectors of goods, wares, merchandise, machinery, etc) ${ }^{67}$;

- Section 5 of the Federal Trade Commission Act (prohibition of "[u]nfair methods of competition") ${ }^{68}$;

- Section 106 of the Bank Holding Company Act of 1970 (anti-tying provisions) ${ }^{69}$.

In this section, we briefly illustrate the treatment of tying and other potentially unfair commercial practices in US antitrust.

\subsubsection{Tying and similar practices in US antitrust law}

Tie-in practices have mainly been treated as a restraint of trade (contractual) or as a conduct to monopolize a market, respectively under Section 1 and 2 of the Sherman Act $^{70}$. Under this regulation, the jurisprudential treatment of tying arrangements seems to have moved from a "per se rule" illegality ${ }^{71}$ to a "rule of reason" approach ${ }^{72}$ through a "modified per se rule" in assessing, case-by-case, the anticompetitive effects of these practices, following the route drawn by the economic literature ${ }^{73}$.

The whole point of the per se illegality is to avoid expensive individualized inquiries concerning competitive effects [...]. The use of an anticompetitive effects requirement probably reflects considerable doubts about the wisdom of the per se rule. (Hovenkamp, 1999, p. 393) 74

${ }^{66} \mathrm{Ibid} . \S 2$.

${ }^{67} \mathrm{Ibid}$. 14.

${ }^{68}$ Ibid. $\S 45(a)(1)$.

${ }^{69} 12$ U.S.C. $§ 1972$ (1).

70 See US DOJ (2008), id.

${ }^{71}$ Standard Oil Co. Of Cal. V. United States (Standard Stations), 337 U.S. 293, 30506 (1949).

72 Although the Court stated that its approach was explicitly referred to the specific sector of "platform innovation for PCs, network computers and information appliances", Microsoft III defines, for the first time, a rule of reason approach for tying arrangements. However, this case was different from the regular cases usually addressed by the Supreme Court: it is a controversial case of technological integration (complex evaluation) and the tying was deemed as value-enhancing both for producers and consumers. United States v. Microsoft Corp., 253 F.3d 34 [Microsoft III] (D.C. Cir. 2001); see Ahlborn et al. (2003), Id.

73 The US Department of Justice, for example, "[...] believes that the historical hostility of the law to tying is unjustified. In particular, the qualified rule of per se illegality applicable to tying is inconsistent with the Supreme Court's modern antitrust decisions and should be abandoned". See US DOJ (September 2008), Chapter $5, i d$.

${ }^{74}$ Hovenkamp, H. (1999), Federal Antitrust Policy. The Law of Competition and Its Practice, second edition, Hornbook Series. 
However, Jefferson Parish 75 "modified per se rule" still holds as dominant legal doctrine for tying. This idiosyncratic per se approach in Jefferson Parish consists of some steps to assess the anti-competitiveness of a tie-in practice. The steps are:

1. Existence of two separate products 76 ;

2. Existence of economic power in the tying market ${ }^{77}$;

3. Influence on a "not insubstantial" amount of interstate commerce ${ }^{78}$.

The existence of economic power is a condition to verify another essential point in the analysis of tying practices: coercion ${ }^{79}$. The economic power to assess a restraint of competition ${ }^{80}$ and the potential subsequent coercion on consumers' choice are usually evaluated through the market share, without setting a specific market share threshold, just a "sufficient" one ${ }^{81}$. It is also true that a mere evaluation of market share cannot give any evidence of coercion and it can provide courts with a misleading view of a firm's ability to force consumers into the tie-in sale. For instance, in Kodak, the Supreme Court - confirming the Jefferson Parish's "modified per se rule"- found Kodak guilty of an illegal tying practice with a market share of only $20 \%$ on the primary market ${ }^{82}$. In its judgment the Supreme Court let prevail an analysis of lock-in effects for consumers, due to relevant information asymmetries. Therefore, the economic power, coming from the lock-in effect on consumers, recreated a similar market setting where the tying firm benefits from the dominant position (the effect is the same). The market share is just a fictitious aspect if consumers are not allowed to freely choose and access the product's substitutes to boost competition in the market. In economic theory, the market power is not a sufficient condition to experience anticompetitive effects ${ }^{83}$. In fact, the progressive distance between the notion of "sufficient market power" and "dominance", in its common meaning, has reduced the critical relevance of market share in the US approach. The incidence of other factors on the definition of market power is straightforward to analyze the anticompetitive effects of tying practices.

Another aspect is the uniqueness of the practice. The practice should not be replicable by other competitors. However, it is not such a valuable condition if the market is segmented due to the lock-in effect and switching costs in an oligopolistic market

\footnotetext{
75 Jefferson Parish Hospital Dist. N. 2 et al. v. Hyde, 466 U.S. 2, 16 (1984).

76 "Separate products are defined to be those where consumer demand exists for the stand-alone products outside of the bundle", Kobayashi (2005), id., p. 4.

77 In Fortner II, the Court mentioned a requirement of economic power in tying market; United States Steel Corp. v. Fortner Enterprises, Inc., 429 U.S. 610 (1977) (hereinafter "Fortner II").

${ }^{78}$ Fortner Enterprises, Inc. v. U.S. Steel Corp., 394 U.S. 495, 499 (1969) (hereinafter "Fortner I")

${ }^{79}$ Jefferson Parish (1984), id.

80 Northern Pacific Railway Co. v. U.S. 356 U.S. 1 (1958). However, the dominance test and the coercion test are two separate tests, even though in their implementation they are commonly seen as a single test.

81 Times-Picayune Publishing Co. et al. v. United States, 345 U.S. 594, 614 (1953).

82 Eastman Kodak Co. v. Image Technical Services, Inc. et al., 504 U.S. 451 (1992).

83 Ahlborn C. et al. (2003), id., p. 5.
} 
setting. In effect, the replicability of the practice become irrelevant if the market is structurally segmented and the competitor cannot enact the practice in the targeted market.

Concerning the anticompetitive effects, it was not required by Jefferson Parish to make this test. However, this test is frequently implicit in the assessment of economic power and power to coerce. In fact, this test would confirm the inefficiency of per se rule standard. The US Department of Justice (DOJ), in line with the modern Supreme Court jurisprudence under Section 1 and 2 of the Sherman Act, prefers as "second best" a costly disproportionality test, i.e. a way to analyze the trade-off between procompetitive and anti-competitive effects. In fact,

"the Department will continue to work to develop conduct-specific
tests and 'safe harbors'. However, in general, the Department
believes that, when a conduct-specific test is not applicable, the
disproportionality test is likely the most appropriate test identified
to date for evaluating conduct [...]".84

The Supreme Court recently acknowledged that "many tying arrangements ...are fully consistent with a free, competitive market"85. In another case, the Supreme Court argued that a per se rule standard is appropriate if courts have sufficient experience with a practice to determine with confidence that the practice is anti-competitive in all circumstances. Therefore, if there is a "limited" official adoption of a rule of reason with Microsoft III, in the judicial treatment of disputes on tying a case-by-case approach (with an implicit analysis of anti-competitive effects) is already frequent use and the passage to the rule of reason is just a matter of time.

\subsubsection{The US ban on tying in the banking sector: few cases and systematic circumvention}

In the US, a specific anti-tying regulation is enacted in the banking sector. The Congress, in 1970, approved the Bank Holding Company Act (BHCA) and in particular the Section 106 (12 U.S.C. $§ 1972$ ) concerning the prohibition of tying arrangements in investment and banking services performed by banks. A bank shall not "extend credit" or "furnish any service" on the condition or requirement that the customer shall obtain some additional credit or other specific banking products. The Federal Reserve Board (Fed) then defines exemptions, whenever they consider a specific practice "usual", without lessening the purposes or substantially modifying the structure of the anti-tying provision.

There are three conditions for the application of Section 106 of the BHCA:

\footnotetext{
${ }^{84}$ US DOJ (2008), id., p. 11.

85 Illinois Tool Works Inc. V. Indep. Ink, Inc., 547 U.S. 28, 45 (2006).
} 
- $\quad$ The tying arrangement;

- The "unusual" requirement;

- The benefits for the bank (the bank should benefit from the tying arrangement).

The coercion is not a requirement for the application of this regulation.

In 1999, the Gramm-Leach-Bliley Act ${ }^{86}$ weakened, however, the content of the BHCA through the possibility for financial institutions to operate as fully diversified financial organizations (through ad hoc subsidiaries). The act led those institutions to offer an array of banking and non-banking products to customers (through the subsidiaries not considered "banks"), lessening the strength of the "unusual" requirement and increasing the possibility to reach economies of scope or the same result of a tying practice but circumventing the BHCA regulation. In effect, few cases of tying have been detected since $1970^{87}$ and additional steps for a sound enforcement should be taken ${ }^{88}$.

On one hand, anti-tying provisions are mainly justified with the risk to compromise the safety and soundness of the main banks' liabilities (deposits) insured by the Federal Government. In effect, tying or bundling could be a way to extend banks activities in other businesses, exposing these deposit-based institutions to risks not properly related with their core services. The instability of these institutions thus might hamper the financial sector and so the financial stability at a systemic level. In addition, some argued that tying restrictions are merely a way to offset the competitive advantage that banks enjoy through the access to discounted credit lines and credit insurance of the central bank, but they should be subject to stricter regulation and supervision. Then, the FED confirmed that tying in banking "may force customers to take unwanted in order to obtain needed services, primarily loan products" 89 .

On the other, over the past few years - and mostly before the financial crisis - the debate over the need to relax anti-tying restrictions has become hectic. Many commentators have argues that such restrictions hampered banks from engaging in beneficial agreements with customers, with the result that important benefits (mostly from one-stop-shop efficiencies) would be foregone.

Lastly, several reasons explain why just few cases of tying have been detected since 1970 and then favoured the circumvention with the GLBA in 1999. Firstly, there is customers' reluctance to report violations since they fear that their personal relationship with the bank would be jeopardized or simply because they do not know that they may obtain credit or buy products at least with the same terms or price somewhere else (feeling the pressure of their own bank on eventually taking the

\footnotetext{
${ }^{86}$ GLBA; Pub. L. No. 106-102, 113 Stat. 1338.

${ }^{87}$ See, US General Accounting Office, "Bank oversight. Few Cases of Tying Have Been Detected, Report to Congressional Committees", May 1997.

${ }^{88} \mathrm{GAO}$ [2003] http://www.gao.gov/new.items/d044.pdf.

89 FED [2005] http://www.aba.com/NR/rdonlyres/B838E06D-5154-4DAE-88BA9675204386A6/38783/AlvarezRiskSpeech2005.pdf.
} 
financial product or service out ${ }^{90}$ ). Secondly, there is a clear difficulty in identifying evidences of illegal tying in related documentation. In addition, without a specific objection it is hard to know where looking for evidences (GAO, 2003). Last but not least, the GLBA (which made the circumvention "systematic") was designed to horizontally enhance competition in financial services and to encourage financial institutions to generate economies of scope or cost savings ${ }^{91}$ to sustain the financial and economic growth of the whole American banking, insurance and investment services markets.

\subsubsection{Preferential or exclusive agreements}

Firms imposing an exclusive dealing arrangement require customers to buy a certain product or service from a specific supplier. This practice often involves the agreement on a contractual term under which the buyer commits not to purchase an additional product from the supplier's rival ${ }^{92}$. This obligation may be induced by a preferential or exclusive agreement between the supplier and a specific provider or because the firm is one of the same group. Such a practice is often observed in business-to-business contracts (B2B) to avoid dealer's risk of free riding ${ }^{93}$ but it is also observed in a business

\footnotetext{
90 Litan [2003], cit.

91 Litan [2003], cit.

92 Louis Kaplow and Carl Shapiro, The Handbook of Law and Economics, Shavell and Polinsky eds., Elsevier, 2008.

93 It usually happens when a dealer in the dominant undertaking's distribution channel agrees to sell also rivals' products, while it is using specific investments and the infrastructure built by the
} 
to consumers (B2C) framework. This contractual practice is helpful in presence of "freerideable" investments ${ }^{94}$ to assure high quality standards in the provision of the final product or economies of scale and scope. In effect, to guarantee investments in pre-sale services and an efficient provision of information, an exclusive agreement can help the seller to avoid that the buyer will free-ride on her investments, for instance, using the pre-sale services from a specific seller and purchasing the product or service from another one. This is usually a common practice in B2B frameworks (producer and distributor).

The antitrust economics of exclusivity suggest that sales conditional to exclusivity should not be considered as per se unlawful, as they can promote investment by making demand and supply more predictable and by reducing free-riding by rivals who may benefit from a firm's investments. Pro-competitive justifications for exclusive dealing include, for the demand side, supply assurance, protection against price fluctuations, and facilitating long term planning by reducing risk; from the supply-side, the reduction of selling expenses, protection against price fluctuations, etc.

The traditional "Chicago" view of exclusive dealing arrangements in antitrust implied that such practices do not pose a threat to competition because a buyer will agree to exclusivity only if the arrangement delivers more surplus than alternative arrangements, including non-exclusive deals. According to Judge Robert Bork,

"there has never been a case in which exclusive dealing or requirements contracts were shown to injure competition. A seller who wants exclusivity must give the buyer something for it. If he gives a lower price, the reason must be that the seller expects the arrangement to create efficiencies that justify the lower price. If he were to give the lower price simply to harm his rivals, he would be engaging in deliberate predation by price cutting, and that ... would be foolish and self-defeating behavior on his part" 95 .

Nevertheless, they can also raise prices and lower consumer welfare by foreclosing a market to rival firms. For example, authors show that the bargaining model that is the core of the Chicago analysis (i.e., that buyers will accept an exclusive relationship only if

dominant firm; see Howard Marvel, "Exclusive Dealing", 25 Journal of Law and Economics 1, 1982; Benjamin Klein and Andres V. Lerner, "The Expanded Economics of Free-Riding: How Exclusive Dealing Prevents Free-Riding and Creates Undivided Loyalty", 72 Antitrust Law Journal 473, 2007, pp. 481-483.

94 Jan B. Heide, Shantanu Dutta and Mark Bergen, "Exclusive Dealing and Business Efficiency: Evidence from Industry Practice", The Journal of Law and Economics, Vol. 41, N. 2, October 1998, pp. 387-408; Alden F. Abbott and Joshua D. Wright, "Antitrust Analysis of Tying Arrangements and Exclusive Dealing", forthcoming in Antitrust Law and Economics, Edward Elgar Publishing, Keith N. Hylton (ed.), George Mason University Law and Economics Research Paper Series, 08-37, p. 29.

95 See Gilbert, R. J. (2000), Exclusive Dealing, Preferential Dealing, and Dynamic Efficiency, Review of Industrial Organization 16: 167-184. 
it is the most efficient) can break down if there are many uncoordinated buyers ${ }^{96}$. Their model has been extended by Segal and Whinston (1997), who show that their reasoning applies with even greater generality when the seller can price discriminate and bargain sequentially with customers ${ }^{97}$.

In our opinion, under EC competition law preferential and exclusive agreements - as we defined them - might be construed as falling into the category of abusive discrimination, and as such could potentially be subject to article Art. 82(c) ECT, which prescribes that a dominant undertaking should not apply dissimilar conditions to "equivalent transactions". These types of practices would in any case fall outside the Commission Guidance paper, which explicitly focuses on exclusionary abuses. However, the application of Article 82(c) ECT to cases of abusive discrimination has so far mostly concentrated on cases in which the dominant undertaking was a legal monopolist, or as a part of a broader series of abusive conducts by a dominant undertaking, as in the case of, i.a. Irish Sugar ${ }^{98}$.

\subsection{Other potentially unfair commercial practices as exclusionary abuses in competition law}

Apart from tying and bundling, this paper looks also at other potentially unfair commercial practices such as conditional and loyalty rebates, preferential or exclusive agreements and aggressive commercial strategies. Of these practices, some may fall under the scope of antitrust law, besides being potential matter for consumer protection: this is undoubtedly the case of rebates and exclusive dealing agreements, but may also occur in the case of conditional sales.

Although the 2008 Guidance paper does not mention other potentially unfair practices that may be relevant for the purposes of this Report, in our opinion the paper provides a relevant background with a general test that may apply to all observed practices, whether alone or in combination with other conducts, even though not explicitly mentioned by the Commission's paper.

\footnotetext{
96 See Rasmussen, E., J. M. Ramseyer, and J. Wiley (1991) 'Naked Exclusion', American Economic Review, 81, 1137-1145

97 Aghion, P., and P. Bolton (1987) 'Contracts as a Barrier to Entry', American Economic Review, 77, 388-401. Segal, I., and M. Whinston (1997), 'Exclusive Dealing and Specific Investments', Technical Report. Harvard University and University of California, Berkeley.

98 T228/97, Irish Sugar v. Commission, [1999] ECR-II 2969, para. 188.
} 
The test requires that the observed conducts lead to (or are likely to lead to):

- Foreclosure of "as efficient competitors" or - under specific circumstances - even "not yet as efficient competitors".

- An adverse impact on consumer welfare, "whether in the form of higher price levels than would have otherwise prevailed or in some other form such as limiting quality or reducing consumer choice ${ }^{\prime \prime 9}$.

In this respect, the Commission clarifies that the main goal of the application of Article 82 to exclusionary abuses is indeed the protection of consumers, rather than competitors $^{100}$. Moreover, in the Guidance paper the Commission identifies a number of factors that might be considered relevant in the assessment of dominance ${ }^{101}$; as well as factors that may be taken into consideration in assessing the likelihood that an observed conduct by a dominant undertaking is likely to lead to anti-competitive foreclosure ${ }^{102}$. The Commission puts emphasis on a more sound economic approach to exclusionary abuses.

It also clarifies that, depending on the circumstances, actual proof of anti-competitive foreclosure may not be needed, and that the mere "likelihood" that a conduct leads to anti-competitive foreclosure could form the basis for a finding of abuse. For example, the Commission states that

"[t]here may be circumstances where it is not necessary for the Commission to carry out a detailed assessment before concluding that the conduct in question is likely to result in consumer harm", and that "[i]f it appears that the conduct can only raise obstacles to competition and that it creates no efficiencies, its anti-competitive effect may be inferred"103.

In other words, the standard of proof for a finding of abuse is likely to change according to the circumstances of the case: truncated analyses and presumption of anti-

\footnotetext{
$99 \quad$ See Guidance Paper, $\$ 19$.

100 Id., para.6, stating that "the Commission is mindful that what really matters is protecting an effective competitive process and not simply protecting competitors. This may well mean that competitors who deliver less to consumers in terms of price, choice, quality and innovation will leave the market".

101 Id., para.12. These factors include: (i) the market position of the dominant undertaking and its competitors; (ii) constraints imposed by the credible threat of future expansion by actual competitors or entry by potential competitors; and (iii) constraints imposed by the bargaining strength of the undertaking's customers (countervailing buyer power).

102 Id., para.20. These factors include: (i) the position of the dominant undertaking; (ii) the conditions on the relevant market; (iii) the position of the dominant undertaking's competitors; (iv) the position of the customers or input suppliers; (v) the extent of the allegedly abusive conduct; (vi) possible evidence of actual foreclosure; and (vii) direct evidence of any exclusionary strategy.

Id., para.22.
} 
competitive behaviour will thus be important in the future treatment of exclusionary abuses under EC competition law.

The figure below illustrates in graphical terms the general approach adopted by the Commission in the Guidance Paper. It is unclear, however, how this test should proceed when the conduct may foreclose an as-efficient competitors but it does not consistently affect consumer welfare.

\section{Figure 3 - The General test adopted in the December 2008 Guidance Paper}

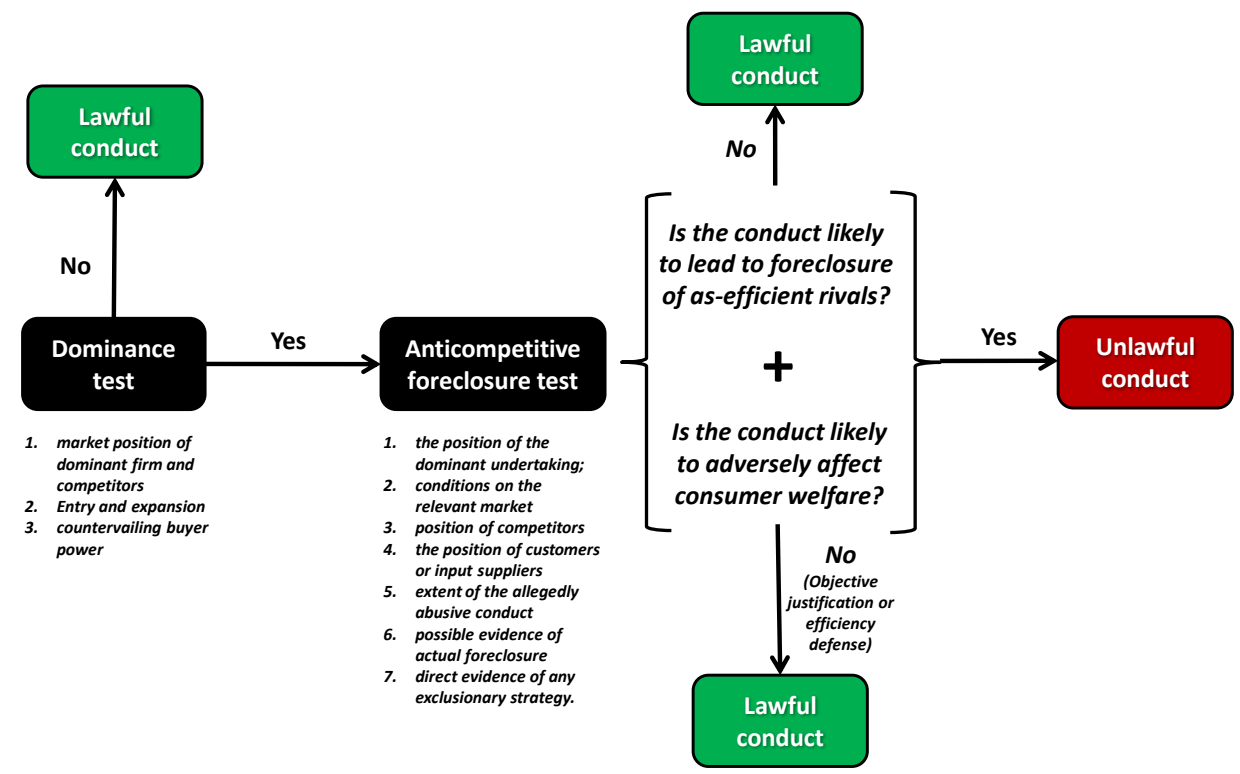

\subsubsection{Conditional sales practices}

\subsubsection{Conditions attached as essential for the conclusion of the contract}

A firm may decide to impose an essential condition for the purchase of a given service. Such conditions may relate, for example, to the payment of the salary into the current account that is linked to a mortgage loan. From the standpoint of competition policy, in principle conditional sales do not lead to an exclusionary abuse, especially when competitors can replicate the same practices, regardless of their scale.

However, under certain circumstances this type of practice can work in the same way as an exclusive dealing arrangement: for example, by requiring the customer to have the 
salary paid into a current account linked to a mortgage loan (the so-called "current account mortgage" practice), a mortgage lender is indeed limiting the attractiveness of competing offers by alternative current account providers, as the customer would not be able to fully profit from better contractual conditions, if the bulk of his savings are in the current account linked to the mortgage loan. Put differently, for many consumers there can only be one "main" current account: tying the "main" account to the mortgage loan also means requiring quasi-exclusivity in current account usage, and thus may foreclose as-efficient competitors in the market for current accounts. As a matter of fact, if a customer has committed to have the salary paid into a given current account, it may be impossible for a more efficient entrant to attract that customer to its own services: this is an example of cases in which contracts may act as barriers to entry.

In competition policy, an exclusive dealing agreement can have harmful effects on consumers especially when enacted by a dominant undertaking ${ }^{104}$, since it can induce to pass on consumers the increased costs borne by the counterparty in the B2B framework. It may have the immediate effect of preventing the entry or the expansion of competing undertakings, once the following factors have been considered:

- The harm suffered by the customer (e.g., opportunity costs);

- The market structure (e.g. contestability, switching costs, etc);

- The extent of the foreclosure effect;

- The duration of the contract at the issue;

- The success in raising rival's costs ${ }^{105}$;

- The business justifications;

- The role of potential competitors ${ }^{106}$.

This practice can be enacted - also by non-dominant undertakings - in the B2C relationship to further increase customers' switching costs and to exploit in a more efficient way lock-in effects. It may eventually reduce customers' mobility and freedom of choice, so objective justifications (as to preserve relevant pre-sale investments) need to be shown in order to consider this practice "fair" (not harmful for customers).

In the Guidance paper on the application of Article 82 to exclusionary abuses, the European Commission clarifies that

104 European Commission (2009), cit., §33-36.

105 See Steven C. Salop \& David T. Scheffman, "Raising Rivals' Costs", 73 AM. ECON. REV., 1983, p. 267; Thomas G. Krattenmaker \& Steven C. Salop, “Anti-competitive Exclusion: Raising Rivals' Costs to Achieve Power Over Price”, 96 YALE L. J., 1986, p. 209.

106 European Commission (2009), cit., §34. 
"[t]he capacity for exclusive purchasing obligations to result in anticompetitive foreclosure arises in particular where, without the obligations, an important competitive constraint is exercised by competitors who either are not yet present in the market at the time the obligations are concluded, or who are not in a position to compete for the full supply of the customers"107.

This is the case in particular when competitors are unable to compete for an individual customer's entire demand since the dominant firm is an "unavoidable trading partner", for example because its brand is a "must stock item" preferred by many final consumers or because the capacity constraints on the other suppliers are such that a part of demand can only be provided for by the dominant supplier. In effect, if competitors can compete on equal terms for each individual customer's entire demand, the Commission considers that
"exclusive purchasing obligations are generally unlikely to hamper effective competition unless the switching of supplier by customers is rendered difficult due to the duration of the exclusive purchasing obligation".

Finally, the Commission considers that the longer the duration of the obligation, the greater the likely foreclosure effect.

Against this background, under EC competition law a conditional sale agreement would be relevant only when it is likely to lead to anti-competitive foreclosure - i.e. both foreclosure of competitors and consumer harm. In the case of conditional sales such as current account mortgages, it all depends on a number of elements, such as: (i) whether the current account on which the salary has to be paid is offered by a dominant mortgage lender or by an affiliated body; (ii) whether the conduct creates or is likely to create efficiencies on the side of the lender; (iii) the likelihood that these efficiencies are shared with customers in the form of better contractual conditions such as i.a. lower interest rates; (iv) whether the combined sale of a mortgage loan and a current account would have been exclusionary even without the additional condition of having the salary paid into that account; ( $v$ ) whether transporting the mortgage to another lender is feasible, etc. 


\subsubsection{Conditional rebates as an antitrust infringement}

A supplier can induce consumers to purchase all or part of the sold products in different ways. In markets structurally affected by high switching costs, a discount system may help to capture new customers and subsequently charge them with higher prices (once locked-in or once competitors have left the market). A widespread discounting practice is the conditional rebate. They are "granted to customers to reward them for a particular form of purchasing behaviour"108. The scheme consists of a rebate on customer's purchases if he or she meets a set target volume. This target can be a percentage of the total volume, a standardised level or an individualised amount on a set reference period. In addition, this non-linear discount scheme can be calculated as:

- A price cut on the incremental products or services over the threshold bought by the customers (incremental rebates

- A rebate granted on all purchases in the reference period after the targeted volume has been bought (retroactive rebates) ${ }^{109}$.

The practice of granting single-product rebates is considered to be potentially very harmful for consumers, especially due to its loyalty-inducing effects and the consequent likelihood of anti-competitive foreclosure ${ }^{110}$. The legal analysis of conditional rebates is usually carried out on the basis of article 82 ECT. It usually involves exclusionary and foreclosure effects similar to exclusive purchasing obligations whether enacted by dominant undertakings under specific conditions ${ }^{111}$. The discount should be applied on a determined reference period. Three elements are relevant in a conditional rebate to assess the loyalty enhancing effect:

1. The level of the threshold. The granting of a rebate is related to the achievement of a specific threshold volume. This volume can be standardised or individualised. An individualised amount easily allows undertakings to define a level to make it more difficult for customers to switch suppliers, creating a strong loyalty-inducing effect ${ }^{112}$. The retroactive discounted basis involves a so-called suction effect ${ }^{113}$ around this targeted volume. In fact, when the threshold is set above the level that would be anyway purchased by the customers, it can induce

108 European Commission (2009), Guidance on the Commission's enforcement priorities in applying Article 82 of the EC Treaty to abusive exclusionary conduct by dominant undertakings”, cit., §37.

109 We will refer to retroactive rebates while incremental rebates, due to the lower harmful effect, will be generally treated in the next paragraph.

110 See, i.a., O’Donoghue, R. and A.J. Padilla, The Law and Economics of Article 82 EC, Hart Publishing, Oxford, 2006.

111 European Commission (2009), cit., §34.

112 Id., $\$ 45$.

113 See F.P. Maier-Rigaud, "Switching Costs in Retroactive Rebates: What's Time Got to Do with It", European Competition Law Review, 2005, 272; in general, on retroactive rebates, see G. Faella, "The Antitrust Assessment of Loyalty Discounts and Rebates", Law and Economics Lab, 2007 available at www.ssrn.com. 
them to buy a volume of products that they would not have bought in absence of retroactive rebates. Therefore, this loyalty-enhancing rebate (due to the suction effect) may be harmful, since it induces customers to make a level of purchases they do not want. It reduces the contested portion of the demand ("contestable share") ${ }^{114}$, with a likely foreclosure effect on actual and potential competitors.

2. The reference period. The length of the reference period is usually considered as a relevant factor for the efficacy of the rebate scheme ${ }^{115}$. Rebates granted over a too short reference period are normally considered insufficient for the anticompetitive effect to materialise. However, such an aspect often cannot exclusively determine the loyalty-inducing effect and, according to the literature, in some cases the reference period may be irrelevant for the competition analysis $^{116 .}$

3. The size of the rebate. The extent of the rebate defines the likely foreclosure effect of the practice. Essentially, the predatory impact of the practice depends on the level of the effective price. In retroactive rebates, the average price of the overall volume should be considered. To evaluate the potential foreclosing impact of the rebate, the effective price should be compared with two measures of cost (Akzo test ${ }^{117}$ ): the long run average incremental costs (LRAIC) and the average avoidable costs (AAC) ${ }^{118}$.

114 European Commission (2009), cit., §40-43.

115 See European Commission (2009), cit., §37; the relevant case law, however, stated that a period of more than three months should be always considered as a requirement to consider the rebate per se unlawful; see Case T-203/01 Michelin v. Commission (Michelin II), 2003 ECR II-4071.

116 Maier-Rigaud (2005), cit., pp. 272-276; G. Faella (2007), cit., pp. 25-26.

117 Case C-62/86 AKZO v. Commission [1991] ECR I-3359, [1993] 5 CMLR 215.

118 The AAC, instead, is a good proxy of the average variable costs (AVC) if no fixed costs occur in the considered incremental products. In fact, the AAC is the average of the costs that could have been avoided if the company had not produced that amount of (extra) output; see European Commission (2009), cit., §26; . 


\section{Figure 4 - The predatory impact of rebates}

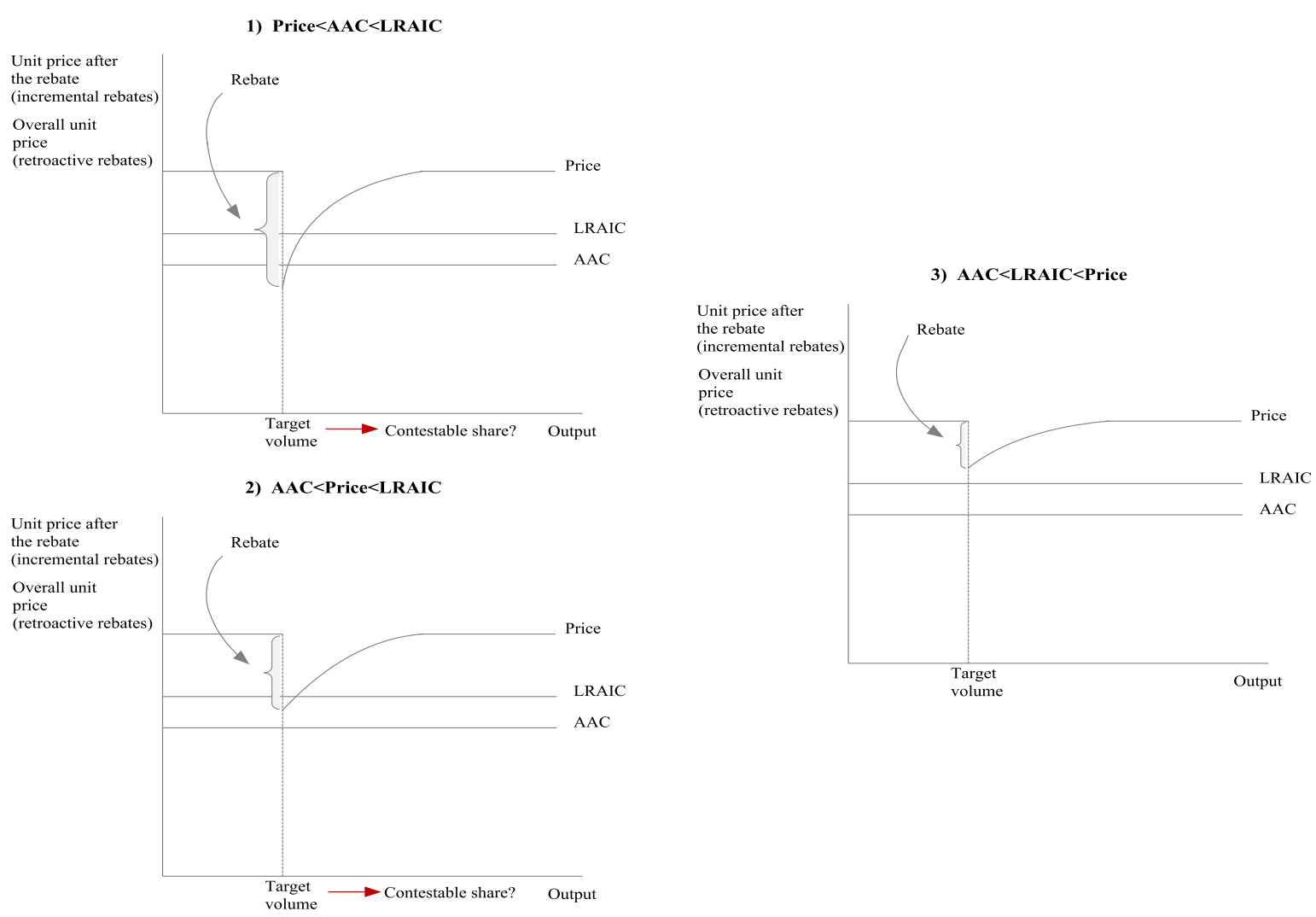

Source: European Commission (2009); authors' elaboration

As shown in the figure above, the exclusionary effect of the rebate depends on the exclusionary impact of the practice. The third outcome can be considered totally lawful, since other competitors can replicate the practice without incurring in loss. When the price is between LRAIC and AAC, the potential harmful effect on competition depends also on other factors, such as the market structure (high fixed costs industry), the time length of the practice and competitors' likely counter strategies ${ }^{119}$. Finally, in outcome 1 , the practice can be considered extremely harmful for competitors, since it does not allow as-efficient competitors to offer services without incurring in losses, also in the short run. The rebate thus aims at foreclosing the market and charging higher prices when other competitors are excluded. In addition, in the long run (multi-period model) also consumers will be harmed by higher prices, charged by the firm to recoup the resources employed to enact the practice in the first period.

Conditional rebates may have also efficiency reasons ${ }^{120}$. These include:

119 European Commission (2009), id., §44.

120 See Case C-95/04 P British Airways v. Commission [2007], ECR I-2331, §86; see also D. Spector, Loyalty Rebates and Related Pricing Practices: When Should Competition Authorities Worry?, in D.S. Evans and A.J. Padilla (eds.), Global Competition Policy: Economic Issues and Impact, 2004, 317; R. O'Donoghue and A.J. Padilla, The Law and Economics of Article 82 EC, Hart Publishing, Oxford 2006; European Commission (2009), id., §46. 
- Direct benefits for consumers (consistent price reduction);

- Search for economies of scale (high fixed costs, need for greater consumption levels; e.g. trading fees' plan in investment services);

- Second-degree price discrimination ${ }^{121}$;

- Reduction of inefficiencies;

- Protection of significant investments in the distribution channel, preventing freeriding by competing suppliers;

- Support to the firm recovering specific investments made to satisfy the needs of a particular customer (it helps to solve the hold-up problem) ${ }^{122}$.

The European Commission clarified in its recent Guidance paper on exclusionary abuses under Article 82 ECT that

"[t]ransaction-related cost advantages are often more likely to be achieved with standardised volume targets than with individualised volume targets. Similarly, incremental rebate schemes are in general more likely to give resellers an incentive to produce and resell a higher volume than retroactive rebate schemes" 123 .

\subsubsection{Loyalty rebates}

A system of loyalty rebates can be put in place by competing firms. It is directed to specific groups of customers, mainly new customers. In effect, it may be used as a tool to catch new customers and to reap, once locked-in, the benefits from charging higher prices, so hampering consumer welfare ${ }^{124}$. Its potentially harmful impact increases with

121 Rebates can be a tool to efficiently price discriminate between consumers. In general, a seconddegree discrimination occurs when "a firm offers different deals to everybody to let different customers to "self-select", choosing one specific deal". If correctly implemented this practice increases the total welfare in the market; see M. Motta (2004), cit., p. 492.

122 Temple Lang, J. and R. O'Donoghue, “Defining Legitimate Competition: How to Clarify Pricing Abuses under Article 82 EC", Fordham International Law Journal, 2002, p. 83.

123 European Commission, Guidance paper, cit., at \#46.

124 OFT (2003), cit., p. 55. 
the market share. For example, the recent Commission case against Intel, which led to a fine of more than $€ 1$ billion, involved loyalty rebates conditional on quasi-exclusivity.

A loyalty discount scheme can be structured with more favourable contractual conditions (e.g., a free credit card, a lower interest rate) without setting any threshold or target volume. It might be offered to customers with lower switching costs and more willing to move with a different supplier. In a multi-period model, in effect, it could be profitable for the firm to adopt a strategy "investing then harvesting", also in a mature market. This is particularly true in specific situations: for example, when a firm - e.g. due to lack of sufficient information - cannot differentiate between new and existing (locked-in) customers for a given product or service, it can adopt rebates schemes aimed at attracting new potential customers and increasing the base of artificially inelastic customers (locked-in) ${ }^{125}$. The emergence of these schemes is also related to other aspects, such as the aggressiveness of competitors and the elasticity of the demand. Increasing the locked-in customer base for all the firms can reduce competitors' aggressiveness in the following period. Vice versa, in a collusive framework a discount scheme can help to attract new customers and to deviate from the cartel agreement.

Finally, the elasticity of the demand may be a good tool to measure the likely impact of a rebate scheme and its efficiency to attract new customers. It may be used as thirddegree price discrimination device to select between customers in relation to specific characteristics $^{126}$. This kind of price discrimination can potentially increase the total welfare if the strategy can be "perfectly" adopted (no arbitrage for consumers). Other efficiencies of a loyalty "unconditional" rebate scheme match with the list in the previous paragraph.

125 It would be extremely costly to make an analysis in depth of every single customer's specific characteristics (e.g. individual's risk aversion), affection by switching costs, and potential locking-up effects. In effect, as described in the following paragraphs, switching costs have so many implications that it makes this analysis not pursuable. For instance, the huge number of customers and limited means to look into customers' idiosyncrasies enhance this difficulty in banking and investment services.

126 A third-degree price discrimination refers to "the possibility that a firm charges different prices to consumers having different (observable) characteristics"; see Motta (2004), cit., p. 492. 


\subsubsection{Aggressive commercial practices in competition law}

Article 82 of the EC Treaty does not only cover exclusionary practices, but also so-called exploitative abuses, which are the result of the behaviour of a dominant firm that damages in primis its customers. The Treaty clearly indicates that these practices consist of "directly or indirectly imposing unfair purchase or selling prices or other unfair trading conditions". Accordingly, provided that the firm that applies the practice is dominant in its own relevant market, certain unfair practices could be conceived as exploitative abuses, which lead to lower consumer welfare and higher profit for the dominant firm. The impact of these practices on rivals, customer mobility and switching costs is normally only indirect: most often, the dominant firm is already shielded from competitive pressure, and accordingly decides to adopt a profit maximising strategy to the detriment of downstream customers.

The most common exploitative abuse is the practice of excessive prices. In particular, since the famous 1976 case United Brands, the Commission has introduced a criterion that relates the "excessive" nature of the price applied by the dominant firm to the "economic value" of the product sold ${ }^{127}$. Subsequent case law has broadly confirmed this approach, although some commentators have criticised it as leading, i.a. to legal uncertainty, as the standard used to assess whether a price is excessive or not is very difficult to define ${ }^{128}$. Can we measure the price of competition? So far, the antitrust treatment of excessive prices has focused on firms with a position of monopoly or very significant market power (the most famous cases being British Leyland, General Motors, Port of Helsingborg and others); in addition, prices can be considered to be "excessive" when there is evidence of a very large price-cost margin and/or the comparison with prices prevailing in more competitive markets suggests that the firm at hand is largely abusing its dominance.

In our opinion, the antitrust treatment of exploitative abuses under Article 82(a) is not limited to excessive prices, but extends to other conducts, including unfair contractual terms. Community case law in this respect ranges from cases (such as BRT/SABAM and $G E M A$, both related to copyright collection societies) in which contract terms were considered abusive since they (i) were not "absolutely necessary for attaining the object of the contract" and (ii) unnecessarily and disproportionately limited the counterparty's freedom of choice ("equity test"); to cases in which the unfair contract terms were only part of a much broader set of abusive conducts, such as Tetra Pak II. Finally, in DSD, the Commission clarified that a contract term may be seen as abusive

"where an undertaking in a dominant position fails to comply with the principle of proportionality" 129 .

\footnotetext{
127 Case 27/76, United Brands Company v. Commission, [1978] ECR 207.

128 See, i.a. O'Donoghue and Padilla, cit., at 603.

129 DSD, OJ 2001 L166/1, para. 112.
} 
Such criterion, according to two authoritative commentators, requires a balancing of "the object of the contract, the terms of the contract, and the contractor's justification for those terms"130.

The case law on exploitative contract terms under Article 82(a) EC Treaty never referred to practices such as unsolicited offers, churning and steering. The need to refer to clearly specified contract terms adopted by a dominant firm makes Article 82(a) difficult to apply to these practices. As will be explained in Section 2.2.1.1 below, the degree of competition is often unrelated with the emergence of these types of unfair commercial practices, especially in the case of services that are high on credence attributes, such as retail financial services. On the contrary, in some cases the increased cost pressure borne by financial advisors due to competition can lead them to adopt even more exploitative behaviour towards their customers.

\section{Tackling tying and other potentially unfair commercial practices in consumer policy}

In this section, we provide an overview of the main reasons why the practices under analysis in this paper may be considered as potentially unfair and detrimental to consumers and SMEs in the retail financial services sector. In June 2005, the European Commission launched a sector inquiry into competition in financial services, pursuant to Article 17 of Regulation (EC) No 1/2003. The financial services sector inquiry focused on two main areas: retail banking (including payment cards) and business insurance. In the European Commission's sectoral inquiry on retail financial services cross-selling strategies and more particularly bundling and tying of bank products were detected among other issues hampering competition in the sector. The interim reports also recalled some of the undesirable consequences of these practices, including the reduction of price transparency, the leveraging of market power into adjacent markets, and entry deterrence. The final report of the sector inquiry was published on 31 January 2007. This final document builds up on the preliminary findings of the interim report by providing new insights and features depicting tying practices across the EU. Some conclusions can be easily drawn:

130 O'Donoghue and Padilla, cit., at 654. 
(i) The product structure of tied bundles shows that "the practice of current account tying appears to be widespread in the EU retail banking sector, whether purchased alongside a mortgage, consumer loan or SME loan. (...)The overall incidence of tying appears to be highest for SME loans."

(ii) Tying practices are more spread within the group composed by new Member States, as result of their intent "to promote the banking sector growth and development."

(iii) Smaller and foreign banks seem to be influenced by the conduct of tying by larger banks and mirror their practices. ${ }^{131}$

(iv) Banks argued that tying allows them to reduce significantly their credit risks and enable them to benefit from economies of scope, which could then be passed on to consumers through price reductions. The inquiry questioned the transmission of benefits to consumers to the extent that many practice involve only the duplication of services and costs for consumers (even though price reductions could be possible).

(v) The impact of the practices at stake on consumer choice and mobility may be high even absent a significant degree of market power on the side of the financial services provider.

The section below describes the main reasons identified by the economic theory for protecting consumers and SMEs against unfair commercial practices. In particular, we identify the specific characteristics of the retail financial services sector, which have specific attention by the policymaker. These include informational asymmetries (including limited effort in "shopping around" and limited financial education of customers), transaction-specific investments and bounded rationality. Section 2.2 analyses more in detail the determinants of switching costs for consumers and the available evidence on customer mobility in retail financial services compared to other economic sectors. Section 2.3 describes how practices under scrutiny - including crossselling, conditional sales and aggressive commercial practices - can affect these market characteristics, and whether such impact is likely to prove unfair and detrimental to consumers and SMEs.

131 To illustrate this, out of eleven Member States in which its largest mortgage banks tied a current account to its mortgage hook product, nine countries exhibit the case for smaller banks mirroring this practice. Other tied bundles (i.e. current accounts tied to personal loans) show a similar pattern. In addition and regarding the case for foreign banks, the final report states the following: "the evidence also suggests that some foreign banks adapt their tying and bundling strategy according to domestic competitive conditions. [...] This suggests that the commercial rewards to foreign entrants are greater from following this type of conduct [...].Thus a high proportion of product tying in a particular Member State is likely to be self-reinforcing, weakening the impact of new entrants on competition." 


\subsection{The rationale for protecting consumers and SMEs against unfair commercial practices}

As acknowledged by the law and economics literature, consumer transactions differ noticeably from the standard paradigm of contractual relations, where parties stand on an equal footing in terms of information and bargaining power. The law and economics literature initially focused mostly on situations in which consumers adhere to a standard form contract offered on a "take-it-or-leave-it" basis ${ }^{132}$. However, the attention of scholars in the past few years has focused also on the pre-contractual level, especially in cases where the informational asymmetry between the seller and the customer is such that the latter heavily depends on information provided by the former or may be not able to process that flow of information (rational ignorance or cognitive biases); and on the phase that follows the conclusion of a contract, when providers can exploit transaction-specific investments and customer lock-in in so-called neoclassical and relational contracts ${ }^{133}$.

As regards the pre-contractual phase, most of these situations may depend on the existence of an informational asymmetry between specialised players (e.g., a financial services provider) and non-specialised customers (consumers or SMEs). A basic tenet of consumer policy is that in business to consumer (B2C) contracts, consumers are often likely to be less informed than their professional counterparts, since the cost associated with the collection of information and understanding of contract conditions is often very high. B2C commercial practices are potentially exposed to the strategic behaviour of the better-informed part in the contractual relationship. Firms normally have more resources to undertake a better-informed transaction, and can spread the cost of acquiring information over a large number of transactions - there are indeed economies of scale in the collection of information on the side of service providers. In these situations, relatively uninformed customers (both consumers and SMEs) are left in a situation in which they are not effectively able to make a precise and informed decision

132 See, for an early scholarly contribution, Todd D. Rakoff, Contracts of Adhesion: An Essay in Reconstruction, 96 Harv. L. Rev. 1174 (1983); and see Baird, D., The Boilerplate Puzzle, Michigan L. Rev Vol. 104, 933, March 2006.

133 As defined by Ian Macneil and later by Williamson (1975); See the pioneering contributions of Klein, B., Crawford, R. e Alchian, A., 1978, Vertical integration, appropriable rents, and the competitive process, 21 Journal of Law and Economics, 21; Macneil, I.R (1974). "The Many Futures of Contracts". Southern California Law Review, Vol. 47, pp. 691-816; Macneil, I.R. (1978). "Contracts Adjustments of Long Term Economic relations under Classical, Neo-Classical and Relational Contract Law". Northwestern University Law Review, Vol. 72, n. 6. pp. 854-905. 13. Williamson, 0. E. (1975): Markets and Hierarchies: Analysis and Antitrust Implications, The Free Press, New York, 286pp; Williamson, O. E. (1983): Credible Commitments: Using hostages to support exchange, American Economic Review, vol. 73 no. 4 (1983), p. 519-540; Williamson, 0. E. (1985): The Economic Institutions of Capitalism: Firms, Markets and Relational Contracting, The Free Press, New York, 450pp. Literature on banking relationships that used this theoretical framework includes Paulin, M., Perrien, J., Ferguson, R. (1997). "Relational Contract Norms and the Effectiveness of Commercial Banking Relationships". International Journal of Service Industry Management, Vol. 8, n. 5, pp. 435452. 
on their contractual behaviour as well as on the existence of alternatives, and include cases in which the price and other conditions associated with a given transaction are not transparent; cases in which the information provided by the counterpart is not reliable or misleading; and cases in which the customer's perception of the costs and benefits associated with the transaction are distorted.

Many of these problems are exacerbated whenever the quality of the good or service to be purchased by the customer is observable only after its use. This is the case of "experience" goods, as defined in the literature ${ }^{134}$. When consumers and SMEs buy experience goods, they may realise too late that their valuation of the product or service was mistaken or not realise it at all in case of credence attributes. This is too late especially when their effective ability to switch to alternative providers is limited. In these cases, the "barriers to exit" from an existing contractual relationship can be very high. In effect, cases in which exit barriers from a contractual relationship are very high may occur both due to the inherent characteristics of the market, but also due to the existence of specific commercial practices by sellers, which have the effect of increasing customer lock-in. In addition, some retail financial services (e.g. financial advice on mortgage loans or investment products) are characterised, as mentioned above, by high credence attributes, and this further weakens the position of customers, as it leaves them with the practical impossibility to observe the quality of the service they are being provided.

All these factors are relevant to the retail financial services sector. In fact, in this sector specific market characteristics suggest that the need for policies protecting consumers and SMEs is particularly strong. These specificities include:

- Informational asymmetries between providers and customers, including limited financial education;

- Bounded rationality and "structural" decision-making biases when facing risky investments ${ }^{135}$;

- Limited customers' effort in "shopping around";

- Customer lock-in and switching costs, including the existence of relationshipspecific investments.

134 Products and services can be classified in three categories: search goods; experience goods; and credence goods. A search good consists in a product or service for which is possible to assess the quality before the purchase. Search elements include those attributes of the relationship that are easily detected and understood by customers, even when they are deciding whether to switch to a competing provider. An experience good, instead, is a product or service for which the buyer can evaluate the quality only after the purchase and its use. Finally, a credence good is a product or service whose value and quality cannot be assessed even after its use, as features cannot be easily compared with other products or services. It is the "grey area" where customers do not have any knowledge of what is in the contract, and what it means in terms of its relationship with the provider. See Darby e Karni, Free Competition and the Optimal Amount of Fraud, 16 Journal of L. and E., 69 (1973); and Nelson, Information and Consumer Behaviour, 78 Journal of Pol. Econ., (1970).

135 For a definition, see below, note 137-138. 
More will be explained in the next paragraphs in order to shed more lights on the concepts listed above and their relation with the consumer policy.

\subsubsection{Informational asymmetry between providers and customers}

The asymmetry of information between providers and customers in consumer contracts depends on what the economic literature refers to as "rational ignorance", and is extensively studied in the consumer protection literature ${ }^{136}$. As customers (both consumers and SMEs) are normally not specialised in financial services, they have to trust their financial service providers, especially when dealing with investment choices involving complex risk calculations. This does not necessarily imply that customers' rationality is bounded or distorted ${ }^{137}$ : it simply means that the cost of acquiring full information on the features, alternatives and likely future values of today's investment products is greater than the benefit of acquiring such information.

Financial services are normally considered to be inherently intangible and with high experience and credence qualities ${ }^{138}$. This is confirmed in the literature: for example, in a recent paper stating that

"[f]rom the perspective of information economics, financial advice
(as a service offered by banks) has all the typical characteristics of
credence goods" and "most of the quality properties of financial
advice-as the above suggests - can be considered credence

136 Rational ignorance occurs whenever an individual rationally chooses not to acquire all the information needed to conclude a contract. As was authoritatively observed, in a number of situations "the costs of becoming informed may exceed the benefit, resulting in rational ignorance of hidden traps in contracts that competition may not dispel". See, e.g., Lucian A. Bebchuk \& Richard A. Posner, One-Sided Contracts in Competitive Consumer Market, 104 MICH. L. REV. 827, 827 (2006).

137 Bounded rationality refers to the fact that human beings - contrary to what occurs in cases of rational ignorance - always take their decisions on the basis of imperfect information, limited capacity of the human mind, and limited amount of time. As a matter of fact, developments in economics and cognitive sciences have highlighted the fact that human beings take satisficing decisions (as Herbert Simon defined them) on the basis of imperfect information, and are often "path-dependent" in their choices, especially when individuals cannot fully appraise the value of something they already possess (or of a contract they have not signed yet). See Herbert Simon, "A Behavioral Model of Rational Choice", in Models of Man, Social and Rational: Mathematical Essays on Rational Human Behavior in a Social Setting, New York: Wiley, 1957; Korobkin Russel B., Thomas S. Ulen, "Law and Behavioral Science: Removing the Rationality Assumption from Law and Economics", California Law Review, Vol. 88, 2000; Sunstein Cass R., Behavioral Law and Economics, Cambridge University Press, 2000; Jolls Christine, "Behavioral Law and Economics", National Bureau of Economic Research, WP No. 12879, January 2007; and - for path-dependency - Arthur, W. Brian. (1989) Competing Technologies, Increasing Returns, and Lock-in by Historical Events, Economic Journal 99: 116-31.

138 See Paswan et al. (2004), Search quality in the financial services industry: a contingency perspective, Journal of Services Marketing, Volume 18, Number 5, 2004, pp. 324-338. 
characteristics whose quality-due to time or cost restrictions-can

neither be inferred before nor after a decision has been made"139.

This is due to several factors:

(i) financial advice is based exclusively on the advisor's promise to perform his service, but this is highly ambiguous for the client at the time he enters the corresponding contract; this relationship is mainly fiduciary (based on trust);

(ii) financial advice giving and taking is cognitively very demanding to the involved parties due to the multitude of factors an investment decision must be based on, and their strong interdependence; and

(iii) due to its decisive role for the development of a client's future situation and the necessity to closely cooperate with the client in developing recommendations, financial advice can also be considered of high value and specificity.

The greater the importance of experience and credence qualities, the more difficult is for customers to compare alternative offers and understand the value for money of a given contractual offer. In addition, the greater are experience and credence qualities, the lower is the interest for customers in shopping around for qualities they will never be able to appraise before actually signing a contract.

A typical example of "credence attribute" in retail financial services is the quality of customer service; in many cases, the competence of the personal advisor belongs to credence attributes, since customers will not be able to fully judge whether they are actually receiving high-quality advice or not. This opens up the possibility of unfair practices such as steering, as will be explained in the next paragraphs. Credence attributes also pave the way to "push" behaviour such as aggressive commercial strategies or unsolicited offers (e.g., "we know what's best for you").

In retail financial services, the information asymmetry between parties may raise two potential harmful common problems in retail markets (a typical principal-agent problem in fiduciary relationships ${ }^{140}$ ): moral hazard and adverse selection.

- Moral hazard ${ }^{141}$ is an informational problem related to the opportunistic behaviour of the more informed party, who tries to exploit the informational advantage and the scarce ability of less informed party to monitor the other's activity.

139 See Oelehr, A. and D. Kohlert, Financial Advice Giving and Taking-Where are the Market's Selfhealing Powers and a Functioning Legal Framework When We Need Them?,. Journal of Consumer Policy (2009) 32: 91-2116.

140 See, in general, the seminal articles of S.A. Ross, "The Economic Theory of Agency: The Principal's Problem", The American Economic Review, 1973; E. F. Fama and M. C. Jensen, "Agency Problems and Residual Claims", The Journal of Law and Economics, 1983.

141 See Holmstrom Bengt, "Moral Hazard and Observability", The Bell Journal of Economics, Vol. 10, No. 1, pp. 74-91, Spring 1979; Milgrom Paul and John Roberts, Economics, Organization \& Management, Prentice Hall Inc., New Jersey, 1992. 
- Adverse selection ${ }^{142}$, instead, is an informational problem structurally related to the difficulty by one of the two parties to process some kind of information, such as the quality of the products ${ }^{143}$. Furthermore, the opportunistic behaviour of the party that is more informed about product quality helps to exclude virtuous practices from the market.

In addition, although the informational asymmetry does not necessarily lead to exploitation of the less informed party, there are situations in which the cost pressure to which financial advisors are increasingly exposed creates incentives for the providers to exploit their superior information to the detriment of their customers. In retail banking, for example, this is not only due to the current financial crisis, but also to other factors such as the fact that the majority of clients do not contribute to profits or are even characterized by a negative profit contribution, and that an average financial advisors in the retail segment have to take care of $850-2,000$ clients $^{144}$. Furthermore, according to a study of the consultancy McKinsey and Company, only $13 \%$ of a financial advisor's working time is dedicated to advising and selling tasks, while the remaining $87 \%$ is spent on administrative duties ${ }^{145}$. Finally, since under the prevalent pricing model the actual service of advice giving is offered free of charge and then cross-subsidized by provisions and fees resulting from the sale of the products subsequent to the advice giving process (service model; e.g., Kaas and Severidt 2002), advisors are under enormous pressure to sell their products as efficiently as possible ${ }^{146}$.

Interestingly, a corollary of this finding is that increased competition does not eliminate the problem, and may even strengthen the incentive for financial advisors to exploit their customers, due to increased cost pressure. Advisors able to exploit unobservable (hidden) information may have a stronger incentive to recommend products with the

142 Akerlof G.A., "The market for 'lemons': qualitative uncertainty and the market mechanism”, Quarterly Journal of Economics, 84, pp. 488-500, August 1970.

143 In Akerlof (1970), the classical example to explain this informational problem is the market for lemon cars. The adverse selection, in effect, arises when products of different quality (e.g. lemon and good cars; junk and good bonds and so on) are sold at a single price because of asymmetric information (inability of the buyer or lender to understand the real quality/risk of the cars/financial product or borrower), so that too much of the low-quality product and too little of the high-quality product are sold. In the market for lemon and good cars, for instance, the equilibrium will result in a market price (due to the inability of the buyer to understand ex ante the quality of the product) a bit higher than lemon cars' real value and consistently lower than good cars' real value. Hence, the market equilibrium, in the mid-term, will determine that only lemon cars are sold in the market. This important issue can basically bring a market to the end, justifying mechanisms of signalling as thirdparty informational role (rating agencies, etc), regulatory interventions or just pre-sale services. See Pindyck and Rubinfeld (2005), id., p. 616; Reinier H. Kraakman, "Gatekeepers: The Anatomy of a Third-Party Enforcement Strategy", Journal of Law, Economics and Organization, Vol. 2, No. 1, Spring 1986.

144 Eichhorn 2004, p. 259; Haferbier 2004, p. 71; Hook and Ulrich 2003.

145 Stiller 2003.

146 See Oelehr, A. and D. Kohlert (2009), Financial Advice Giving and Taking, cit. 
highest commissions, or riskier investments, knowing that they will be able to justify any negative result by invoking exogenous, unpredictable shocks ${ }^{147}$.

In this respect, stronger competition policy alone is not likely to lead to any improvement in the quality of financial advice, since financial advisors compete on observable qualities, and normally economise on unobservable ones ${ }^{148}$. Put differently, none of the oft-quoted self-healing properties of consumer markets (screening, signalling, self-selection, guarantees, alignment of interests, reputation-transfer, and reputational constraints ${ }^{149}$ ) is observable and operational in retail financial advice. Improving the quality of information exchange is not profitable and thus not interesting for the financial service provider.

\subsubsection{Financial education and customer effort in "shopping around"}

As reported by the European Commission in its Communication on Financial Education in 2007, "numerous international surveys have demonstrated consumers' generally low level of understanding of financial matters and of basic economics"150. The fact that individuals find financial matters difficult to understand, and often overestimate their understanding of these matters, constitutes a key obstacle to their ability to shop around for the best deal, when these opportunities exist. At the same time, the limited understanding of financial issues exposes customers to misleading information by their

147 Id.

148 A similar rationale has led to concluding that competition does not necessarily solve the problem of unfair contract terms in the literature. See, i.a. Bebchuk, L.A. and R. A. Posner, One-sided contracts in competitive consumer markets, in Ben-Shahar, 0. (Ed.), Boilerplate. The foundation of market contracts, Cambridge University Press, 2007.

${ }^{149}$ See Oelehr, A. and D. Kohlert (2009), Financial Advice Giving and Taking, cit., at 97.

150 See COM(2007)808 of 18 December 2007. 
financial services providers, thus magnifying the scope for, and impact of, unfair commercial practices in this field ${ }^{151}$.

The effect of the lack of information and financial education on the customers' side in the retail financial services sector is also combined and enhanced by the limited effort that customers seem to devote to the search for a better deal in this sector. As a matter of fact, many retail financial products (mortgage loans, current accounts, insurance products, etc.) are considered as a necessity, but hardly attract the curiosity of customers (also since they normally exhibit a low degree of differentiation): search costs are perceived as very high by the average customer. This is reflected in empirical analyses that show that customers exhibit a particularly low tendency to switch provider in current accounts, life insurance, etc. ${ }^{152}$ The issue of habit and practical convenience in dealing with financial providers is a particular reason for remaining loyal to a given institution. For example, a survey by nVision in 2003 revealed that UK consumers remained loyal to their bank mostly for practical reasons.

In addition, as reported by the Nordic Competition Authorities, "lack of interest seems to be a common feature among bank customers". The report quotes a survey performed by Berg and Borgeraas ${ }^{153}$ among retail banking customers, which concluded that two of the reasons for low customer mobility relate to the facts that "customers have an unconsidered relationship with the banking market", and that "bank affairs are low interest areas". It seems that many customers do not compare prices and services and have a lack of interest and commitment when it comes to financial services ${ }^{154}$, because of the excessive cognitive demand that comes along with it ${ }^{155}$.

151 See Commission Communication on Financial Education, COM(2008)808, 12 December 2008, http://ec.europa.eu/internal_market/finservices-retail/docs/capability/ communication_en.pdf.

152 Especially in some countries, there is ample evidence that consumers exhibit on average limited interest in shopping around. See, i.a., Better informed consumers, FSA consumer research report 1 (2000); Informed decisions? FSA consumer research report 5 (2000); Polarisation FSA consumer research report 9 (2002). See also Cook, Malcolm, Earley, Fionnuala, Smith, Sarah and Ketteringham, Jody, Losing Interest: How Much Can Consumers Save by Shopping Around for Financial Products? (October 2002). Financial Services Authority Occasional Paper No. 19.

153 Lisbet Berg \& Elling Borgeraas (2003), Hindrances for mobility in the bank market, Paper presented at the 6th Conference of the European Sociological Association, Murcia, September 23-26, 2003.

154 See also the interesting analysis provided by Berg, L. (2008), Loyalty, naivety and powerlessness among Norwegian retail bank customers, International Journal of Consumer Studies Vol. 32, n. 3, at 222-232.

155 See Oehler and Kohlert (2009), Financial Advice Giving and Taking, cit., at 99 (quoting Jungermann 1999; Jungermann and Belting 2004; Oehler and Kohlert 2008). 


\subsubsection{Information asymmetry, relationship banking and switching costs}

The asymmetry of information between providers and customers leads to the emergence of other market effects. For example, the fact that customers face important obstacles in appraising whether their counterpart is behaving correctly and providing a high-quality service also implies that customers that are already involved in a contractual relationship with a financial service provider may be discouraged from switching, as this would imply investing again in familiarising with a new service provider, with limited chance of being able to appraise the reliability of the counterpart before signing and executing a new contract. For this reason, experience and credence qualities may represent a transaction-specific investment for the customer, which makes it very difficult to switch to competing banks (so-called path-dependency or status quo bias) ${ }^{156}$.

In financial services, the relationship between the provider and the customer is particularly important, mostly due to the trust-based relation that must be created in a situation of informational asymmetry. This also means that customers perceive the relationship as a long-term one, and build their relation with the service provider overtime $^{157}$. This can be qualified as a transaction-specific investment (TSI) as illustrated in the seminal contribution by Oliver Williamson (1975) ${ }^{158}$. Faced with this "sunk" investment, customers perceive high switching costs: changing provider would indeed mean, at once, losing the previous TSI and having to face a new, equally "sunk" investment in familiarising with the new provider. This effect is particularly strong for investment products, where the fiduciary role of the service provider may be essential

\footnotetext{
156 See supra, note 167 and accompanying text.

157 See data on the duration of relationship in this sector, as reported by the European Commission in the Sector Inquiry on Current accounts and related services (2006), cit.The literature on marketing is consistent in indicating the role of trust, satisfaction and average perceived cost (including switching costs) as determinants of loyalty. See, i.a., Raoul Graf, Fabien Durif, Mario Belzile (2008), "Echo Generation": switching costs and the relational approach in the banking industry, Innovative Marketing Vol. 4, Issue 1, at 77-86; and Graf, R., Perrien, J. (2005), "The Role of Trust and Satisfaction in a Relationship: the Case of High Tech Firms and Banks", Proceedings of the 34th EMAC Conference, Milan, Italy.

158 Williamson O.E. (1975), "Markets and Hierarchies: Analysis and Antitrust Implications - A Study in the Economics of Internal Organization, New York: Free Pr.
} 
for retail investors. ${ }^{159}$ The information and behavioural biases involved can lead to rather high "perceived" switching costs, difficulties in evaluating alternatives, and consequently low price transparency and customer mobility ${ }^{160}$.

This leads customers to rely on proxies to establish the value of a given investment option - the proxy, in this case, being the advice received by their service provider. For this reason, the so-called "relationship banking" often attracted specific interest in the law and economics literature ${ }^{161}$. Moreover, as will be explained in the next sections, rational ignorance is also one of the reasons why aggressive commercial practices and unsolicited offers can have very similar effects to contractual tying: accordingly, merely banning tying may lead to the emergence of other practices which de facto reach the same result by "inducing", rather than "forcing" consumers to buy additional products. The turmoil induced by the financial and economic crisis has tended to result in pronounced disturbance and perturbation of the markets. The increased volatility of financial indicators and proxies progressively blurred the information available ${ }^{162}$. Therefore, the current context tends to amplify the specific characteristic of information asymmetry between providers and customers in the retail financial market.

More in detail, the provider-customer relationship can be described by two main dimensions, according to the literature: the "depth" of the relationship, stemming from the "off-contract" entrepreneur-banker relationship, and the thickness, defined as the information conveyed to the bank through the multiple financial contracts and services. In particular, the thickness of the provider-customer relationship offers customers a range of potential advantages, but is also associated with the possibility, for the more informed provider, to capture rents in the relationship by exploiting by engaging in

159 See David T. Llewellyn, "Regulation of Retail Investment Services", Economic Affairs, Vol. 15, N. 2, 1995, pp. 12-17.

160 In this respect, the retail financial services sector can be said to differ noticeably from other economic sectors. For example, in telecommunications or energy sectors consumers are less likely to suffer from an information asymmetry, provided that they have visibility of the quality of service and relative price of the offer. At the same time, the elements of "trust", "transaction specific investments" and "bounded rationality" are much less important in these fields. Finally, especially in the telecommunications sector consumers are more likely to shop around for better offers.

161 See Office of the Comptroller of the Currency, Today's Credit Markets, Relationship Banking, and Tying, International and Economic Affairs Department Law Department, September 2003, at http://www.occ.treas.gov/law/tyingwhitepaper.pdf. See also Boot, Arnoud W. A., 2000, Relationship Banking, What Do We Know?, Journal of Financial Intermediation 9, 7-25; and Berry, L.L, Thompson, T.W. (1982). "Relationship Banking: the Art of Turning Customers into Clients". Journal of Retail Banking, Vol. 4, n. 2, pp. 64-74.

162 As recently observed by the OFT in its consultation document on the financial services strategy, adopted in April 2009, The financial crisis may change consumers' behaviour in many ways: (i) Prior to the crisis, competition in financial services took place on parameters such as price, rates offered, product range, quality and brand. Consumers may now place greater weight on factors such as security and soundness of financial institution. (ii) Customer behaviour based on these parameters may result in reinforcing the existing status-quo and reduced opportunities for small innovative players to enter the market. (iii) Consumer preferences may also change with regard to the type of products they seek. Consumers may move away from long-term savings and investment products in favour of shorter-term, more liquid, products. See the OFT document, 1077con, cit. at B27-B29. 
hold-up behaviour and false representation of both market and contractual conditions. In many case, this relationship is strengthened by personal feelings with the person who represents the provider.

\subsubsection{Behavioural economics and decision-making biases}

In addition to market and product attributes, consumer choice may also be distorted due to purely structural factors, which do depend neither on the type of relationship, nor on the abusive behaviour of banks, but pertain to the sphere of bounded rationality and risk aversion. Where these cognitive biases are observed, markets may fail irrespectively of the behaviour of providers. Faced with these problems, legislators have the specific role of devising, where possible, rules that minimise the impact of cognitive biases on consumer choice. The behavioural law and economics literature, coupled with modern neuroeconomics, is advancing in the direction of identifying ways of "debiasing through law"163. This stream of literature is particularly relevant for the financial services sector, as testified by the emphasis put on financial services by recent reports both at OECD level and by the UK OFT ${ }^{164}$.

People are not always "rational" in the sense that economists suppose. But it does not follow that people's behavior is unpredictable, systematically irrational, random, rule-free, or elusive to social scientists.

(Cass R. Sunstein 2000, p. 1)

163 See Jolls, C. and Sunstein, C. R., "Debiasing through Law" (March 2005). U Chicago Law \& Economics, Olin Working Paper No. 225; Harvard Law and Economics Discussion Paper No. 495. Available at SSRN: http://ssrn.com/abstract=590929.

164 See i.a., Tapia, W. and J. Yermo (2007), "Implications of Behavioural Economics for Mandatory Individual Account Pension Systems", OECD Working Papers on Insurance and Private Pensions, No. 11, OECD Publishing; Ramsay, I. (2004), Consumer credit regulation as 'The third way'?, available online at the following website: http://www.consumer.vic.gov.au/CA256902000FE154/Lookup/CAV SeminarsConferences Nationa l Credit 2004 November/\$file/ramsay.pdf; 
Financial services are natural candidates for a policy intervention in this respect, given that customer decisions in these markets often involve risk, uncertainty and ambiguity ${ }^{165}$. Important behavioural biases that surface in particular in retail financial services include choice/information overloads, endowment biases, self-serving biases, overconfidence, framing effects, difficulty in handling uncertainty and risk, and misevaluation of future benefits and costs ${ }^{166}$. In the UK, for example, the Financial Services Authority (FSA) has analysed cognitive biases as one element of "financial capability" than can explain failures in decisions over uncertain investment options ${ }^{167}$. The OFT has proceeded along similar lines in its market study on personal current accounts ${ }^{168}$. The OECD, instead, identified a list of potential effects that are most likely to emerge when consumers deal with risky or ambiguous situations ${ }^{169}$. We list these biases in two categories: biases affecting judgement and biases conditioning the decision-making process.

On the judgement side, we can identify a list of potential biases:

- Choice/information overload bias: economic models suggest that the benefits from extra choice and information are unbounded. Even the theory of "bounded rationality" does not suggest that extra choice and information is detrimental. Market research however, in products as diverse as jams and retirement savings, suggests that past a point, when provided with more choice and information, we either walk away from markets, choosing not to choose, or we choose randomly.

- Self-serving bias affects judgment when individuals face a matter with room for disagreement. They will tend to interpret information in a direction serving their own interests. This is a judgment error, a distortion of people's perception, for instance, of what is fair. This self-serving assessment can impede

165 See, i.a., Camerer C. F., Loewenstein G. and Prelec D. (2005) Neuroeconomics: How neuroscience can inform economics, Journal of Economic Literature, Vol. XLIII (March 2005), pp. 9-64.

166 See also Ulen and Korobkin (2006), cit.; Jolls (2007), cit.

167 See http://www.fsa.gov.uk/pubs/consumer-research/crpr69.pdf.

168 Office of Fair Trading, Personal Current Accounts in the UK, Market Study, July 2008, available at http://www.oft.gov.uk/advice and resources/publications/reports/financial/. The OFT in particular looked at six factors: (i) Perceived behavioural control: People's perceptions of their behavioural control of current account switching were high overall; (ii) Temporal myopia: People's discounting of future events was not related to switching behaviour. (iii) Overconfidence: People were overconfident about the likelihood that they would encounter charges. (iv) Loss aversion: Concern about losses during switching was slightly lower for switchers, but the overall level of concern was not misplaced. (v) Cognitive engagement: The overall level of cognitive engagement was low: People do not spend much time or effort thinking about their current account. (vi) Fairness: Overall, charges were not perceived as unfair, though those who were charged rated charges less favourably than those who were not charged. Increased awareness of charges and warnings about charges were associated with a smaller difference in fairness ratings between those charged and those not charged.

169 OECD, 7th Global Forum on Competition, Introductory Note, February 2008. 
negotiations ${ }^{170}$ and it might affect people's perception of social norms, in particular what is "moral" in the market; for instance, the credit "immorality" in subprime (irresponsible) borrowing.

- Anchoring and adjustment biases ${ }^{171}$ : prospect theory ${ }^{172}$ (theory violating the axiom of context-independence) also characterizes judgment behaviours; for instance, these biases shape the probabilistic assessment because people frequently fail to "adjust" their assessment from pre-existing cognitive anchors or reference points. There are two effects violating the assumption of context independence: the compromise and the contrast effect (Kelman et al. in Sunstein 2000). The former implies that the relative ranking of two options depends on the presence or absence of other options; the latter effect, by contrast, implies that the same option is evaluated more favourably in case there are similar but more inferior options than in the absence of such options. In addition,

- Overconfidence bias: people tend to overestimate (to be overconfident about) the probability of an outcome if an example of the event has recently occurred (linked to the prospect theory and the precedent behaviour). Therefore, consumers are generally overconfident in their abilities and in their future fortunes. For example, many people invest, believing that they can beat the stock market, or they underestimate the risk that illness or unemployment may cause difficulty in repaying a loan. Again, this bias is important in financial services.

- Optimism bias ${ }^{173}$ : it involves the belief that good/bad things are more/less likely than average to happen to us. This bias is strictly linked with the selfinterest and overconfidence bias above. The borrower, for instance, is affected by this bias especially when she has to consider a deferred-costs transaction like a mortgage contract. Consumers change current consumption with future consumption, relying on a belief that the income in the following period will be higher. There is the perception, due to a mis-evaluation of benefits and costs (hyperbolic discounting myopia), that it will be more likely that she will receive a higher income in the next period. Consumers do not rationally weigh up present against future benefits and costs; rather they put too much weight on the immediate. This bias, in addition, is manifest in outcomes such as low retirement savings in the absence of compulsion.

170 Linda Babcock and George Loewenstein, "Explaining Bargaining Impasse: The Role of Self-serving Biases", 11 J. Econ. Persp. 109, winter 1997.

${ }^{171}$ Amos Tversky and Daniel Kahneman, "Rationale Choice and the Framing of Decisions", The Journal of Business, Vol. 59, N. 4, Part 2: The Behavioral Foundations of Economic Theory, October 1986, pp. 251278.

172 Daniel Kahneman and Amos Tversky "Prospect Theory: An Analysis of Decision under Risk", Econometrica, Vol. 47, N. 2, March 1979, pp. 263-292.

173 Neil D. Weinstein, "Unrealistic Optimism About Future Life Events", 39 J. Personality \& Soc. Psychol. 806, 1980. 
- Hindsight bias ${ }^{174}$ is the tendency of actors to overlook the ex ante prediction that they made concerning with the likelihood of an event after learning that it actually occurred. This bias has particular effects in tort liability.

On the decision-making process, instead, other biases affect its rational wellfunctioning:

- Loss aversion bias: is one of the biases defined as corollary to the prospect theory and it is one of the two biases related to the reference point and framing effects. With this bias, an individual will value a decision differently if it is specified in losses instead of gains. In particular, if a decision is perceived as "losses" (or "gains"), relatively to a reference point, the same individuals will be risk-seeking (or risk-adverse). Consumers are influenced not only by the objective information provided by suppliers, but also by the "frame" of that information. For example, a claim "92\% fat free" elicits a different response than "8\% fat." The frame in which choices are considered influences consumer's perceptions of the consequences of uncertain outcomes. When gambles (such as insurance choices) are considered in isolation, consumers tend to be irrationally risk averse. When consumers consider themselves to be in a loss situation (such as becoming heavily overcommitted on a credit card) they tend to behave recklessly. Furthermore, consumers often have difficulty in thinking rationally about possible outcomes with very low probability. Therefore, they experience relevant difficulties in handling uncertainty and risk.

- Status quo bias: it is a bias that mixes the reference point framing and the endowment effect. People create a reference point for the sense of ownership defined by the endowment effect. Therefore, they would be less willing to deviate from that status, so they will choose the closer solution. The status quo bias backs behaviours that in contract law do not allow contractual solutions deviating from default rules. This behaviour, then, may lead low and moderateincome borrower to accept very high interest rates and/or unfavourable terms.

- Endowment effect bias ${ }^{175}$ : is a bias mixing loss aversion and status quo biases. It proves that the invariance assumption of the Coase's Theorem ${ }^{176}$ fails to describe the real bargaining process for entitlements allocation. The initial allocation of entitlements matters, due to the endowment effect. Moving from that reference point thus will always include a trade-off. Hence, the irrelevance of legal rules, recalled in some circumstances, is a claim that no longer holds. What one has is valued more than what one might have. Consumers are often

\footnotetext{
174 Baruch Fischhoff, "Hindsight $\neq$ Foresight: The Effect of Outcome Knowledge on Judgment Under Uncertainty", 1 J. Experi. Psychol. Hum. Perception \& Performance 288, 1975; Jay J. J. ChristensenSzalanski and Cynthia Fabian Willham, "The Hindsight Bias: A Meta Analysis", 48 Org. Behav. \& Hum. Decision Processes 147, 1991.

175 See Daniel Kahneman and Amos Tversky "Prospect Theory: An Analysis of Decision under Risk", Econometrica, Vol. 47, N. 2, March 1979, pp. 263-292.

176 See Ronald H. Coase, "The Problem of Social Cost", Journal of Law and Economics, Vol. 3, 1960.
} 
reluctant to switch suppliers because of a loyalty, which may be misplaced, to existing suppliers. This is particularly evident in telecommunication and financial services.

All these biases, as described above, are particularly likely in the retail financial services sector. All of them should be taken into account in appraising the likely impact of observed practices. In effect, individuals seem to make systematic errors in risk assessment, for instance, overestimating certain risks that can be vividly recalled, and underestimating others. In more operational terms, the existence of structural cognitive biases can be included in the overall assessment of barriers to customer mobility, as well as in the overall assessment of the likelihood that providers exploit the risk attitude of their customers by imposing unfair commercial terms. For example, the literature on prospect theory explains that individuals' willingness to pay for a product is systematically lower than the compensation they would require to accept the loss of a product they are already consuming. This, in and of itself, explains part of the hesitance of customers when deciding whether to switch ${ }^{177}$.

Finally, for what concerns financial advice (both pre- and post-contractual), a very relevant effect to be taken into account is the information overload. For many reasons, as complexity and cognitive biases to assess an array of alternatives, customers with low financial education will suffer from the reception of a huge flow of information ${ }^{178}$.

\subsection{A closer look into switching costs}

As explained above, the specific conditions observed in retail financial markets lead to the emergence of limited customer mobility and switching costs ${ }^{179}$. As will be shown below, the emergence and extent of such costs can be the consequence of practices such as cross-selling and some conditional sales practices. This impact depends i.a. on the

177 Kahneman, D. and Tversky, A. (1979) Prospect Theory: An Analysis of Decision under Risk, Econometrica 47(2), 263-292.

178 See Oehler and Kohlert (2009), Financial Advice Giving and Taking, cit., at 103.

179 OFT (2009), cit. 
products and services taken into consideration. In this section, we analyse more in detail the nature of switching costs and their emergence in different sectors.

Switching costs allow the firm to unilaterally increase the price of services and products higher than the rival, since customers are locked-in. The lock-in effect in a mature and oligopolistic market, such as financial services, ignites a competitive mechanism à la Cournot $^{180}$, since few incentives exist to compete on price. In effect, firms should offer a price discount that should be higher than the switching costs, to attract rivals' customers and induce them to switch and bear the related costs. The final outcome thus is potentially more harmful than the monopolistic outcome due to the consumer lock-in effect, which will hamper customers' freedom choice and mobility and so even competition.

In effect, the artificial final equilibrium can strongly deter market entry, since an oligopolistic equilibrium at market level prevails, while at firm-consumer level the lockin effect may induce firms to charge a supra-competitive price (up to the monopolistic price) ${ }^{181}$. In addition, in a growing market with switching costs, firms are willing to price very low in order to attract new customers and then to reap benefits once lockedin, increasing market price ("bargain then rip-off"182).

In the retail financial services sector, the following costs are likely to impede switching by consumers:

- Transaction costs, e.g. documentation, time, fees, search costs, other information costs, learning costs, etc.;

- "Exit" costs, due to, i.a. loyalty programs, early repayment penalties (especially in the case of mortgages), etc.;

- Uncertainty costs, especially in financial services, since the quality or suitability of a product can only be observable after purchase (experience attributes), or can never be fully observed by the customer (credence attributes) ${ }^{183}$;

- Psychological costs, mainly in case of goods with high significant credence attributes ("mutual trust"), e.g. investment advices, life insurance, etc. ${ }^{184}$

180 The presence of high switching costs artificially supports the perception of product's differentiation (by old customers) in the Cournot's model, although the outstanding assumption of product homogeneity has special validity for new customers (not locked-in yet). See Cournot (1838), cit;; Motta (2004), cit., p. 556.

181 This likely market outcome can be only seen as result of no-collusive firms' behaviours. In fact, markets with high switching costs undermine the severity of any retaliation for deviation from a collusive agreement (punishment very costly). The impact of switching costs on a collusive agreement is indefinable; see OFT (2003), id., p. 4.

182 See Armstrong, OFT (2008), id., p.28.

183 See supra, note 168 and accompanying text.

184 See in general, P. Klemperer, "Competition When Consumers Have Switching Costs: An Overview with Applications to Industrial Organisation, Macroeconomics and International Trade", Review of 
There is ample evidence that customers in the retail financial services sector do not switch provider very often. For example, Pomp et al. (2005) report the results of a survey run by the Dutch Consumentenbond in 2002 on the switching behaviour of consumers in a number of different markets (1,091 respondents). As illustrated in the figures below, characteristics of the financial services included in the sample appear quite clearly. Very few customers in mortgage, current account and life insurance were planning to switch (Figure 5); and very few were aware of the existence of alternatives (Figure 6), especially for current and savings accounts.

\section{Figure 5 - Percentage of customers that plan to switch}

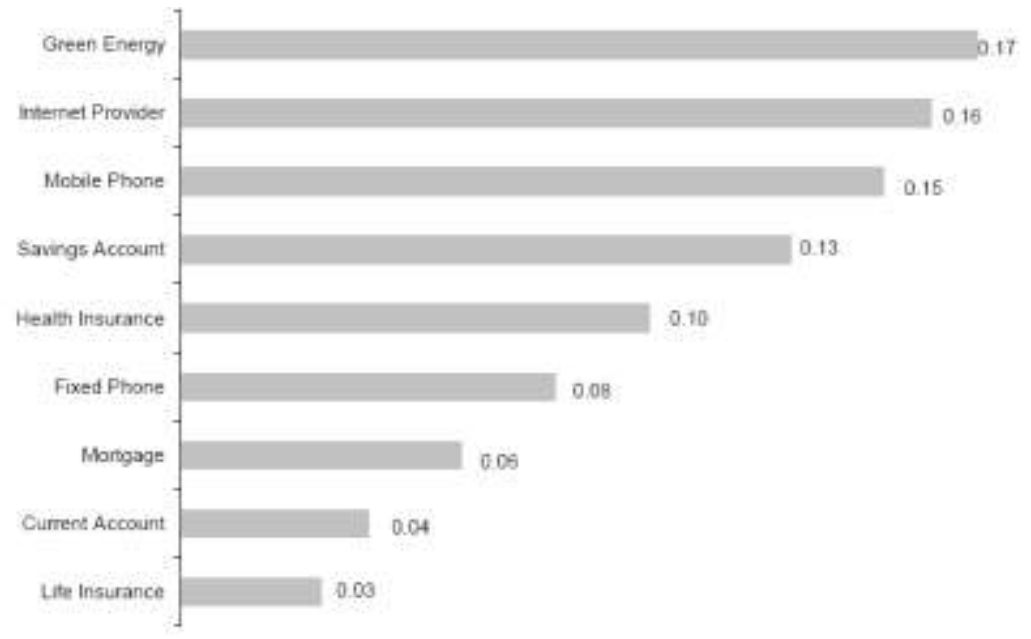

Source: Pomp et al. (2005)

Figure 6 - Customers that are aware of the possibility of choice

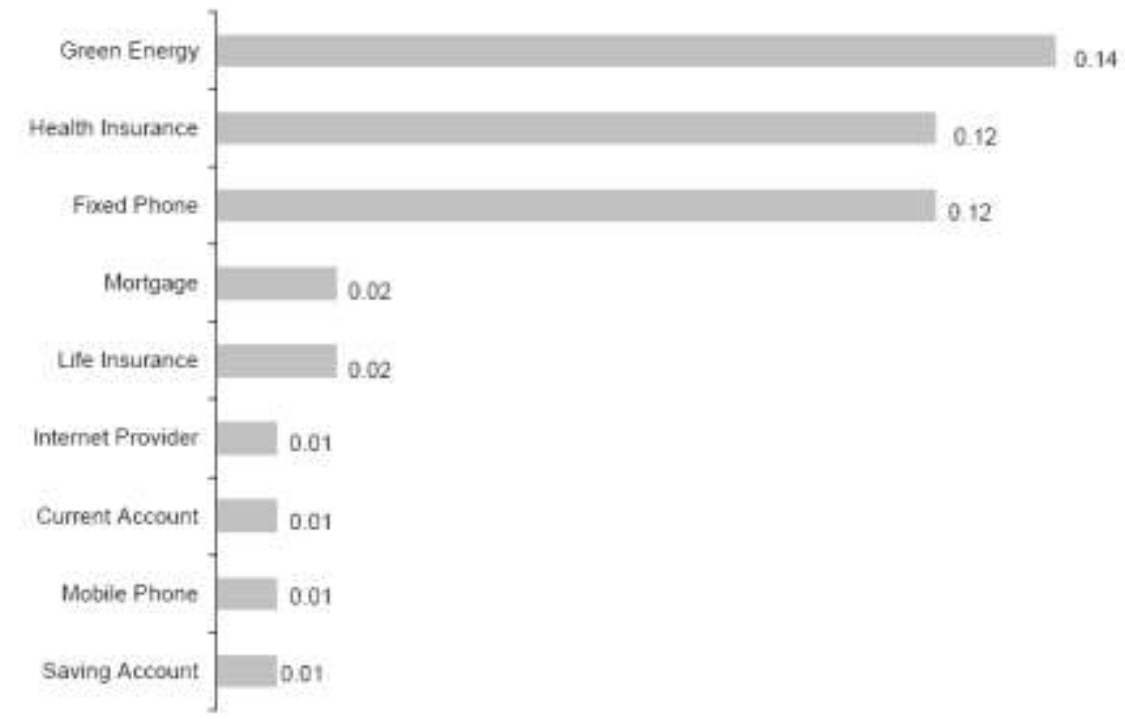

Source: Pomp et al. (2005)

Economic Studies, 62, pp. 515-539, 1995; OFT (2003), id.; OFT, “Assessing the effectiveness of potential remedies in consumer markets", OFT 994, April 2008. 
The results above are complemented by other surveys regarding the length of banking relationship. As reported by a recent study of the Nordic Competition Authorities, in Norway there is evidence that $85 \%$ of SMEs have had the same principal bank for three years or more. Two thirds of the SMEs have had the same principal bank for six years or more. A 2006 survey concluded that $63 \%$ of consumers have been loyal to their bank for more than 10 years ${ }^{185}$. Only $5 \%$ have switched bank during the last year. In countries with a not so developed banking system, as Hungary, only $16 \%$ of the customers have ever switched banks. In UK the estimated annual switching rate is 4-6\%, and in France it is roughly $5 \%$.

In addition, a Eurobarometer Flash was published in January 2009 based on a survey carried out in 2008 by the Gallup Organization upon the request of the European Commission on Consumers' views on switching service providers in a number of sectors ${ }^{186}$. Switching banking services was found to be difficult by $43 \%$ of those who did not want to stay with their current product or provider. The survey also found eloquent results as regard to the consumers' perception of the comparability of offers, as shown in the figures below. In this respect, retail financial services dominate all other services as regards the difficulty of comparing alternative offers. European consumers find it quite difficult to compare offers in services such as savings or investments, mortgage loans, long term loans, and even current accounts. A breakdown between vulnerable and non-vulnerable consumers highlights that this problem is widespread, not confined to a specific category or group.

\section{Figure 7 - Comparability of offers}

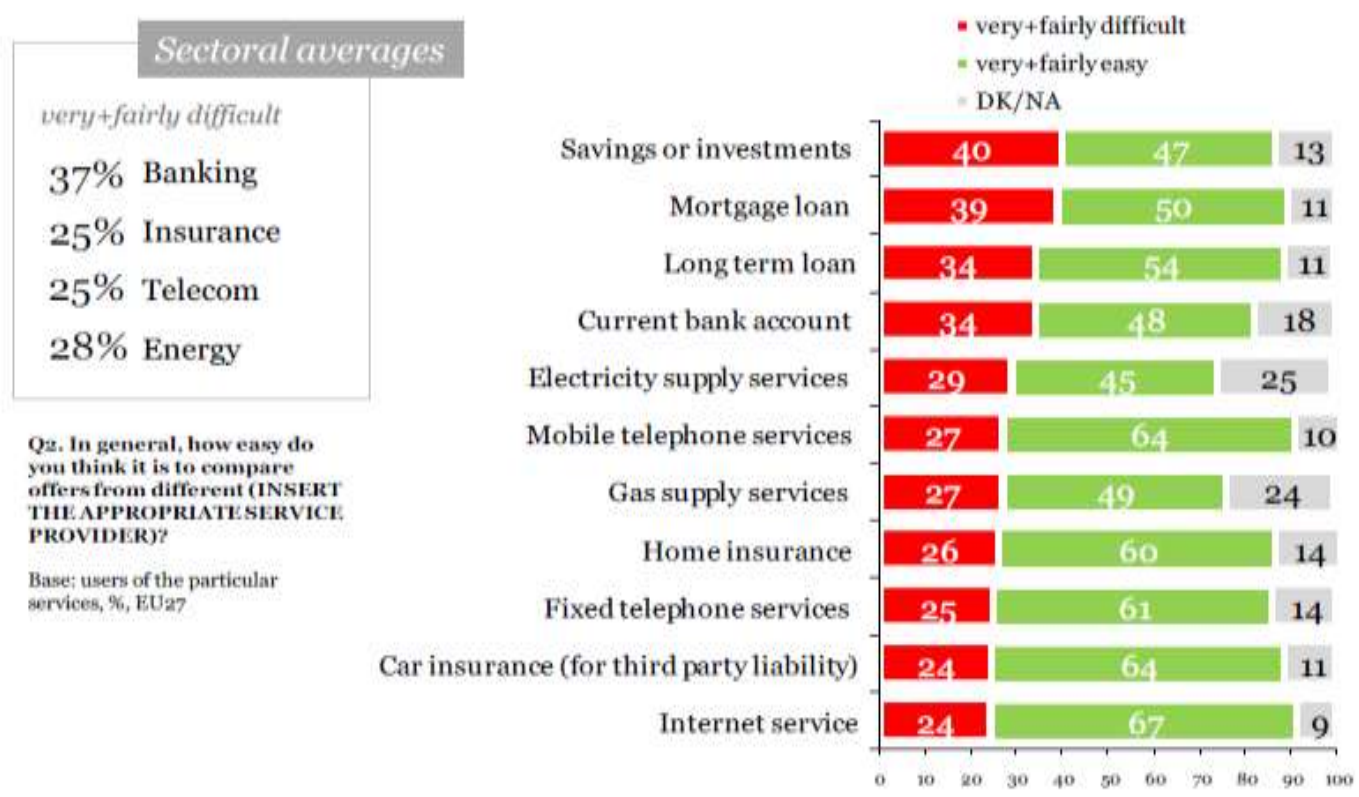

Source: Eurobarometer Flash 243, January 2009

185 Juul, H. (2006): Mobiliteten i den nordiske finansielle sektor, Nordic Council of Ministers TemaNord 2006:507

186 Available at http://ec.europa.eu/public opinion/flash/fl 243 sum en.pdf. 
The results of the recent surveys are particularly interesting for the purposes of our report, as they suggest that European citizens consider it to be very difficult to compare alternative offers. Accordingly, they do not switch provider very often, nor seem particularly eager to switch. Looking more closely at the reasons why customers do not switch, we may identify very interesting findings. For example:

- Compared to other services, consumers consider that the cost and effort required in switching is too large for all retail financial services - a "hassle" factor that seems stronger than in all other surveyed sectors.

- For mortgages and long term loans, a relatively high number of consumers responded that "their contract makes switching difficult". This suggests that contract terms may include penalties for early contract termination or rule it out entirely.

- In the case of long-term loans, a relatively high proportion of consumers declared that they did not know they could switch.

- The second most frequently cited reason, especially for savings and investment services, is "other".

\subsection{Potentially unfair commercial practices in the retail financial services sector}

In the financial services sector, also due to the particular features of the providercustomer relationship and the limited information often exhibited by customers, the practices under scrutiny could end up being detrimental to consumers even when they are not applied by a dominant firm. Under a consumer policy perspective, it is not the exclusionary impact of the practices, but rather its exploitative nature, that determines the unfairness of the conduct.

In this section, we analyse the potential impact of cross-selling practices (including tying, pure and mixed bundling, and preferential or exclusive agreements); conditional 
sales practices (such as single-product rebates or the obligation to have the salary paid into the current account as a condition to access a mortgage loan); and aggressive commercial practices (such as unsolicited offers, pressure/inertia selling, churning and steering) in the retail financial services sector.

\subsubsection{Cross-selling practices}

In this group of practices, we have included tying, pure and mixed bundling, and preferential or exclusive agreements. The potential for these practices to prove detrimental to customers is related to a number of factors listed above. Below, we analyse tying and pure bundling separately from mixed bundling and preferential/exclusive agreements.

\subsubsection{Tying and pure bundling}

As already explained in Section 1 of this paper, tying occurs when two or more products are sold together in a package and at least one of these products is not sold separately. Pure bundling occurs when none of the package components is available separately, and the components are offered in fixed proportions ${ }^{187}$.

In the economics literature, the most significant negative effects that may be associated with tying from the viewpoint of consumer policy - i.e., independently of the degree of market power of the financial service provider - are the following:

- $\quad$ Tying and pure bundling can lead to higher switching costs and lower customer mobility. Since tying forces customers to purchase all the tied products from the same provider, when these products are durable goods or services customers will face an increased cost of switching to an alternative provider, since they would lose the products they have bought from that provider altogether, and would need to renegotiate the purchase of all the tied product with a different provider. Customers may thus be reluctant to move to competing providers: this may reduce customer mobility and distort customer choice.

This effect depends also on what products or services are included in the bundle. For example, when products have different durations, the customer may be reluctant to switch to an alternative provider of a product with a shorter duration, even if this would be easy absent the tying or pure bundling practice. The lifespan of the contractual relationship thus tends to become equal to that of the product or service with the longest duration. For this reason, products such as mortgage loans are often used as "gateway" products by service providers wishing to retain their customers through cross-selling strategies. 
Finally, the impact of tying and pure bundling on switching costs may depend on the thickness of the contractual relationship. As observed above, once the customer has invested in a relationship with a personal banker or financial advisor, he or she may find it beneficial to enter into multiple contracts and services with the same provider: at the same time, this also means that switching would be more complicated, as it would entail losing the investment associated with building a relationship with the service provider, and having to bear the additional cost of searching for an alternative one, and testing over time the quality of the new service provider.

These effects have various consequences on customers. On the one hand, tying products with different duration may lead to customer lock-in, which may be detrimental to end customers without providing potentially countervailing efficiencies; on the other hand, the "thickness" of a relationship exhibits both beneficial and detrimental effects to customers, although it may expose the latter to exploitative behaviour of their counterparts during the course of the relationship.

It could be objected that, if the market is sufficiently competitive and all the products in the bundle can be offered by other firms, customers may find it profitable to switch even if they have bought a large bundle of goods. However, beyond offering a better deal to customers, these competitors would have to compensate them for the sunk investment they have borne to enter the current contractual relationship, as well as for the risk associated with entering a new contract or set of contracts. This can represent an important obstacle to customer mobility in the market.

- $\quad$ Tying can reduce price transparency and the comparability of offers. Tying practices make it difficult for customers to single out the price they pay for each product included in the bundled offer. Especially when competitors do not offer exactly the same bundle of products, customers will find it difficult to compare the price they are currently paying for the bundled products with alternative offers by alternative providers. This, in turn, can distort customer choice and lead to reduced customer mobility.

The economics of price comparability has shown interesting developments in the past few years, especially as behavioural economics is increasingly considered to play a role in devising consumer protection rules. In particular, Joshua Gans (2005) elaborated on the concept of "confusopoly" by referring to the existence of competing providers with offers that are structured so differently that it is impossible for an average consumer to compare them ${ }^{188}$.

188 Gans, The Road to Confusopoly (2005), available on the ACCC conference website (slides), http://www.accc.gov.au/content/index.phtml/itemId/658141/fromItemId/ 
At the same time, reducing price transparency can help financial service providers in introducing cross-subsidies between different products, in particular in the case of add-on contracts: for example, sellers may entice customers to buy a particular product through a low "introductory" price, knowing that they will be able to sell a number of additional products once the customer has entered the relationship ${ }^{189}$. Sellers wishing to compete for only one of the bundled products may have to offer a product below their own cost in order to entice customers to switch.

- $\quad$ Tying can force customers to purchase unwanted products, or force customers to renounce a better deal by "mixing and matching". An interesting example in this respect is that of payment protection insurance (PPI). As will be explained in Section 4 below, some legal systems in the EU27 consider it legitimate for a mortgage lender to force the borrower to also purchases PPI. In this way, the lender may better manage the risk associated with the borrower's default, sickness or death, then possibly leading to lower interest rates on the loan. However, requiring that the borrower purchases PPI is different from forcing the customer to purchase PPI from the same provider. If the borrower could choose to buy PPI elsewhere, then he would be able to shop around to find the best deal. In the UK, this problem has led the OFT to propose new rules for the PPI policies market. In France, the Loi Lagarde will prohibit this cross-selling practice from 1 January $2010^{190}$.

At the same time, there is widespread consensus that tying can also bring benefits for both providers and consumers ${ }^{191}$. The potential beneficial effects of tying practices include the following:

- On the supply side, tying can lead to cost savings through economies of scope. In the financial services sector, tying can allow firms to reduce the costs associated with customer management by using the same information for the provision of more than one service. This also means that a service provider may economise on the investment needed to learn the average riskiness and reliability of their customers, and can apply this information to the provision of more than one service. These savings can be also beneficial to customers, if market conditions lead financial service providers to pass on the efficiencies downstream to their clients in the form of lower prices.

- $\quad$ Tying can also lead the provider to more efficient pricing, by avoiding the risk of double marginalisation, and to efficient price discrimination, through the capture of

189 See Gans, J. (2005), 'Protecting consumers by protecting competition': Does behavioural economics support this contention?, 13 Competition \& Consumer Law Journal. In the literature, this has been referred to as "acquisition pricing" or "introductory pricing". See, i.a., Blattberg, Getz \& Thomas (2001), Customer Equity: Building and Managing Relationships as Valuable Assets, Harvard business publishing, at pages $47 \mathrm{ff}$.

190 See below, Sections 4.2.1.6 and 4.2.2.14 for details.

191 See infra Section 2.1.1 for a more detailed illustration. 
heterogeneous customer preferences by offering a wide range of products in a single package.

- On the demand side, tying can reduce transaction costs and lead to "portfolio effects" (or "one-stop-shop" effects). Customers having different needs often prefer to purchase one package of services and products from a single provider, instead of shopping around to find the best deal offered by different providers. This way, they can profit from a reduction in transaction costs, including search, information and negotiation costs. Available empirical evidence shows that consumers prefer to more than one service from a single provider for practical reasons, instead of shopping around for the best deal on all services ${ }^{192}$.

Overall, it seems clear that tying does not always constitute an unfair practice for customers, as the effects that may be generated by this practice are often beneficial. At the same time, tying can harm consumers and SMEs in the retail financial services sector:

(i) when it involves products of different duration;

(ii) when it forces customers to buy products they did not demand; and

(iii) when it does not produce demand-side efficiencies, or supply-side efficiencies that will be passed-on downstream to the customer in the form of lower prices or better quality.

\subsubsection{Mixed bundling and multi-product rebates}

Compared to tying and pure bundling, mixed bundling is normally considered to be less problematic from the standpoint of customer mobility and switching, and accordingly also from the viewpoint of consumer protection. As a matter of fact, mixed bundling entails no coercion of customers, and the purchase of products from separate providers is always possible. In the case of multi-product rebates, customers even benefit from a discount on the overall price, and can freely choose whether to purchase the products individually from different providers, or to obtain the discount and choose one single provider. In addition, regardless of whether customers obtain a financial benefit, purchasing the bundle may benefit them in other ways, e.g. through one-stop-shop effects and accordingly a reduction of transaction costs.

From this viewpoint, when there are no competition policy concerns, mixed bundling and multi-product rebates should not create any concerns from a consumer policy perspective either. However, adding a behavioural economics perspective to our analysis, two additional factors may be taken into account.

- Does coercion really make a difference? It may be observed that, given the limited information of consumers and the high switching costs associated with the

192 See Section 2.2 for an explanation based on empirical data. 
experiential nature of retail financial services and the need to "shop around", the effect of mixed bundling may be very similar to that of tying or pure bundling, since customers would be enticed to purchase the package in order not to face the hassle of having to shop around for better deals.

- Why tie what could be sold through mixed bundling? Because of the abovementioned characteristics of retail financial services, mixed bundling features the same potential benefits of tying for customers, without entailing coercion. In addition, from a consumer perspective, mixed bundling: (i) preserves the incentive for service providers to pass-on downstream the supply-side efficiencies generated by cross-selling, especially when specialised providers are able to offer comparable services and thus exert competitive pressure on the multi-product provider; and (ii) allows customers to compare the price of standalone products with the price of the bundle, in case the latter is offered at a discount. In a nutshell, mixed bundling is as beneficial as tying and pure bundling for customers, but may have a weaker impact on customer mobility. More specifically, mixed bundling preserves customer choice especially before the contract is concluded, as customers have an incentive to shop around and, if convenient, "mix and match" by purchasing products from different providers. However, mixed bundling can still affect customer mobility once the contract has been concluded.

\subsubsection{Preferential or exclusive agreements}

Compared to tying and bundling, preferential and exclusive agreements include: (i) case in which the provider forces the consumer to purchase an additional product from another provider, e.g. an affiliated body; and (ii) cases in which the customer spontaneously demands an additional product, and the service provider either offers a better deal conditional upon the choice of a designated provider (preferential agreement), or directly imposes a counterpart (exclusive agreement). In the former case, the rationale that applies is identical to the one we exposed for tying and bundling in the previous two sections, with the difference that the combined product is purchased from a different provider. Below, we focus on the latter case.

In line with the reasoning above, exclusive agreements are more likely than preferential agreements to lead to a reduction of customer mobility, and force customers into a contractual relationship with a provider they have not freely chosen. This, in turn, provides sellers with the possibility to exploit locked-in customers, although the magnitude of this effect is likely to be smaller due to the fact that the product has been spontaneously demanded by the customer.

None of these practices exerts a substantial impact on price transparency, whereas exclusive agreements affect the comparability of offers. At the same time, both types of practices can create supply-side efficiencies for providers, when the financial services 
involved are complementary. Providers may then be able to exploit economies of scale and scope by dealing with a preferred partner. In the case of preferential agreements, though, the provider has greater incentive to pass on these efficiencies downstream to the end customer, rather than keeping them as extra-profits.

\subsubsection{Conditional sale practices}

\subsubsection{Action-conditioned practices}

In these types of practices, without compliance with the specific condition, the product is not sold at all. A typical example of this type of practice is the obligation to have the salary paid into the customer's current account as a condition to obtain a mortgage loan ${ }^{193}$. From the standpoint of consumer policy, this practice creates concerns to the

193 See European Commission, White Paper on the Integration of the EU Mortgage Credit markets, COM(2007)807, 18 December 2007. 
extent that it forces customers to undertake specific actions in order to access a given service. This also means that customers will be hampered in their freedom to choose where to have their salary paid, and will have problems in choosing, for example, an alternative personal current account that offers better contractual conditions (e.g. a higher interest rate).

At the same time, such a practice can create supply-side efficiencies related to better risk management, since the provider knows that the customer will keep a sufficient amount of money into the current account that is coupled with a mortgage loan. The extent to which these efficiencies could be converted into better contractual conditions for the customer depends on the competitiveness of the markets involved, as well as on the degree of customer lock-in. For example, in the UK the so-called "offset mortgage" and "current account mortgage" offers a number of advantages to borrowers, including lower interest rates and tax advantages (savings will not generate any investment income to be taxed. Instead, less interest will be payable on the mortgage) ${ }^{194}$.

Against this background, the potential for a conditional sale practice to be considered as unfair to consumers strongly depends on: (i) whether the latter has the possibility of choosing alternative contractual schemes - this includes the possibility, for competitors, to replicate the conditional sale arrangement; and (ii) whether the conditional sale allows better contractual conditions, i.e. the efficiencies generated are shared with the customer.

It must also be recalled that conditional sale agreements are probably the only practices, among the ones under scrutiny in this paper that may end up being regularly included in a standard form contract. Other than by antitrust rules, they may thus be captured also by legislation on unfair terms such as the EU Directive on unfair terms in consumer contracts. An example of a conditional sale is the inclusion, in the standard contract terms, of clauses that impose heavy sanctions for the case of failure to perform on the side of the customer. One example is the so called "cross collateralization" clause, or "add-on" clause, which was at hand in the famous US Court of Appeals decision in Williams v. Walker Thomas Furniture ${ }^{195}$. In that case, besides the claim that the clause at

194 See FSA, Lifting the Lid on Financial Services, 2007. Offset mortgages are defined as those that combine savings with a mortgage to reduce the real value of the loan (offsetting). These mortgages allow customers to benefit from offsetting savings against borrowings but still keep all the elements of finance separate. Current account mortgages go one step further by combining all savings and debts into one account, i.e. combining a mortgage with a current account. This effectively acts like a single large overdraft into which salary payments are made and current expenditure deducted.

195 Cross-collateralization is a term used when the collateral for one loan is also used as collateral for another loan. If a person has borrowed from the same bank a home loan secured by the house, a car loan secured by the car, and so on, these assets can be used as cross-collaterals for all the loans. If the person pays off the car loan and wants to sell the car, the bank may veto the deal because the car is still used to secure the home loan and other loans. Technically, cross-collateralization expires when the borrower has no outstanding loans with the bank. In Williams v. Walker-Thomas Furniture, Walker-Thomas extended credit from 1957 to 1962 to Mrs. Williams for a series of furniture purchases. The contract was written in such a way that no furniture could be paid off until all of it was. When Mrs. Williams defaulted on the contract in 1962, Walker-Thomas tried to repossess all 
hand was unknown to the plaintiff and unconscionable, another important question that arose was whether the cross-collateralization clause was essential for the seller to secure payment; and whether, absent that clause, the plaintiff would not have had any access to the goods purchased, due to excess risk of default. The main problem with the clause was the lack of information and possibility of choice on the side of the customer, not the clause in and of itself.

In summary, conditional sale practices such as the obligation to have the salary paid into the current account or cross-collateralization clauses may be detrimental to customers when they deprive consumers of their freedom to choose alternative products. However, when the practice is replicable by competitors and the "condition" specified in the conditional sale agreement leads to benefits for customers, there is no reason for concern from the standpoint of antitrust or consumer policy ${ }^{196}$.

\subsubsection{Behaviour-conditioned practices}

One example of these practices is banks that charge no credit card fee if the cardholder spends more than a given amount of money every year. We term these practices conditional rebates ${ }^{197}$. The usual nature of a conditional rebate is that the customer is given a rebate if its purchases over a defined reference period exceed a certain threshold, the rebate being granted either on all purchases (retroactive rebates) or only on those made in excess of those required to achieve the threshold (incremental rebates)". The loyalty-enhancing impact of these rebate schemes has attracted the attention of competition authorities ${ }^{198}$.

Like cross-selling practices, also these practices are not always to be considered as unfair to customers. On the contrary, some of them - especially rebates - could even be beneficial to end users. However, under certain conditions, they may negatively affect consumer welfare due to the particular characteristics of the market in which they are observed. For example, loyalty schemes in the retail financial services sector have been found to be potentially enhancing complexity, making it even more difficult for customers to compare products, prices and services, and thus leading to "confusopoly".

the furniture sold since 1957. The District of Columbia Court of Appeals ruled that the lower court could rule the contract unconscionable and refuse to enforce it, and returned the case to the lower court to decide whether or not the contract was in fact unconscionable. See Korobkin, R. B. (2004), $A$ 'Traditional' and 'Behavioral' Law-and-Economics Analysis of Williams v. Walker-Thomas Furniture Company, UCLA School of Law, Law \& Econ. Research Paper No. 03-24 and University of Hawaii Law Review, Vol. 26, p. 441, 2004.

196 In the case of the obligation to have the salary paid into the current account, the practice does not create antitrust concerns if it is replicable by an as-efficient competitor; in addition, it does not create concerns from a consumer policy perspective if it proves beneficial to the customer. For example, for the UCPD to be applicable, the latter should be detrimental to customers.

197 See supra, Section 1.1.2.1.

198 See OECD; cit; and the recent report by the International Competition Network, Unilateral Conduct Working Group, Report on the Analysis of Loyalty Discounts and Rebates Under Unilateral Conduct Laws, Presented at the 8th Annual Conference of the ICN Zurich, Switzerland, June 2009. 
At the same time, loyalty discount schemes can increase switching costs, since alternative providers must compensate customers for the loss of the discount if to entice them to switch.

\subsubsection{Aggressive commercial strategies}

As observed above, many features of the financial services sector call for the creation of an ad hoc test to assess the potential impact of observed practices. Particular features include, most notably, the informational asymmetry between sellers and customers; the strong element of trust and path-dependency embedded in "relationship finance" (especially for some products such as personal current accounts); the limited interest and awareness of customers in "shopping around" for best deals; the importance of switching costs; and a series of cognitive biases such as choice/information overloads, endowment biases, overconfidence, framing effects, difficulty in handling uncertainty and risk, and misevaluation of future benefits and costs. In effect, these strategies frequently put pressure on consumers also through the use of misleading information or the exploitation of emotional states, to induce the customer to purchase the product or service.

In the universe of retail financial services markets, it is possible to identify some practices not related to specific contractual conditions offered to customers, but to the information flow between the service provider and the customer. In effect, the asymmetric information observed between the seller/intermediary and buyer/investor may induce the more informed party to pursue a set of aggressive commercial practices, potentially "unfair". In retail financial services, as recalled above, the information asymmetry between parties may raise two potential harmful common problems in 
retail markets, moral hazard and adverse selection. In this scenario, three aggressive commercial practices can be recognized in retail financial services:

- Unsolicited offers (e.g. so-called "pressure selling" or "inertia selling" of products that were not requested ${ }^{199}$ );

- Churning; and

- $\quad$ Steering.

The "unfairness" of these practices is essentially linked to the fiduciary relationship between service provider and the potential buyer/investor ${ }^{200}$. Accordingly these practices are more likely to emerge for those retail financial services that require sophisticated financial advice. The asymmetric flow of information between parties involves a high potential risk of customers' exploitation and harm, with sliding effects also on market competition (increasing switching costs). One stop-shop effects and such informational problems may lead the buyer/investor to choose a package of products from a single provider and/or with "bad" contractual conditions, instead of choosing their "best deal" across a consistent range of services' providers.

Lastly, there are many other sector-specific practices, which are not included as general categories of potentially "unfair" practices, since they are related to niches of the broad market for financial services. These include "loan flipping"201, "laddering"202,

199 The term "pressure selling" is often used in the literature on consumer contracts. The European Commission used this term in a number of occasions, often coupled with misleading marketing. Pressure selling, in the Commission's definition, includes (i) implying that the consumer cannot leave the shop until they sign a contract; (ii) conducting personal visits to the consumer's home and ignoring the consumer's request to leave or not to return; and (iii) demanding payment for products supplied by the trader, but which were not requested by the consumer (inertia selling). Misleading advertising includes practices such as (i) claiming to be a signatory to a code of conduct when the trader is not; and (ii) describing a product as "gratis", "free", "without charge" etc. if the consumer has to pay anything other than unavoidable delivery or collection costs. See, i.a., the Press Release "EU law to ban pressure selling: Commission welcomes Council's common position", IP/04/1364 of 16 November 2004.

200 A relationship is "fiduciary" when is based on confidence and trust between two or more parties. One party (agent) will act on behalf of another in circumstances in which the other party (principal) has not enough knowledge or means to unilaterally undertake a specific action. The fiduciary relationship exposes a beneficiary/principal to two distinct types of wrongdoing: first, the fiduciary may misappropriate the principal's asset or some of its value (negligence); and second, the fiduciary may neglect the asset's management (failure to perform). See Cooter R. and B. J. Freedman, "The Fiduciary Relationship: Its Economic Character and Legal Consequences”, 66 N. Y. U. Law Review, pp. 1045-1075, 1991.

201 In which a lender persuades homeowners to refinance their mortgages repeatedly and in short intervals; see Engel K. C. and P. A. McCoy, "A Tale of Three Markets: The L\&E of Predatory Lending", Texas Law Review, Vol. 80, No. 6, May 2002, p. 1263.

202 Banks involved in initial public offers can allocate initial shares to institutional investors, which commit to buy additional share in the secondary market to artificially increase prices, usually attracting retail buyers who are unaware of this private commitment; see Walter I., "Conflicts of Interest and Market Discipline Among Financial Service Firms", European Management Journal, Vol. 22, No. 4, 2004, p. 366. 
"stuffing"203, "failure to execute"204 and other operations more related to the provision of misleading information and the violation of privacy, which are not specific subject of this report or do not have a broad impact on the retail financial services sector.

\subsubsection{Unsolicited Offers}

A product or service offer is unsolicited when customers do not expressly request it and it involves a particular pressure on them to purchase that specific offer ${ }^{205}$. Hence, this practice may be extremely harmful because, on the one hand, it increases switching costs and affects customers' freedom of choice; on the other hand, it does not entail any efficiency that can be shared by customers ${ }^{206}$.

In order to consider an offer "unsolicited", three aspects should be verified ${ }^{207}$ :

1. Service provider makes persistent and unwanted contact via personal relations or various forms of remote media, whereas

2. The consumer has not expressly requested such services or has given his/her consent to be contacted, unless

3. There is no prior contact between customer and bank on related financial services.

For instance, this kind of practice is widespread in the US mortgages market ${ }^{208}$. It may have an implicit impact on the over-indebtedness of customers (unsolicited credit). However, it can be also employed as a risk management tool in the limited set of cases in which the customer is not able to understand the necessity of a service or product that would enable its counterparty to better manage risk.

203 Investment firms, which are high exposed with specific firms, can place unwanted securities on account where they have full discretion to reduce their exposure to losses; Walter I. (2004), id., p.365.

204 It is potentially used in securities or payments transactions to increase the float conveying important benefits to the firm; Walter I. (2004), id., p. 364.

205 Art. 15 EC Dir. 2005/29 on unfair business to consumer commercial practices in the internal market, amending art. 9 EC Dir. 97/7, expressly asks the national legislator "to exempt the consumer from any obligation in the event of unsolicited supplies".

206 "There should be no high-pressure selling, and adequate time should be allowed for the borrower to reflect on the terms and conditions of the loan and to obtain independent advice before signing", Office of Fair Trading, Non-Status Lending. Guidelines for Lenders and Brokers, OFT 192 (revised), November 1997, p. 7, §6.

207 See Annex I, N. 26, Unfair Commercial Practice Directive (UCPD), Dir. 2005/29/EC.

208 See Federal Trade Commission, Statement on Consumer Protection in Financial Services, before the House Committee on Financial Services, Washington D.C., 13 June 2007, p. 7. 


\subsubsection{Churning}

"Churning" is a legal term used to define a practice imported from securities regulation. The Securities and Exchange Commission (SEC) defined it as an "excessive buying and selling of securities in your account by your broker, for the purpose of generating commissions and without regard to your investment objectives"209. However, the definition is basically broadened to cover other practices in disparate areas of the financial services sector (not only securities) ${ }^{210}$. Hence, this practice consists in the excessive use, for example, of the current account or the investment portfolio induced by the financial intermediary (agent) who exploits the informational gap of the other party (principal). It is a misuse of the fiduciary role between intermediary and customer ${ }^{211}$, due to the lack of monitoring by the latter (e.g. due to information asymmetry) ${ }^{212}$.

The unnecessary number of services should be assessed in the light of the investor experience and objectives. For instance, the excessive trading or the unnecessary services (in size and frequency) requested to generate extra commissions or fees may potentially affect the suitability of the investment decision or the financial product or service in general ${ }^{213}$. Therefore, a case of churning can be considered "unfair" whenever it is not justified, e.g. by potential efficiencies for consumers such as quality improvements or better contractual conditions. The trade-off between the economic benefits of the excessive services or products and the extra-fees would certainly be negative in these cases $^{214}$.

As regards efficiencies, it might be difficult to assess relevant market efficiencies for this widespread practice. The restriction to customer freedom of choice and mobility cannot be easily justified by economies of scale or scope, since through this practice consumers are systematically charged of unwanted commissions compromising their potential choice to use alternative products or services. However, especially in investment decisions, churning (activism) can be a mechanism of signalling of a more informed

209 See SEC at http://www.sec.gov/answers/churning.htm. It was firstly judicially defined in Hecht v. Harris Upham \& Co., 430 F.2 days 1202 (2nd Cir. 1970); see also A.M. Pacces, Financial intermediation in the securities markets law and economics of conduct of business regulation, International Review of Law and Economics, Vol. 20, 2000, pp. 479-510; Walter I., "Strategies in Banking and Financial Services Firms: A Survey", December 2003, available at www.ssrn.com.

210 See Walter I. (2004), id., pp. 361-376.

211 See ibid., p.362.

212 Churning differs from other practices such as "loan flipping", since the former is a result of misbehaviour of the agent due to the lack of control of the principal; to the contrary, loan flipping typically occurs when a borrower is unable to meet scheduled payments, or repeatedly consolidates other unsecured debts into a new, home-secured loan at the urging of a lender.

213 In case of investment and ancillary services, suitability and appropriateness as well as best execution requirements are relevant investor protection rules included in the Markets in Financial Instruments Directive (MiFID) and implemented at national level in all the 27 countries; art. 19 and 21 EC Dir. 2004/39 and Annex 1, Section A and B.

214 S.B. Cohen, The Suitability Rule and Economic Theory, 80 Yale Law Journal, 1971, pp. 1604-1626. 
status for securities professionals ${ }^{215}$; and potentially increases market liquidity (often considered a "public good") of financial markets, thus improving their efficiency ${ }^{216}$. In the long run, though, the performance of "over-active" funds does not hold 217.

\subsubsection{Steering}

"Steering" is a practice, especially used in the mortgages market, consisting of stressing the credit risk of a potential borrower to steer him $\backslash$ her to higher cost loans ${ }^{218}$. The prospect of securing higher fees (and consequently profits) for brokers or intermediaries, who succeed to sell a more expensive financial product or service, may lead to the adoption of this practice. In general, steering can be construed as an intentional misjudgement of the individual's risk by the financial intermediary, aimed at extracting a rent over a relatively long time period. It may consist of higher interest rates, worse contractual conditions, additional fees, higher closing fees, the imposition of specific requirements (higher collateral provision, etc), etc.

The risks linked to this practice are potentially high, taking into consideration the full discretion of intermediaries in the assessment of the risk and the financial situation of a retail buyer/investor. The fundamental role of this assessment for the transaction's success needs to be guided by well defined and clearly disclosed criteria of suitability and adequateness - as it is the case for investment services under MiFID - to avoid the widespread diffusion of the practice. However, the enforcement of these criteria may be difficult. In effect, complying with these principles involve relevant investments and the need to modify traditional business models and methods in this field. Therefore, potential failures in the implementation of these principles may affect the market efficiency through the imposition of ineffective burdens.

215 See A.M. Pacces (2000), id., p. 495.

216 See J. Dow and G. Gorton, Noise Trading, Delegated Portfolio Management, and Economic Welfare, Journal of Political Economy, Vol. 105, N. 5, 1997.

217 See M.L. Detzler, The Value of Mutual Fund Rankings to the Individual Investor, University of Massachusetts, Boston, July 1999, available at www.ssrn.com.

218 Ernst Keith, Debbie G. Bocian and Wei Li, Steered Wrong: Brokers, Borrowers and Subprime Loans, Center for Responsible Lending, www.responsiblelending.org, 8 April 2008; "steering incentives" are officially prohibited by the new US Mortgage Reform and Anti-Predatory Lending Act, Sec. 103(c) H.R. 1728, May 2009. 


\section{Measuring the impact of tying and other potentially unfair practices in the retail financial services sector: a multi-stage test}

Tying and other potentially unfair practices represent a wide set of commercial strategies commonly used across industries and also in the retail financial services market. As mentioned above, a case-by-case approach is seemingly the best way to assess whether their potential harmful effect offset the benefits brought to the market and final users, from a competition and consumer policy view. Efficiency reasons can be found in most of the practices previously taken into consideration, with the exception of aggressive commercial practices. There are three main categories in which potential efficiencies can be easily classified:

- Efficiency reasons related to the provision of the services. In effect, crossselling strategies are so widespread because they potentially increase the demand reducing the variability of reservation prices, thereby favouring economies of scale and scope. In other cases, as tying and multi-product rebates, these practices seemingly reduce transaction costs and may avoid double marginalization (with complementary products and prices set independently). Finally, some of these strategies can protect "free-rideable" investments (as presale services) or transaction-related investments which create a hold-up problem.

- Efficiency reasons related to the consumer welfare. Notably, consumers can potentially enjoy, at least in the short run, several efficiencies which are mostly concentrated in tying and multi-product rebates. Price reduction is a common benefit for consumers in all of the practices mentioned above, while transaction costs' reductions and quality improvements are further efficiency reasons linked to tying and multi-product rebates.

- Efficiency reasons related to the total welfare ${ }^{219}$. Tying (and multi-product rebates), conditional rebates and loyalty rebates might represents devices respectively enacting first-degree, second-degree and third-degree price discrimination strategies. In effect, whether "perfectly" enforced these strategies can increase the total welfare for the whole society. However, distributional concerns may arise from the adoption of specific cross-selling strategies. For instance, the "leverage effect" may involve - as previously described (Section 2.1.1.1) - distributional concerns since the supplier can potentially extract the entire surplus enjoyed by consumers, even though the practice increases the total welfare.

\footnotetext{
219 Such efficiencies refer to practices that increase the total welfare for the society, namely the sum of consumers and suppliers' surplus. However, these efficiencies do not address any concerns on the redistribution of this increased surplus between suppliers and consumers.
} 
Then, these practices may impact on switching costs, price comparability and customers' freedom of choice (see table below). We try to classify the reasons why commercial practices may end up being unfair to customers in the retail financial services sector, and whether competition law and consumer protection law can effectively address these situations, once assessed on which aspects the practices have impacted the most.

Competition law (Article 82 of the EC Treaty) can capture most of the practices under scrutiny, and in particular tying and bundling, exclusive dealing arrangements, conditional and loyalty rebates, to the extent that they lead to anti-competitive foreclosure of competitors. The economic literature on tying and bundling uses a caseby-case approach to analyze these practices because the anti-competitiveness of the practice is strongly linked to market and product settings in which the strategy is enacted. Aggressive commercial practices in which a dominant firm engage could, in principle, be construed as exploitative abuses, although the case law under Article 82(a) EC Treaty never referred to practices such as unsolicited offers, churning and steering. The need to refer to clearly specified contract terms practiced by a dominant firm makes Article 82(a) very difficult to apply systematically and fully effectively to these practices.

Our analysis also reveals that there are many instances in which an unfair commercial practice may not be captured by antitrust laws. This is mostly because Article 82 ECT requires that the undertaking that engages in the practice holds a dominant position in at least one of the relevant markets involved. In all other cases, the practice does not lead to anti-competitive foreclosure, abusive discrimination or exploitation as defined in Community competition law, and as such is not relevant for the application of Article 82 .

Many features of the financial services sector call for the development of an ad hoc test to assess the potential impact of observed practices. Particular features include, most notably, the informational asymmetry between sellers and customers; the strong element of trust and path-dependency embedded in "relationship banking" (especially for some products such as personal current accounts); the limited interest and awareness of customers in "shopping around" for best deals; the importance of switching costs; and a series of cognitive biases such as choice/information overloads, endowment biases, overconfidence, framing effects, difficulty in handling uncertainty and risk, and misevaluation of future benefits and costs. In effect, these strategies frequently put pressure on consumers also through the use of misleading information or the exploitation of emotional states, to induce the customer to purchase the product or service.

Some practices may be detrimental to consumers since they reduce customer mobility by increasing switching costs, even if they are not relevant under a competition policy perspective. The impact on switching costs depends on a number of factors, including the type of "gateway" products/services involved; the number and type of bundled services offered; the "exit cost" involved; the existence of switching facilities; and of 
course the characteristic of the demand, especially as regard the customer's preference to stable relationships. Certainly, practices such as tying and pure bundling and conditional sales increase switching costs for customers, thus reducing their mobility.

Some practices can harm consumers by reducing price transparency and the comparability of offers. Even practices that do not directly increase the cost of exit from an existing contract may reduce customer mobility. Mixed bundling, conditional and loyalty rebates and other practices related to "introductory" or "acquisition" pricing have this potential, as they may lead to a final outcome in which customers have difficulties in singling out the individual price of products they have purchased, and/or fail to fully calculate the price of alternative offers on the market.

Other practices do not affect directly switching costs or price transparency, but can prove unfair to customers as they result from a strategic behaviour of the financial advisor. This is the case of aggressive sales practices such as pressure and inertia selling, churning and steering, in which the financial advisor exploits his superior information and capitalises on the trust-based relationship with the customer, which characterises most retail financial services (especially mortgage, insurance and investment services). 
Table 2 - Main economic impacts of the practices under scrutiny

\begin{tabular}{|c|c|c|c|c|c|c|c|c|}
\hline \multirow{2}{*}{ Practices } & \multicolumn{3}{|c|}{ Cross-selling } & Conditional sale & \multicolumn{4}{|c|}{ Aggressive commercial practices } \\
\hline & $\begin{array}{c}\text { Tying and pure } \\
\text { bundling }\end{array}$ & $\begin{array}{l}\text { Mixed bundling and } \\
\text { multi-product rebates }\end{array}$ & $\begin{array}{c}\text { Preferential or } \\
\text { exclusive } \\
\text { agreements }\end{array}$ & $\begin{array}{l}\text { Conditional sales and } \\
\text { single-product rebates }\end{array}$ & $\begin{array}{c}\text { Unsolicited } \\
\text { offers and } \\
\text { pressure selling }\end{array}$ & $\begin{array}{l}\text { Inertia } \\
\text { selling }\end{array}$ & Churning & Steering \\
\hline $\begin{array}{l}\text { Price compa- } \\
\text { rability }\end{array}$ & $\begin{array}{c}\text { Lower } \\
\text { Customers cannot } \\
\text { easily single out the } \\
\text { price/conditions of } \\
\text { individual products }\end{array}$ & $\begin{array}{c}\text { Preserved } \\
\text { Customers still have the } \\
\text { chance to observe } \\
\text { individual } \\
\text { prices/conditions }\end{array}$ & $\begin{array}{c}\text { Preserved } \\
\text { Customers still } \\
\text { have the chance } \\
\text { to observe } \\
\text { individual } \\
\text { prices/conditions }\end{array}$ & $\begin{array}{c}\text { Lower } \\
\text { Risk of "confusopoly" for } \\
\text { loyalty programmes }\end{array}$ & $\begin{array}{c}\text { No impact } \\
\text { Related to pre- } \\
\text { contractual phase }\end{array}$ & $\begin{array}{l}\text { No impact } \\
\text { Related to pre- } \\
\text { contractual } \\
\quad \text { phase }\end{array}$ & $\begin{array}{c}\text { No impact } \\
\text { Related to pre- } \\
\text { contractual phase }\end{array}$ & $\begin{array}{c}\text { No impact } \\
\text { Related to pre- } \\
\text { contractual phase }\end{array}$ \\
\hline $\begin{array}{l}\text { Customer } \\
\text { freedom of } \\
\text { choice }\end{array}$ & \begin{tabular}{|} 
Reduced choice \\
May imply coercion of \\
customers (mostly in \\
non-competitive \\
markets)
\end{tabular} & $\begin{array}{c}\text { Preserved } \\
\text { Customers still have the } \\
\text { chance to "mix and match" }\end{array}$ & \begin{tabular}{|} 
Reduced \\
choice \\
Only in the case of \\
exclusive \\
agreements
\end{tabular} & $\begin{array}{l}\text { Reduced choice } \\
\text { Especially in the case of } \\
\text { "current account mortgage" }\end{array}$ & $\begin{array}{l}\text { Distorted } \\
\text { Pressure selling } \\
\text { can distort } \\
\text { consumer } \\
\text { behaviour }\end{array}$ & $\begin{array}{l}\text { Distorted } \\
\text { Inertia selling } \\
\text { can distort } \\
\text { consumer } \\
\text { behaviour }\end{array}$ & $\begin{array}{c}\text { Distorted } \\
\text { Exploitation of } \\
\text { customer's lack of } \\
\text { information }\end{array}$ & \begin{tabular}{|} 
Distorted \\
Exploitation of \\
customer's lack of \\
information
\end{tabular} \\
\hline $\begin{array}{l}\text { Supply-side } \\
\text { efficiencies }\end{array}$ & $\begin{array}{l}\text { Potentially high } \\
\text { - Economies of } \\
\text { scale/scope } \\
\text { - Reduction of } \\
\text { inefficiencies } \\
\text { - Better risk } \\
\text { management } \\
\text { - No double } \\
\text { marginalization } \\
\text { - First-degree price } \\
\text { differentiation }\end{array}$ & $\begin{array}{l}\text { Potentially high } \\
\text { - Economies of } \\
\text { scale/scope } \\
\text { - Reduction of } \\
\text { inefficiencies } \\
\text { - } \text { Better risk management } \\
\text { - No double } \\
\text { marginalization } \\
\text { - First-degree price } \\
\text { differentiation }\end{array}$ & $\begin{array}{l}\text { Moderate } \\
\text { - Better risk } \\
\text { management }\end{array}$ & $\begin{array}{l}\text { Potentially high } \\
\text { - Economies of scale and } \\
\text { scope } \\
\text { - Reduction of inefficiencies } \\
\text { - Better risk management } \\
\text { - Protection of "free- } \\
\text { rideable" investments } \\
\text { - Solution to the hold-up } \\
\text { problem } \\
\text { - Second and third-degree } \\
\text { price discrimination }\end{array}$ & $\begin{array}{l}\text { Low/none } \\
\text { - Economies of } \\
\text { scale/scope } \\
\text { - Protection of } \\
\text { "free-rideable" } \\
\text { investment }\end{array}$ & $\begin{array}{l}\text { Low/none } \\
\text { - Economies of } \\
\text { scale/scope } \\
\text { - Protection of } \\
\text { "free- } \\
\text { rideable" } \\
\text { investment }\end{array}$ & $\begin{array}{l}\text { Low/none } \\
\text { - Economies of } \\
\text { scale/scope } \\
\text { - Protection of } \\
\text { "free-rideable" } \\
\text { investment }\end{array}$ & $\begin{array}{l}\text { Low/none } \\
\text { - Economies of } \\
\text { scale/scope } \\
\text { - Protection of } \\
\text { "free-rideable" } \\
\text { investment }\end{array}$ \\
\hline $\begin{array}{l}\text { Demand-side } \\
\text { efficiencies }\end{array}$ & $\begin{array}{l}\text { Potentially high } \\
\text { - Lower transaction } \\
\text { costs } \\
\text { - Lower price or } \\
\text { better conditions } \\
\text { - Quality } \\
\text { improvements }\end{array}$ & $\begin{array}{l}\text { Potentially high } \\
\text { - Lower transaction costs } \\
\text { - Lower price or better } \\
\text { conditions } \\
\text { - Quality improvements }\end{array}$ & \begin{tabular}{|l|} 
Moderate \\
- Lower \\
transaction \\
costs (no \\
search costs) \\
- Lower risk
\end{tabular} & $\begin{array}{l}\text { Moderate } \\
\text { - Lower transaction costs } \\
\text { ("current account } \\
\text { mortgage") } \\
\text { - Better contract conditions } \\
\text { - Lower price (rebates) } \\
\text { - Quality improvement }\end{array}$ & None & None & None & None \\
\hline
\end{tabular}


Figure 8

\section{A Multi-stage test (author's elaboration)}

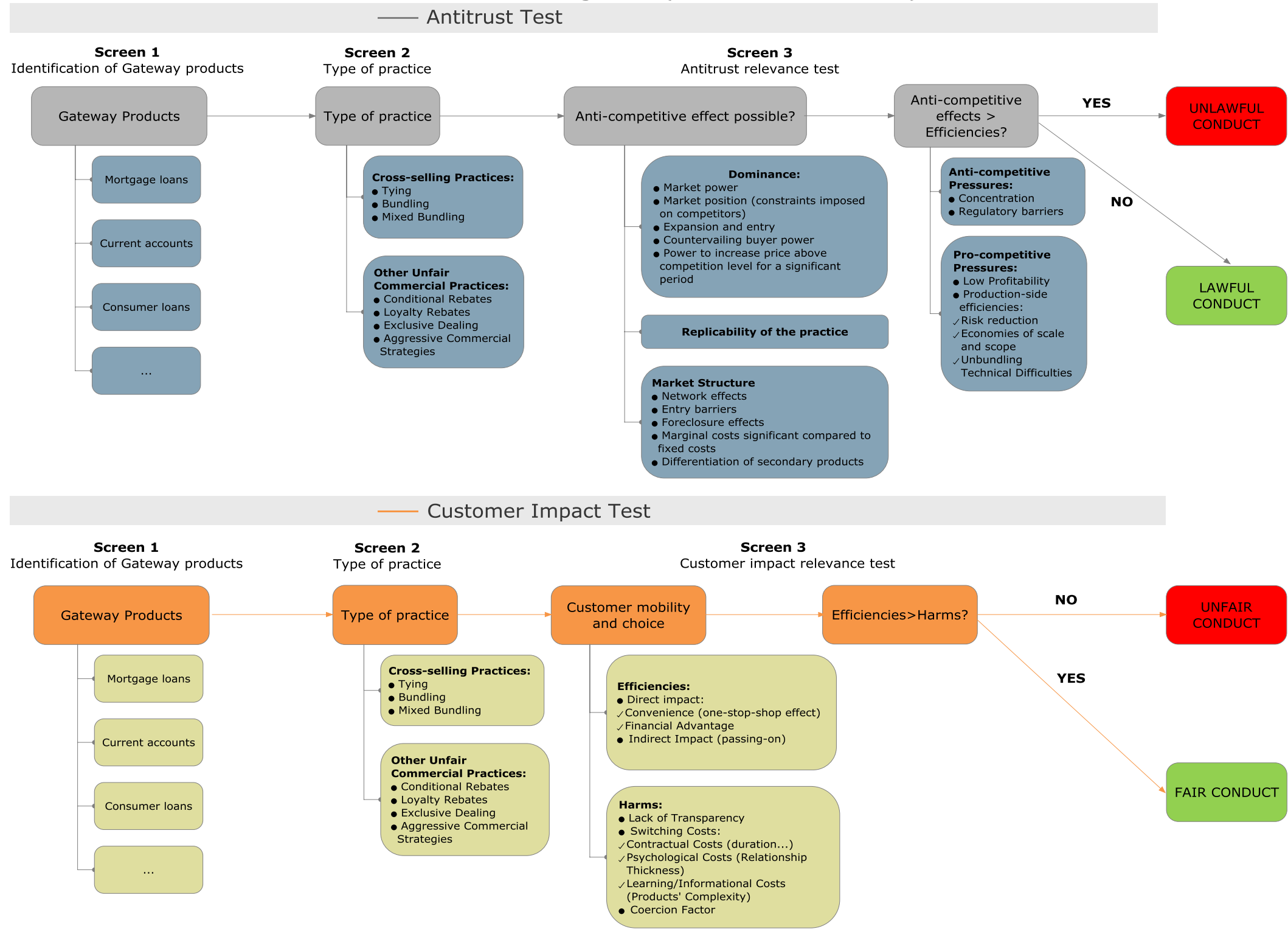


In order to assess whether the practices empirically observed are likely to be anticompetitive or unfair from a consumer policy's point of view, we designed a multi-stage test based on three different level of analysis. The logical steps of the test are graphically showed in the figure above. In particular, in the "preliminary test" stage we identify and score the type of gateway product and the type of practice associated with that product. We then look at the type of practice, as for different gateway products, the same type of practice is likely to lead to different results. For example, a mixed bundling solution of mortgage loans with another product may have a different impact than tying it. In fact, having different combinations of gateway products and practices can help us later in the test, e.g. by evaluating the production and demand-side efficiencies associated with each specific practice observed.

In the "antitrust impact test", we check whether the anti-competitive effect is possible - this depends on whether the firm is dominant and whether the practice is likely to lead to anti-competitive foreclosure; then, following the Commission' 2008 Guidance paper on exclusionary abuses under Article 82 of the EC Treaty, we ask whether the practice features redeeming efficiencies, which are likely to be shared with customers. An overall balance of harmful effects and efficiencies leads to determining whether the conduct is likely to be found anti-competitive, and thus unlawful.

In the "customer impact test", the steps are different, and mirror to the extent possible the unfairness test of the EU Unfair Commercial Practices Directive (UCPD). We then ask whether the practice is likely to reduce customer mobility and choice; and whether it is objectively justified. This latter test includes an assessment of demand-side efficiencies generated by the practice. If the practice overall is found to be beneficial for consumers, we consider it to be lawful. Practices that restrict customer choice and mobility without producing efficiencies for consumers are considered to be unfair, if not objectively justified.

We have common stages in assessing consumer impact and antitrust effects, as described below.

- In screen 1, we define the type of gateway product we are going to investigate. A product is defined as gateway or platform if there is a relevant likelihood that practices involving this product may lead to customer lock-in and reduced mobility. Many financial products and services may be used as "gateway" or "hook" for end customers (e.g. current accounts, mortgage, life insurance, etc).

- Second, in screen 2 we look at the type of practice. For different gateway products, the same type of practice is likely to lead to different results. For example, bundling mortgage loans with another product may have a different impact than tying it; and of course some potentially unfair practices do not even require combined sales. As a matter of fact, having different combinations of gateway products and practices can help us in the test, e.g. by evaluating the 
production and demand-side efficiencies associated with each specific practice observed.

In the antitrust assessment of the practice (top areas in the graph), we identified the following steps: (i) we check whether the anti-competitive effect is possible - this depends on whether the firm is dominant and whether the practice is likely to lead to anti-competitive foreclosure; (ii) then, following the Commission's 2008 Guidance paper on exclusionary abuses under Article 82, we ask whether the practice features redeeming efficiencies, which are likely to be shared with customers.

A trade-off between harmful effects and efficiencies will determine whether the conduct is likely to be found anti-competitive, and thus unlawful.

In the customer impact test, the steps are different, and mirror to the extent possible the unfairness test of the UCPD. In our test, we consider the likelihood that the practice reduces customer mobility and choice. In such cases, the results of the test may provide an indication of whether a practice is likely to materially distort the economic behaviour of an average consumer, as required under the UCPD test, and whether the practice is objectively justified. This latter test includes an assessment of demand-side efficiencies generated by the practice (see paragraphs above). If the practice overall is found to be beneficial for consumers, we consider it to be lawful. Practices that restrict customer choice and mobility without producing efficiencies for consumers are considered to be potentially unfair, since they cannot be justified by the existence of efficiencies. Compared to the unfairness test of the UCPD, it was not possible for us to perfectly mirror the extent to which the practice is contrary to professional diligence: this assessment is normally performed by the judge on an ex post basis, and referred to an individual practice under scrutiny. In our case, we must rely on the qualitative interpretation of the results of our test to infer whether the practice can be considered in line with, or contrary to, professional diligence.

\section{Conclusions}

The paper firstly described the rationales for applying both antitrust and consumer protection legislation to practices widely adopted in the retail financial services area, i.e. tying, bundling and other diffused commercial practices. The first part explored the main findings of the legal and economic theory as regards the applicability of antitrust rules to the practices at hand and main policy findings. The second section, instead, illustrates the law and economics of tying and other unfair commercial practices from a consumer policy perspective. This paper shows new empirical data on switching costs and consumer behaviours in retail financial services and other sectors. Finally, the last part designed a test for the assessment of these practices under the umbrella of the competition and consumer policy. We then draw conclusions on the potential impact of the practices under scrutiny on consumer welfare. 
From a competition policy view, we can identify several conclusions, looking at the potential application of antitrust law. However, there are several practices that do not directly fall under competition law and therefore can only be alleged to have violated competition law with exclusionary or exploitative ${ }^{220}$ abuses if the firm adopting the practice is dominant in one of the market involved.

a. The economic literature on tying and bundling does not give a definitive answer about the trade-off between costs and benefits borne by society. It suggests a caseby-case approach (rule of reason) to analyze these practices because the anticompetitiveness of the practice is strongly linked to market and product conditions in which the strategy is enacted. High marginal costs and lack of product differentiation may increase the likelihood that tying harms consumers.

b. A multi-product rebate may infringe Article 82 if a firm holding a dominant position in at least one of the bundled products and whether competitors cannot replicate the bundle or the single product offer, as the LRAIC test on the whole bundle or single offer shows anticompetitive advantages.

c. Preferential or exclusivity agreements may be helpful in presence of "freerideable" investments ${ }^{221}$ to assure high quality standards in the provision of the final product or economies of scale and scope. In other cases, they may hamper competition and lead to anti-competitive foreclosure especially when competitors are unable to compete for the full supply to customers, also if equally efficient. However, the probability to be prosecuted under Art. 82 ECT is very low.

d. Conditional rebates represent a diffused practice that can stimulate competition, economies of scale (efficiency) and provide benefits to consumer. However, these practices can be considered as anti-competitive when they lead to actual foreclosure of rivals, as well as consumer harm in the medium to long run, due to loyalty-inducing effects.

e. The overall impact of loyalty rebates may be more difficult to assess as it depends on firms' market shares, the market's competitive structure and the characteristics of customers' demand. Then, incremental rebates have basically a

${ }^{220}$ Article 82 also applies to so-called exploitative abuses by dominant undertakings. However, the case law on unfair contract terms as Article 82 offenses has remained very limited, and confined to IPrelated cases such as BRT/SABAM, GEMA II and DSD. In general, Article 82 cannot be considered as a consumer policy tool and specific legislation is more able to capture the problems that arise in consumer transactions.

${ }^{221}$ Jan B. Heide, Shantanu Dutta and Mark Bergen, "Exclusive Dealing and Business Efficiency: Evidence from Industry Practice", The Journal of Law and Economics, Vol. 41, N. 2, October 1998, pp. 387-408; Alden F. Abbott and Joshua D. Wright, "Antitrust Analysis of Tying Arrangements and Exclusive Dealing", forthcoming in Antitrust Law and Economics, Edward Elgar Publishing, Keith N. Hylton (ed.), George Mason University Law and Economics Research Paper Series, 08-37, p. 29. 
lower harmful impact than conditional-retroactive rebates, which can induce consumers to harmful loyalty.

f. For aggressive commercial practices, the application of Art. 82 is more difficult, as usually there is no dominance by firms enacting these practices or no recognition of the exploitative abuse over consumers as a problem of competition.

More recently, a tendency to expand the reach of antitrust role to capture specific problems of consumer policy has emerged. For example, the UK the Office of Fair Trading (OFT) has examined and taken action in many financial services markets with a dual mandate of competition and consumer policy, through many investigation in several areas. These new initiatives were aimed at pursuing four overarching objectives of competition, choice, fairness and responsibility ${ }^{222}$. Also in other countries, the need to develop a more consumer-oriented competition policy has emerged. For instance, the recent initiative of the US Fair Trade Commission's report on mortgage disclosures, taking a stance in favour of consumer information ${ }^{223}$.

In the past few years, also important contributions in the literature highlighted the need to reconcile the two separate worlds of antitrust and consumer protection in order to pursue more effectively a good functioning of markets in the interest of consumers ${ }^{224}$. This, in many cases, requires antitrust to take into account consumer policy, which may identify a number of relationships between market conditions and psychological factors, on the one hand, and the contractual weakness of customers in specific retail financial services on the other hand. Therefore, in consumer policy, we may identify a list of potential other aspects that should be taken into consideration when assessing the unfairness of the service or product provided.

a. Information asymmetry. The asymmetry of information that characterises most consumer contracts is particularly evident in retail financial services, and especially in complex and risky transactions such as investment services. This material condition feeds the concepts of bounded rationality and rational ignorance.

b. Decision-making biases (or cognitive biases). Financial services are characterised by widespread biases (or cognitive biases) affecting consumers' choice, such as

\footnotetext{
222 See the document, OFT1077con, at http://www.oft.gov.uk/shared oft/consultations/oft1077con.pdf.

223 See http://www.ftc.gov/opa/2007/06/mortgage.shtm.

224 See J. Vickers, Economics for Consumer Policy, 125 Proc. Brit. Acad. 287-310, 289 (2004); Timothy Muris, The Interface of Competition and Consumer Protection, Paper presented at Fordham Corporate Law Institute's 29th Annual Conference on International Antitrust Law and Policy, New York (Oct. 31, 2002); Armstrong (2008), Interaction between Competition and Consumer Policy, a report for the OFT, OFT 991, April 2008; Lande, Robert H. and Averitt, Neil W., Consumer Sovereignty: A Unified Theory of Antitrust and Consumer Protection Law. Antitrust Law Journal, Vol. 65, p. 713, 1997. See also a dedicated section of the OECD Global Forum on Competition; the Seventh Global Forum on Competition, 21-22 February 2008, Paris (France), Section IV.
} 
framing and endowment effects, the overestimation of future proceeds or the mis-evaluation of deferred costs, and difficulties in handling uncertainty and risk. In particular, endowment and framing effects (e.g. reference point) lead to high switching costs, as customers prefer a certain contractual relationship to a hypothetical improvement associated with switching.

c. Experience and credence factors. The majority of retail financial services exhibit significant experience and credence attributes. Therefore, customers are exposed to exploitative behaviour on the side of providers, as they may not assess the quality of the purchased service or product also after the use (e.g. credence goods). This limited ability put the seller in a more informed position, which may push customers into purchases that are not in their best interest and generate only higher commission fees (e.g. steering and churning practices).

d. Financial literacy and customers' effort to "shop around". Lack of financial literacy and limited effort in shopping around to compare offers exacerbate the impact of the information asymmetry in the retail financial services sector, increasing switching costs and reducing incentives for sellers to improve their quality of service.

e. Customer switching and mobility. The long and risky nature of the relationship between customer and the financial services provider may increase switching costs for customers, due to high sunk investments associated with the contractual relationship, as well as psychological and educational factors mentioned above. Therefore, this situation leaves customers in a weak position vis-à-vis their counterparts.

f. Relationship finance. The complexity of the relationship and financial products and services increases probability that providers can engage in exploitative behaviours, especially when customers cannot observe the quality of the service provided to them in the long run, due to low financial education and psychological aspects.

Finally, we can draw two main conclusions in relation to the retail financial services market. Firstly, effects of the provision of these services on competition and consumer protection will vary depending on the characteristics of the service/product (or package of services/products) and the market. Secondly, all these factors potentially impact on customer's (actual or perceived) switching costs, and thus on customer mobility and choice. The provision of financial services to retail investors, therefore, should balance tools of competition and consumer policy, as the impact of anticompetitive and/or unfair practices may harm customers' mobility, choice and welfare, thereby thwarting the integration of the European internal market. 